\title{
ipen
}

AUTARQUIA ASSOCIADA À UNIVERSIDADE DE SÃO PAULO

\section{SÍNTESE E CARACTERIZAÇÃO ELÉTRICA DE MATERIAIS COM COMPORTAMENTO TERMISTOR À BASE DE ÓXIDOS DE MANGANÊS, DE NÍQUEL DE COBALTO}

\author{
JOSÉ MÁRIO FERREIRA JÚNIOR
}

Dissertação apresentada como parte dos requisitos para obtenção do Grau de Mestre em Ciências na Área de Tecnologia Nuclear-Materiais.

Orientador:

Dr. Reginaldo Muccillo

São Paulo 
INSTITUTO DE PESQUISAS ENERGÉTICAS E NUCLEARES

Autarquia associada à Universidade de São Paulo

SÍNTESE E CARACTERIZAÇÃO ELÉTRICA DE MATERIAIS COM COMPORTAMENTO TERMISTOR À BASE DE ÓXIDOS DE MANGANÊS, DE NÍQUEL E DE COBALTO

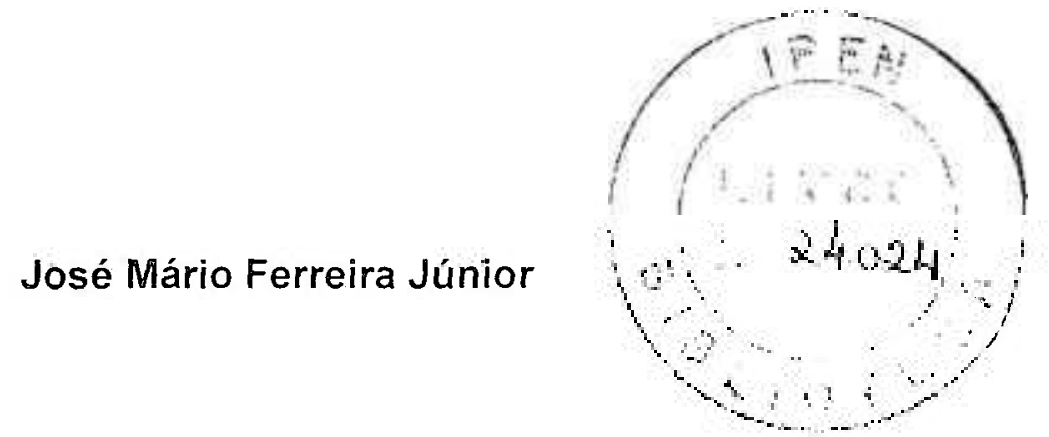

Dissertação apresentada como parte dos requisitos para a obtenção do Grau de Mestre em Ciências na Área de Tecnologia Nuclear Materiais.

Orientador: Dr. Reginaldo Muccillo

São Paulo

2007 


\section{AGRADECIMENTOS}

Ao RHAE-CNPq pela bolsa de estudos.

Ao Dr. Reginaldo Muccillo, pela orientação, ensinamentos e paciência durante a realização deste trabalho.

Ao IPEN pela oportunidade de realizar este trabalho.

Ao Prof. Dr. Jivaldo do Rosário Mattos do Departamento de Química Analitica da Faculdade de Química da USP pelas análises térmicas, pelo apoio e incentivo.

Ao Prof. Dr. Douglas Gouvêa do Departamento de Engenharia Metalúrgica e Materiais da Escola Politécnica da USP pelo incentivo aos estudos.

Ao Dr. J. R. Martinelli pelas análises de distribuição de tamanho de particulas.

À Dr. Eliana N. S. Muccillo pelos ensinamentos.

À Yone $V$. França pelas análises de Fluorescência de raios $X$ e ensinamentos durante minha fase inicial no CCTM.

Ao técnico Celso $V$. Moraes pelas análises de microscopia eletrônica de varredura.

A todos os amigos de trabalho, do grupo e do Centro de Ciência e Tecnologia de Materiais, CCTM.

Ao Sr. Adubaldo, Maria Parecida, Arthur e Arciso pela confiança, respeito e por ter proporcionado um segundo lar.

Aos meus pais, José Mário Ferreira e Dervanda Defina, pela força coragem e determinação, que carrego em mim.

À Fernanda, Bruno e Veridiana por terem compreendido meus erros e ajudado em todos os meu acertos fazendo crer que em momento algum estive só. 
Resumo

Abstract

1. INTRODUÇÃO

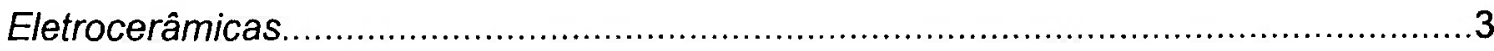

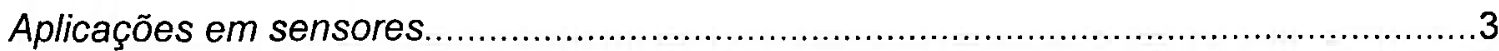

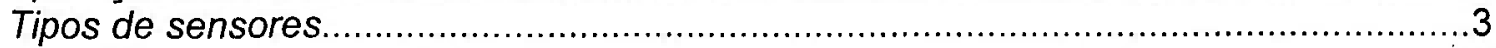

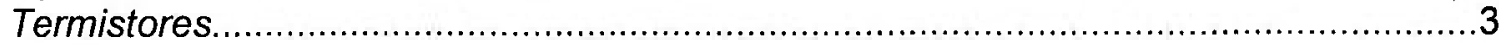

PTC

NTC

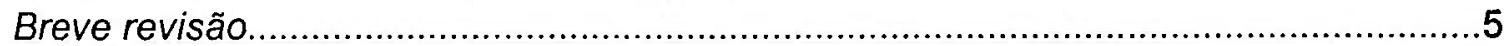

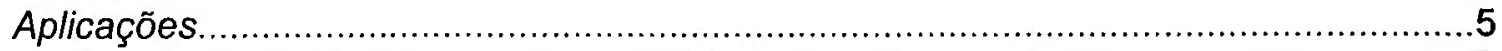

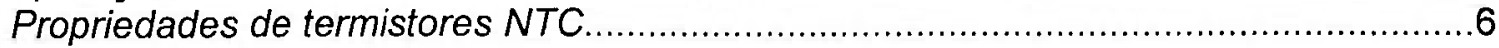

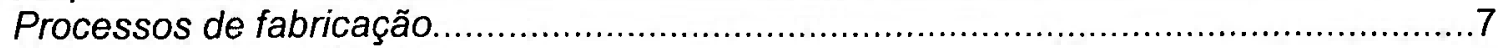

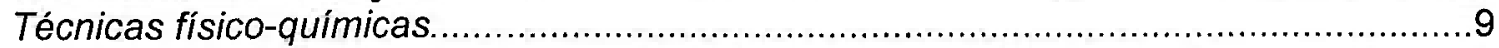

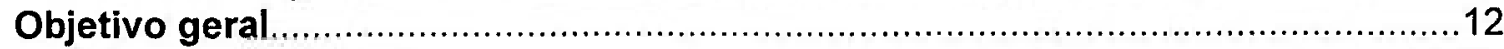

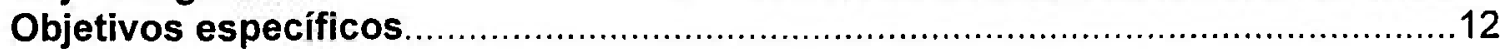

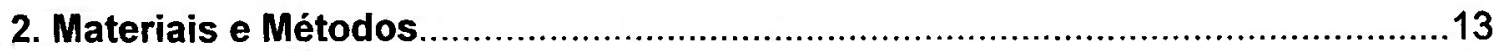

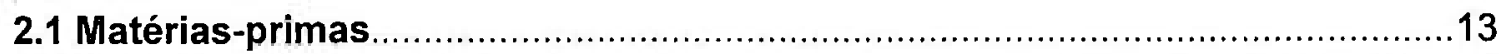

Caracterização dos óxidos precursores...............................................................13

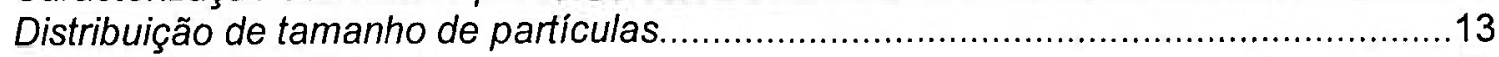

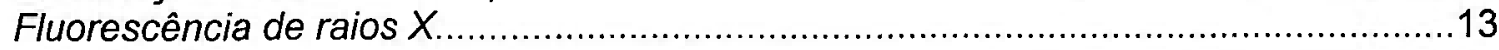

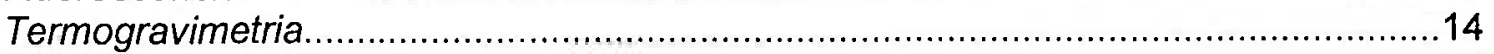

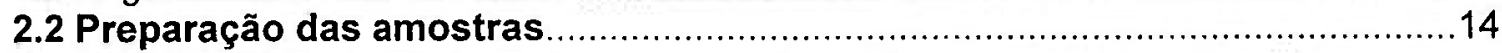

2.2.1 Diferentes concentrações de óxidos de manganês, de níquel e de

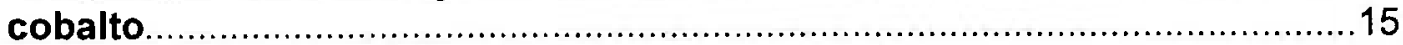

2.2.2 Diferentes concentraçōes de óxido de manganês.......................................15

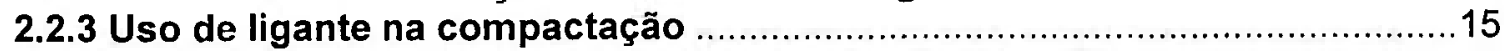

2.2.4 Diferentes perfis de temperatura/tempo de sinterização .............................15

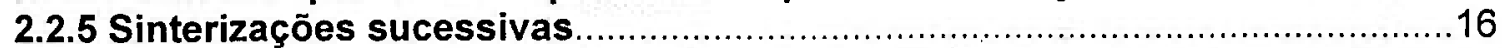

2.2.6 Estudo da dependência da resistividade elétrica com a ciclagem térmica a

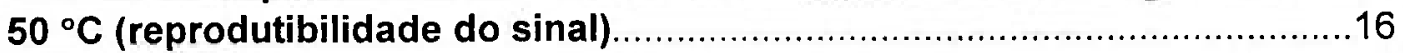

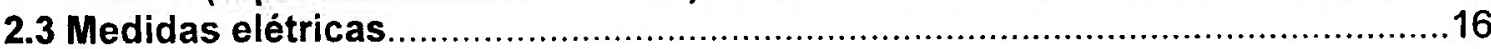

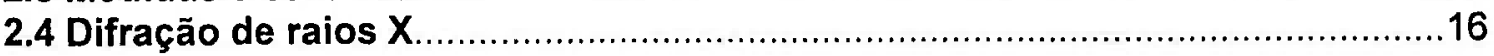

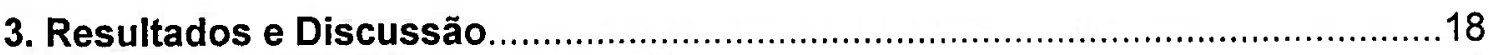

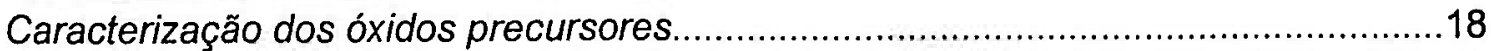

Distribuição de tamanho de particulas.................................................................18

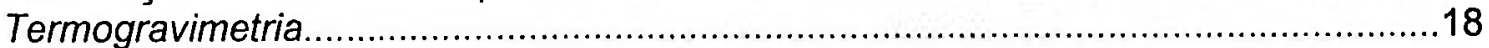

3.1 Diferentes concentrações de óxidos de manganês, de níquel e de cobalto

3.2 Diferentes concentraçōes de óxido de manganês...........................................43

3.3 Uso de ligante na compactação (polietileno glicol)........................................48

3.4 Diferentes perfis de temperatura/tempo de sinterização................................50

3.5 Sinterizações sucessivas ..........................................................................51

3.6 Estudo da dependência da resistividade elétrica com a ciclagem térmica a 50

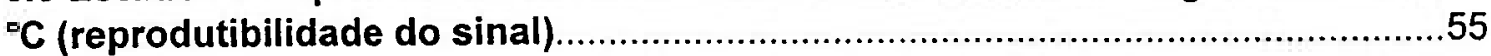

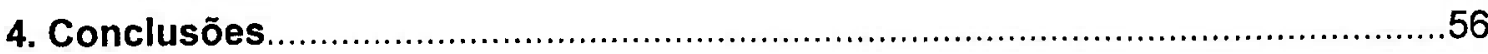

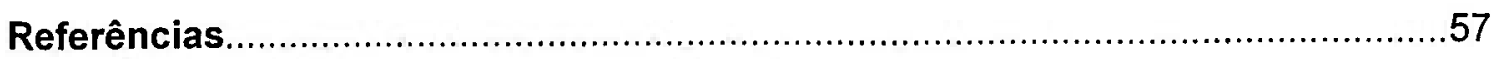

Apêndice 


\section{Lista de Figuras}

Figura 1: Representação esquemática do conjunto para medidas de resistência elétrica.

Figura 2: Curvas TG/DTG do óxido de níquel: a) sob atmosfera dinâmica de $\mathrm{N}_{2}$

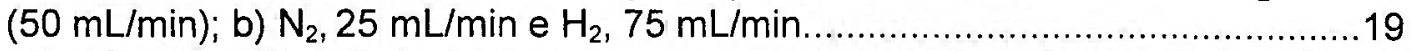

Figura 3: Curvas TG/DTG do óxido de manganês: a) sob atmosfera dinâmica de ar a $100 \mathrm{~mL} / \mathrm{min}$; b) $\mathrm{N}_{2}, 25 \mathrm{~mL} / \mathrm{min}$ e $\mathrm{H}_{2}, 75 \mathrm{~mL} / \mathrm{min}$.................. .....................20

Figura 4: Curvas TG/DTG do óxido de cobalto: a) sob atmosfera dinâmica de ar a 100

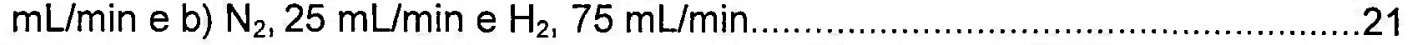

Figura 5: Curvas TG/DTG da mistura 50\% $\mathrm{NiO}-50 \%$ de $\mathrm{MnO}_{2}$ : a) sob atmosfera dinâmica (ar), $20 \mathrm{~mL} / \mathrm{min}$; $\quad$ b) $\mathrm{N}_{2}, \quad 25 \mathrm{~mL} / \mathrm{min}$ e $\mathrm{H}_{2}, 75$

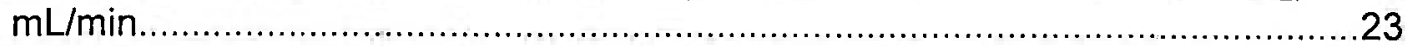

Figura 6: Curvas TG/DTG da mistura $50 \% \mathrm{NiO}-50 \% \quad \mathrm{Co}_{3} \mathrm{O}_{4}$ : a) sob atmosfera dinâmica (ar), $100 \mathrm{~mL} / \mathrm{min}$; $\quad$ b) $\mathrm{N}_{2}, 25 \mathrm{~mL} / \mathrm{min}$ e $\mathrm{H}_{2}, 75$

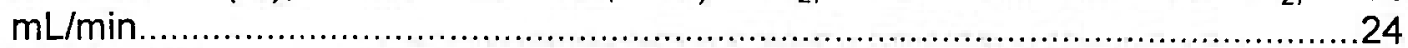

Figura 7: Curvas TG/DTG da mistura $50 \% \mathrm{MnO}_{2}-50 \% \mathrm{Co}_{3} \mathrm{O}_{4}$ : a) sob atmosfera dinâmica (ar), $100 \mathrm{~mL} / \mathrm{min}$; b) $\mathrm{N}_{2}, 25 \mathrm{~mL} / \mathrm{min}$ e $\mathrm{H}_{2} \quad 75$

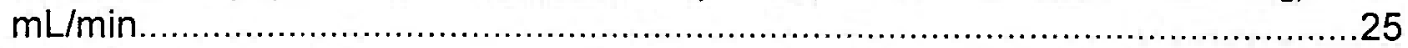

Figura 8: Curvas TG/DTG da mistura $33,3 \% \mathrm{NiO}-33,3 \% \mathrm{MnO}_{2}-33,3 \% \mathrm{Co}_{3} \mathrm{O}_{4}$ sob

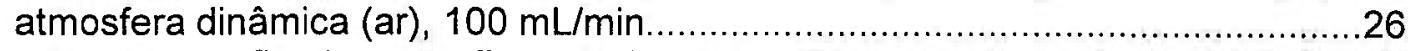

Figura 9: Micrografia de superfície de fratura obtida em microscópio eletrônico de varredura da cerâmica de composição $50 \% \quad \mathrm{NiO}-50 \% \quad \mathrm{MnO}_{2}$; região típica.

Figura 10: Micrografia de superfície de fratura obtida em microscópio eletrônico de varredura da cerâmica de composição $50 \% \mathrm{NiO}-50 \% \mathrm{MnO}_{2}$; região de maior densidade.

Figura 11: Micrografia de superfície de fratura obtida em microscópio eletrônico de varredura da cerâmica de composição $50 \% \quad \mathrm{NiO}-50 \% \quad \mathrm{MnO}_{2}$; região do

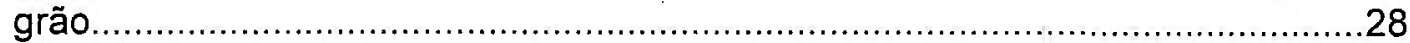

Figura 12: Micrografia de superfície de fratura obtida em microscópio eletrônico de varredura da cerâmica de composição $50 \% \mathrm{NiO}-50 \% \mathrm{Co}_{3} \mathrm{O}_{4}$; região típica.

Figura 13: Micrografia de superfície de fratura obtida em microscópio eletrônico de varredura da cerâmica de composição $50 \% \mathrm{NiO}-50 \% \mathrm{Co}_{3} \mathrm{O}_{4}$; região mais densa.

Figura 14: Micrografia de superfície de fratura obtida em microscópio eletrônico de varredura da cerâmica de composição $50 \%$ de $\mathrm{NiO}-50 \% \mathrm{Co}_{3} \mathrm{O}_{4} ;$ região do gräo...

Figura 15: Micrografia de superfície de fratura obtida em microscópio eletrônico de varredura da cerâmica de composição $50 \% \mathrm{MnO}_{2}-50 \% \mathrm{Co}_{3} \mathrm{O}_{4}$; região típica.. 30

Figura 16: Micrografia de superfície de fratura obtida em microscópio eletrônico de varredura da cerâmica de composição $50 \% \mathrm{MnO}_{2}-50 \% \mathrm{Co}_{3} \mathrm{O}_{4}$; região mais densa......

Figura 17: Micrografia de superficie de fratura obtida em microscópio eletrônico de varredura da cerâmica de composição $50 \% \quad \mathrm{MnO}_{2}-50 \% \quad \mathrm{Co}_{3} \mathrm{O}_{4}$; região do

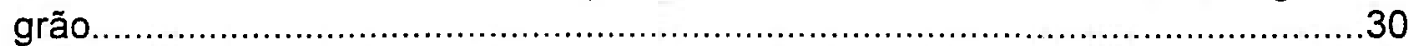

Figura 18: Micrografia da cerâmica termistora de composição 33,3\% NiO - 33,3\%

$\mathrm{MnO}_{2}-33,3 \% \mathrm{Co}_{3} \mathrm{O}_{4}$; região típica................................................... 31

Figura 19: Micrografia da cerâmica de composição $33,3 \% \mathrm{NiO}-33,3 \% \mathrm{MnO}_{2}-33,3 \%$ $\mathrm{Co}_{3} \mathrm{O}_{4} ;$ região mais densa.......................................................... 31

Figura 20: Micrografia da cerâmica de composição 33,3\% $\mathrm{NiO}-33,3 \% \mathrm{MnO}_{2}-33,3 \%$

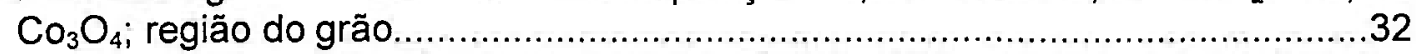

Figura 21: Micrografia da cerâmica de composição $50 \% \mathrm{NiO}-25 \% \mathrm{MnO}_{2}-25 \% \mathrm{Co}_{3} \mathrm{O}_{4}$;

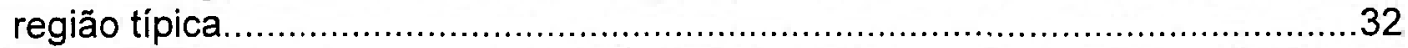

Figura 22: Micrografia da cerâmica de composição $50 \% \mathrm{NiO}-25 \% \mathrm{MnO}_{2}-25 \% \mathrm{CO}_{3} \mathrm{O}_{4}$; região mais densa. 33 
Figura 23: Micrografia da cerâmica de composição $50 \% \mathrm{NiO}-25 \% \mathrm{MnO}_{2}-25 \% \mathrm{Co}_{3} \mathrm{O}_{4}$;

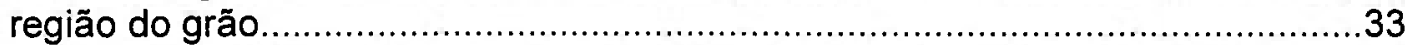

Figura 24: Micrografia da cerâmica de composição $25 \% \mathrm{NiO}-50 \% \mathrm{MnO}_{2}-25 \% \mathrm{Co}_{3} \mathrm{O}_{4}$; região típica.................................................................................... 34

Figura 25: Micrografia da cerâmica de composição $25 \% \mathrm{NiO}-50 \% \mathrm{MnO}_{2}-25 \% \mathrm{Co}_{3} \mathrm{O}_{4}$;

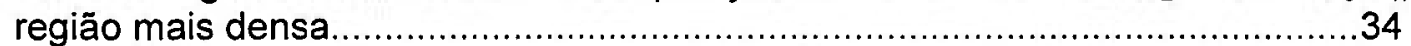

Figura 26: Micrografia da cerâmica de composição $25 \% \mathrm{NiO}-50 \% \mathrm{MnO}_{2}-25 \% \mathrm{Co}_{3} \mathrm{O}_{4}$;

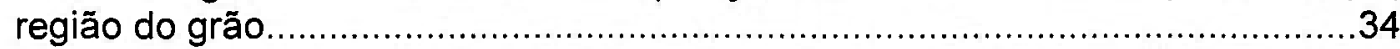

Figura 27: Micrografia da cerâmica de composição $25 \% \mathrm{NiO}-55 \% \mathrm{MnO}_{2}-50 \% \mathrm{Co}_{3} \mathrm{O}_{4}$;

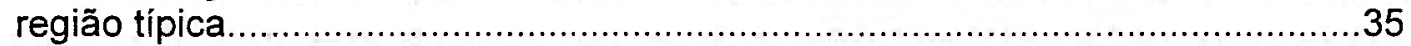

Figura 28: Micrografia da cerâmica de composição $25 \% \mathrm{NiO}-55 \% \mathrm{MnO}_{2}-50 \% \mathrm{Co}_{3} \mathrm{O}_{4}$;

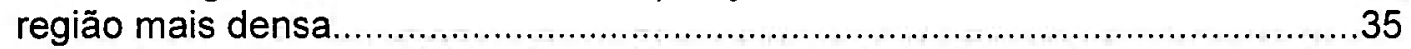

Figura 29: Micrografia da cerâmica de composição $25 \% \mathrm{NiO}-50 \% \mathrm{MnO}_{2}-25 \% \mathrm{Co}_{3} \mathrm{O}_{4}$, com aumento de 1000 vezes; região do grão..............................................

Figura 30: Difratogramas de raios $X$ das composiçōes: a) $50 \% \mathrm{NiO}-50 \% \mathrm{MnO}_{2}$; b) $50 \% \mathrm{NiO}-50 \% \mathrm{Co}_{3} \mathrm{O}_{4}$; c) $50 \% \mathrm{MnO}_{2}-50 \% \mathrm{Co}_{3} \mathrm{O}_{4}$; d) $33,3 \% \mathrm{NiO}-33,3 \% \mathrm{MnO}_{2}$ $33,3 \% \mathrm{Co}_{3} \mathrm{O}_{4}$; e) $50 \% \mathrm{MnO}_{2}-25 \% \mathrm{NiO}-25 \% \mathrm{Co}_{3} \mathrm{O}_{4}$; f) $50 \% \mathrm{NiO}-25 \% \mathrm{MnO}_{2}$ -

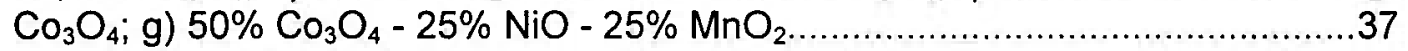

Figura 31: Resistividade elétrica em função da temperatura da composição $49,2 \% \mathrm{NiO}$ $-50,8 \% \mathrm{MnO}_{2}$ sinterizada a $1300^{\circ} \mathrm{C}$

Figura 32: Resistividade elétrica em função da temperatura composição $48,7 \% \mathrm{NiO}$ $51,3 \% \mathrm{Co}_{3} \mathrm{O}_{4}$ sinterizada a $1300^{\circ} \mathrm{C}$

Figura 33: Resistividade elétrica em função da temperatura da composição $47,3 \%$ $\mathrm{MnO}_{2}-52,7 \% \mathrm{Co}_{3} \mathrm{O}_{4}$ sinterizada $1300^{\circ} \mathrm{C}$.

Figura 34: Resistividade elétrica em função da temperatura composição $32,9 \%$ de NiO - 33,2\% $\mathrm{MnO}_{2}-33,9 \%$ de $\mathrm{Co}_{3} \mathrm{O}_{4}$, sinterizada a $1300^{\circ} \mathrm{C}$. ................................40

Figura 35: Resistividade elétrica em função da temperatura da composição 49,2,9\% $\mathrm{NiO}-25,3 \% \mathrm{MnO}_{2}-25,5 \% \mathrm{Co}_{3} \mathrm{O}_{4}$ sinterizada a $1300^{\circ} \mathrm{C}$.

Figura 36: Resistividade elétrica em função da temperatura composição $25,2 \% \mathrm{NiO}$ $48,7 \% \mathrm{MnO}_{2}-26,1 \% \mathrm{Co}_{3} \mathrm{O}_{4}$ sinterizada a $1300^{\circ} \mathrm{C}$

Figura 37: Resistividade elétrica em função da temperatura da composição $24,8 \% \mathrm{NiO}$ - 25,3\% $\mathrm{MnO}_{2}-49,9 \% \mathrm{Co}_{3} \mathrm{O}_{4}$ sinterizada a $1300{ }^{\circ} \mathrm{C}$.

Figura 38: Resistividade elétrica em função da temperatura para sete composições de termistores (Cf. Tabela 2)...............................................................................43

Figura 39: Difratograma de raios $X$ da composição $50 \%$ NiO - $50 \%$

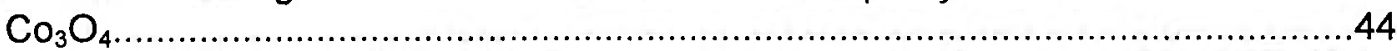

Figura 40: Resistividade elétrica em função da temperatura da composição $50 \%$ NiO -

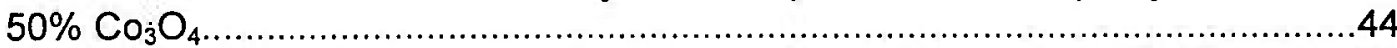

Figura 41: Difratograma da composição $45 \% \mathrm{NiO}-45 \% \mathrm{Co}_{3} \mathrm{O}_{4}-10 \%$

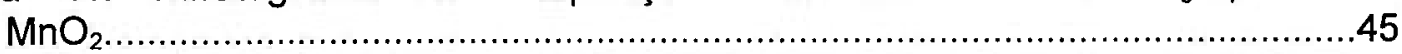

Figura 42: Resistividade elétrica em função da temperatura da composição $45 \%$ NiO -

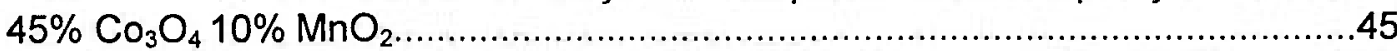

Figura 43: Difratograma da composição $40 \% \mathrm{NiO}-40 \% \mathrm{Co}_{3} \mathrm{O}_{4}-20 \%$

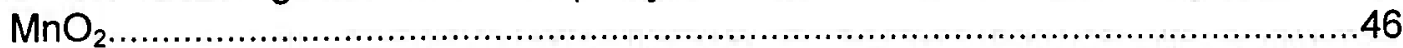

Figura 44: Resistividade elétrica em função da temperatura da composição $40 \%$ NiO -

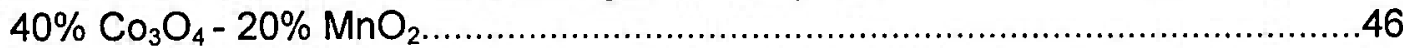

Figura 45: Difratograma da composição $35 \% \mathrm{NiO}-35 \% \mathrm{Co}_{3} \mathrm{O}_{4}-30 \%$

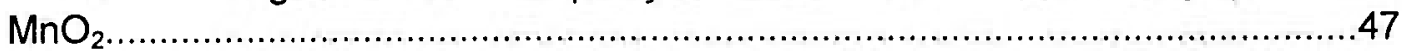

Figura 46: Resistividade elétrica em função da temperatura da composição 35\% NiO -

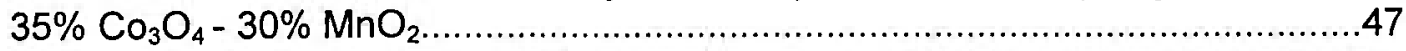

Figura 47: Resistividade elétrica em função da temperatura para quatro composições $50 \% \mathrm{NiO}-50 \% \mathrm{Co}_{3} \mathrm{O}_{4}, 45 \% \mathrm{NiO}-45 \% \mathrm{Co}_{3} \mathrm{O}_{4}-10 \% \mathrm{MnO}_{2}, 40 \% \mathrm{NiO}-40 \%$ $\mathrm{Co}_{3} \mathrm{O}_{4}-20 \% \mathrm{MnO}_{2}$ e $35 \% \mathrm{NiO}-35 \% \mathrm{Co}_{3} \mathrm{O}_{4}-30 \% \mathrm{MnO}_{2} \ldots \ldots \ldots \ldots \ldots \ldots \ldots \ldots \ldots \ldots . . . \ldots 8$

Figura 48: Resistividade elétrica em função da temperatura da composição $33,3 \% \mathrm{NiO}$ - 33,3\% $\mathrm{MnO}_{2}-33,3 \% \mathrm{Co}_{3} \mathrm{O}_{4}$ com ligante, sinterizada a $1250^{\circ} \mathrm{C} \ldots \ldots \ldots \ldots \ldots \ldots \ldots . . . . .49$

Figura 49: Resistividade elétrica em função da temperatura da composição $33,3 \% \mathrm{NiO}$

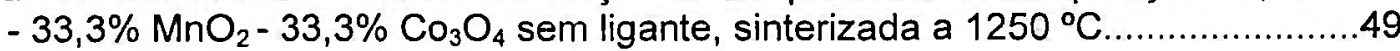


Figura 50: Difratogramas de raios $\mathrm{X}$ da composição $33,3 \% \mathrm{NiO}-33,3 \% \mathrm{MnO}_{2}-33,3 \%$ $\mathrm{Co}_{3} \mathrm{O}_{4}$ : a) sinterizada a $1300{ }^{\circ} \mathrm{C} / 1 \mathrm{~h}$ (rota 1); com prévia queima a $600{ }^{\circ} \mathrm{C}$

Figura 51: Resistividade elétrica em função da temperatura da composição $33,3 \% \mathrm{NiO}$ - 33,3\% $\mathrm{MnO}_{2}-33,3 \% \mathrm{Co}_{3} \mathrm{O}_{4}$ : a) sinterizada a $1250^{\circ} \mathrm{C} / 1 \mathrm{~h}$; com prévia queima a $600{ }^{\circ} \mathrm{C}$.

Figura 52: Difratogramas da composição $33,3 \% \mathrm{NiO}-33,3 \% \quad \mathrm{MnO}_{2}-33,3 \% \mathrm{Co}_{3} \mathrm{O}_{4}$ sinterizada a $1250^{\circ} \mathrm{C} / 2 \mathrm{~h}$ : a) uma sinterização, b) duas e c) três.

Figuras 53: Resistividade elétrica da composição 33,3\% $\mathrm{NiO}-33,3 \% \mathrm{MnO}_{2}-33,3 \%$ $\mathrm{Co}_{3} \mathrm{O}_{4}$ a $1250{ }^{\circ} \mathrm{C} / 2 \mathrm{~h}$ submetida a sucessivos tratamentos térmicos de sinterização: a) um b) dois e c) três.

Figura 54: Resistividade elétrica da composição $50 \% \mathrm{NiO}-50 \% \mathrm{Co}_{3} \mathrm{O}_{4}$ após ciclagem térmica a $50^{\circ} \mathrm{C}$

Figura 55: Resistividade elétrica da composição $45 \% \mathrm{NiO}-45 \% \mathrm{Co}_{3} \mathrm{O}_{4}-10 \% \mathrm{MnO}_{2}$ após ciclagem térmica a $50^{\circ} \mathrm{C}$

Figura 56: Resistividade elétrica da composição $40 \% \mathrm{NiO}-40 \% \mathrm{Co}_{3} \mathrm{O}_{4}-20 \% \mathrm{MnO}_{2}$ após ciclagem térmica a $50^{\circ} \mathrm{C}$

Figura 57: Resistividade elétrica da composição $35 \% \mathrm{NiO}-35 \% \mathrm{Co}_{3} \mathrm{O}_{4}-30 \% \mathrm{MnO}_{2}$ após ciclagem térmica a $50^{\circ} \mathrm{C}$.

\section{Lista de Tabelas}

Tabela 1: Reagentes para a preparação das cerâmicas termistoras.

Tabela 2: Concentração em massa dos óxidos adicionados na mistura.

Tabela 3: Valores das concentrações de $\mathrm{NiO}, \mathrm{MnO}_{2}$ e $\mathrm{CO}_{3} \mathrm{O}_{4}$ adicionados e os obtidos por fluorescência de raios $X$ (entre parêntesis).

Tabela 4: Valores obtidos por EDS para as sete diferentes composições de cerâmicas termistoras em três diferentes regiōes.....

Tabela 5: Resistividade elétrica $\rho$ a $50^{\circ} \mathrm{C}$ e os parâmetros $\alpha$ e $\beta$. 


\title{
SÍNTESE E CARACTERIZAÇÃO ELÉTRICA DE MATERIAIS CERÂMICOS COM COMPORTAMENTO TERMISTOR À BASE DE ÓXIDOS DE MANGANÊS, DE NIQUEL E DE COBALTO
}

\author{
José Mário Ferreira Júnior
}

\begin{abstract}
Resumo
Materiais cerâmicos à base de óxidos de manganês, de níquel e de cobalto foram preparados por meio de mistura de óxidos seguida de homogeneização e sinterização controlada em $1250^{\circ} \mathrm{C}$. Os óxidos foram caracterizados por meio das técnicas de difração de raios $X$, fluorescência de raios $X$, termogravimetria $e$ determinação de distribuição de tamanho de partículas por espalhamento laser. A caracterização dos corpos sinterizados foi feita por meio de análise por microscopia eletrônica de varredura, difração de raios $X$ e fluorescência de raios $X$. $O$ comportamento termistor foi estudado por meio de medidas de resistividade elétrica pela técnica dc de duas pontas de prova entre temperatura ambiente e $220^{\circ} \mathrm{C}$. Os principais resultados mostram ser possivel a preparação de termistores em ampla faixa de resposta elétrica por meio da variação da composição relativa dos óxidos de manganês, de niquel e de cobalto.

Palavras-chave: termistor, NTC, sensor de temperatura.
\end{abstract}




\title{
SYNTHESIS AND ELECTRICAL CHARACTERIZATION OF CERAMIC THERMISTORS BASED ON MANGANESE, NICKEL AND COBALT OXIDES
}

\author{
José Mário Ferreira Júnior
}

\begin{abstract}
Ceramic thermistors based on manganese, nickel and cobalt oxides were prepared by mixing these oxides followed by pressing and sintering at $1250{ }^{\circ} \mathrm{C}$ range. The oxides were characterized by $\mathrm{X}$-ray diffraction, $\mathrm{X}$-ray fluorescence, thermogravimetry and differential thermal analysis, and by the determination of particle size distribution by laser scattering. After sintering, $\mathrm{X}$-ray diffraction, $\mathrm{X}$-ray fluorescence and scanning electron microscopy analyses were carried out. The thermistor behavior was studied by two-probe dc electrical resistivity measurements in the room temperature-220 ${ }^{\circ} \mathrm{C}$ range. The main results show the possibility of designing thermistors with the required electrical response by suitable choice of the relative concentrations of the precursor oxides.
\end{abstract}

Keywords: thermistor, NTC, temperature sensor. 


\section{INTRODUÇÃO}

\section{Eletrocerâmicas}

O termo eletrocerâmicas foi adotado para designar materiais cerâmicos com propriedades elétricas, magnéticas ou ópticas especificas, podendo apresentar características de isolante, semicondutor, condutor, supercondutor, ferroelétrico, ferromagnético, etc..

Materiais eletrocerâmicos apresentam um forte apelo tecnológico, tendo as mais variadas aplicações: sensores, atuadores, substratos, capacitores, transdutores piezoelétricos, e uma grande variedade de termistores [1].

\section{Aplicações em sensores}

Cerâmicas de alta tecnologia são parte essencial da eletrônica, sendo utilizadas nos mais diversos equipamentos em várias áreas industriais. Cerâmicas eletrônicas são componentes integrais dos circuitos usados nos computadores, processadores de sinal, telecomunicações e tecnologias de controle. Alguns tipos de sensores cerâmicos como os de temperatura (termistores), pressão, campo magnético, espécies químicas, têm um papel importante na vida de grande parte da população mundial [2].

\section{Tipos de sensores cerâmicos}

Sensores cerâmicos podem apresentar as mais variadas funções devido as suas caracteristicas físicas. Sensores de temperatura utilizam materiais condutores (como a platina, o cobre ou o níquel) ou semicondutores (termistores) que exibem uma variação da resistência elétrica com a variação de temperatura. Os termistores são geralmente obtidos por uma mistura de óxidos metálicos semicondutores, como os óxidos de manganês, de níquel, de cobalto, de cobre, de ferro e de titânio [3].

\section{Termistores}

Termistores são resistores termicamente sensiveis, cujas características físicas levam à mudança na resistência elétrica com a variação da temperatura, devido principalmente à alteração na concentração de portadores de carga. São 
divididos em dois principais grupos e classificados segundo seu comportamento sob variação de temperatura [4]: PTC e NTC.

\section{PTC (Positive Temperature Coefficient)}

Termistores PTC apresentam aumento da resistência elétrica com o aumento da temperatura, resultando em um coeficiente positivo de temperatura; a variação da resistência ocorre apenas em um intervalo limitado de temperatura, próximo a uma transição de fase. Neste intervalo, a variação na resistência é muito grande devido ao efeito de contornos de grão. A partir deste ponto (maior temperatura) exibe uma acentuada variação ohmica (potências de 10) caracterizando grande sensibilidade e linearidade [5].

\section{NTC (Negative Temperature Coefficient)}

Termistores do tipo NTC apresentam diminuição da resistência elétrica com o aumento da temperatura. Consistem em misturas de óxidos de metais de transição do grupo 3d, sob diferentes arranjos: óxidos de manganês e de niquel; de manganês e de cobalto; de niquel e de cobalto; de manganês, de niquel e de cobalto; e de manganês, de níquel, de cobalto e de ferro. Todos possuem estrutura espinélio e fórmula típica $\mathrm{AB}_{2} \mathrm{O}_{4}$. Nesta estrutura, são dois os tipos de sítios disponiveis para os cátions, tetraédrico (sítio-A) e octaédrico (sítio-B). Por ser um elemento resistivo que exibe variação ohmica em ampla faixa de temperatura, apresenta vantagem em relação aos termistores PTC e, por isso, são utilizados para controle e medição.

As cerâmicas NTC dissipam potência, representada pelo aquecimento produzido pela passagem da corrente elétrica. Esta característica pode assumir um caráter destrutivo, pois o seu efeito é de avalanche térmica. Pela elevação da temperatura, a resistência ohmica do NTC diminui, aumentando a circulação de corrente que, por sua vez, produz mais aquecimento. Esta situação poderá levar a mais calor, menor resistência, maior consumo, maior aquecimento (avalanche térmica) [6]. Consequentemente, a microestrutura é importante para o funcionamento de um termistor sem degradação pelo uso contínuo. 


\section{Breve revisão}

Desde o trabalho publicado pelo laboratório Phillips em 1947 ("Semiconductors with large negative temperature coefficient of resistance" [7]), as pesquisas sobre termistores se intensificaram e mudaram seu foco ao longo do tempo, atentando para diversos fatores tais como preparação, estudo das propriedades termistoras, aplicações e, mais recentemente, aos aspectos microestruturais.

A grande variedade de pesquisas realizadas ao longo destes anos está apoiada na grande aplicabilidade comercial destas cerâmicas devido a vantagens, tais como alta sensibilidade, baixo custo, amplos valores de resistência elétrica, disponibilidade em tamanho reduzido, grande variedade de formas, e pequeno tempo de resposta [8].

Vários trabalhos de pesquisa mostram que: a adição de ions $\mathrm{Cu}^{2+}$ promove o aumento da resistividade elétrica, com diminuição da estabilidade elétrica [9]; pequenas quantidades de $\mathrm{Fe}^{3+}$ causam aumento significativo na resistividade elétrica e aceleram o processo de envelhecimento com menor estabilidade elétrica [10]; e a adição de bismuto diminui a resistividade elétrica, aumentando o teor de defeitos na rede cristalina [11].

Foi também verificado que: o aumento da concentração de íns $\mathrm{Ni}^{2+}$ causa aumento da estabilidade elétrica devido a maior ocupação de sítios na estrutura espinélio [12]; o envelhecimento em cerâmicas termistoras compostas pelos óxidos de ferro, níquel e manganês está relacionado com a migração de $\mathrm{Fe}^{3+}$ e de $\mathrm{Mn}^{3+}$ na estrutura cristalina [13]. Nestas cerâmicas de comportamento termistor, os íons $\mathrm{Mn}^{3+}$, $\mathrm{Mn}^{4+}$ e $\mathrm{Ni}^{2+}$ têm ordem de ocupação preferencial para o sítio $\mathrm{B}$ [13].

\section{Aplicações}

As principais aplicações são em elementos associados de proteção (proteção de motores e circuitos elétricos, interruptores térmicos para a proteção de sistemas), acionadores de mecanismos e sensores de temperatura (principalmente em condicionadores de ar, frigoríficos, congeladores, desumidificadores, aquecedores, cafeteiras, portas de fornos e termostatos). São também utilizados como compensadores de temperatura para transistores, na proteção contra aquecimento excessivo de conversores de freqüencia e leitores de todos os tipos [14]. Os 
termistores são amplamente utilizados como sondas de temperatura em aplicações industriais, em aparelhagem médica, em eletrodomésticos, em instrumentação para investigação científica, no setor automobilístico, em telecomunicações, etc.. Em algumas aplicações, servem para medir valores absolutos de temperatura, como é o caso das aplicações médicas, ao passo que em outras, como as aplicações industriais, para aferir altas temperaturas. Outra distinção importante consiste na precisão da medida de temperatura. Em alguns casos, uma precisão de $1^{\circ} \mathrm{C}$ na medição da temperatura é suficiente, ao passo que em outras é necessária uma precisão da ordem de décimos ou, até mesmo, de centésimos de grau [15].

\section{Propriedades de termistores NTC}

Os fatores para avaliar a qualidade das propriedades de termistores NTC são a razão da resistência caracteristica, o coeficiente de temperatura e a estabilidade.

A razão da resistência característica (fator $\beta$ ) é a razão da resistência elétrica medida em duas temperaturas especificas, geralmente 25 e $100^{\circ} \mathrm{C}$, e obtida pelas expressões:

$$
\begin{aligned}
& R=R_{0} \cdot \exp \beta\left\{\left[(1 / T)-\left(1 / T_{0}\right)\right]\right\} \\
& \beta=\left[\left(T_{0} \cdot T\right) /\left(T-T_{0}\right)\right] \cdot \ln \left(R_{0} / R\right)
\end{aligned}
$$

$R$ e $R_{0}$ são os valores de resistência elétrica nas temperaturas $T$ e $T_{0}$, respectivamente.

O fator $\beta$ depende da temperatura e os valores para materiais NTC comerciais estão na faixa de 2000 a $6000 \mathrm{~K}$ [16].

O coeficiente de temperatura ( $\alpha$ ) é a mudança relativa da resistência elétrica pela mudança na temperatura, ou seja, representa a sensibilidade do termistor. A sensibilidade de um termistor pode ser obtida pela equação que relaciona resistência elétrica e temperatura de tolerância, representada abaixo, calculada em pequenos intervalos de temperatura [17].

$$
\begin{aligned}
& \alpha=\left(1 / R_{T}\right) \cdot\left(d R_{T} / d_{T}\right) \\
& \alpha=-\beta / T^{2}
\end{aligned}
$$

$\mathbf{R}_{\mathbf{T}}$ é a resistência elétrica à temperatura $\mathbf{T}$. 
Estabilidade é a propriedade de um termistor de reter caracteristicas especificadas após ser submetido às condições de testes ambientais ou elétricos em função do tempo. Termistores de boa qualidade apresentam variação de $1 \%$ de sua resistividade em um ano [18].

\section{Processos de fabricação}

As propriedades dos materiais, em particular das eletrocerâmicas, são fortemente influenciadas pela qualidade das matérias-primas a partir das quais são fabricadas, e pela microestrutura final.

Qualquer tentativa de controle das propriedades de um produto deve passar pelo entendimento das características físico-quimicas dos materiais empregados, bem como pelo processo de fabricação, durante o qual a microestrutura final se desenvolve. O papel de cada uma dessas etapas e, principalmente, a inter-relação entre elas no desenvolvimento da microestrutura responsável pelas propriedades finais do material, tem sido objeto de intensos estudos. A preparação de eletrocerâmicas é feita, em sua grande maioria, a partir de insumos que necessitam de controle, tanto no processo de obtenção do pó, para garantir caracteristicas importantes (teor de pureza e granulometria), quanto durante a conformação e tratamento térmico para a produção de peças e produtos finais (sinterização).

O sucesso e a comercialização das cerâmicas dependem basicamente da qualidade e baixo custo dos insumos (pós, aditivos, etc.), o que deve ocorrer com o aperfeiçoamento dos métodos de processamento [19].

A preparação de materiais cerâmicos pelo método convencional pode ser dividida em mistura e homogeneização dos pós, conformação, e sinterização. A mistura e a homogeneização podem ocorrer por mistura de pós, ou por um grande número de diferentes técnicas de processamento.

A sintese de estado sólido ou por mistura de pós consiste no tratamento térmico de uma mistura de sólidos para se obter estequiometria inicial preservada e adequada microestrutura. Estas propriedades refletem a capacidade difusional dos íns dentro ou entre as partículas dos sólidos. A extensão de formação do produto depende da área interfacial de contato e da facilidade de difusão das espécies; estas dependem dos defeitos estruturais, dos contatos de contornos de grão e de impurezas. A ordem de grandeza da difusão em sólidos é muitas vezes menor que 
em líquidos ou gases, exigindo temperaturas altas para que as reações ocorram em uma escala de tempo razoável.

Os produtos obtidos pela técnica de mistura de óxidos apresentam geralmente inadequada homogeneidade quimica, diferentes formas e ampla faixa de distribuição de tamanho de partículas. Tais características influenciam o processamento e as propriedades do corpo sólido sinterizado, dificultando sua reprodutibilidade. Em compensação, esta técnica é de simples operação e usa óxidos de fácil obtenção, otimizando a relação custo/benefício [20].

As rotas químicas são muito utilizadas na obtenção de eletrocerâmicas por apresentarem algumas vantagens em relação à técnica de mistura de pós, como controle estequiométrico e da microestrutura final. No entanto, também apresentam desvantagens como preço mais elevado e processos especiais para adequada reprodutibilidade. Há várias técnicas de síntese química como co-precipitação, solgel, sintese hidrotérmica, decomposição evaporativa de soluções, dos precursores poliméricos e outras [21].

Para facilitar o manuseio após mistura, os pós são geralmente preparados em uma forma conveniente (conformação). O objetivo desta etapa do processamento cerâmico é conferir ao pó um formato preliminar e estabelecer os pontos de contato entre as particulas para sua efetiva consolidação durante o tratamento térmico de sinterização. Existem varias técnicas de conformação tais como compactação uniaxial e isostática, colagem de barbotina, moldagem por injeção, extrusão e outras. A compactação uniaxial consiste na aplicação de pressão sobre um molde contendo o material na forma de pó, através de punções. Podem ocorrer variações na densidade devido ao atrito entre as particulas e as paredes do molde, o que pode ser minimizado ou evitado com o uso de lubrificantes. A forma e a pressão na conformação também são parâmetros importantes, influenciando a microestrutura final. Após a conformação o material é submetido ao processo de sinterização, geralmente para ser densificado [22].

Sinterização è um processo em que compactos de partículas de pós cristalinos ou não de um composto são submetidos a tratamento térmico a temperaturas tal que não ocorra fusão do composto; geralmente há união entre as 
partículas do composto por meio de transporte atômico no estado sólido, sendo que em alguns casos envolve a formação parcial de uma fase líquida. A sinterização é a etapa mais importante na fabricação de peças cerâmicas, pois é quando geralmente ocorre densificação, que definirá as propriedades destas peças. A sinterização por reação de estado sólido em cerâmicas pode ser dividida em três estágios: inicial, intermediário e final. O primeiro é caracterizado pela formação de pescoço entre as partículas, por mecanismos de transporte de superficie e/ou volume. O transporte não conduz à densificação da cerâmica, mas apenas a um rearranjo das partículas e no segundo caso o transporte conduzirá a uma densificação inicial por difusão volumétrica e de contorno de grão. $O$ estágio intermediário é caracterizado por uma alta taxa de retração. Neste estágio, os poros são ainda interconectados, ocorrendo difusão pelos contornos de grão e diminuição de tamanho de poros. É comum ocorrer o crescimento de grãos na parte final do estágio intermediário, sendo possivel o isolamento de poros e a lenta taxa de sinterização. O estágio final de sinterização é caracterizado pela diminuição de porosidade, aumento da razão de crescimento de grãos e coalescência dos poros com seu conseqüente arredondamento. A sinterização é influenciada por vários fatores: tamanho e distribuição de tamanho das partículas, temperatura e tempo de tratamento térmico, atmosfera e outros. Para o processamento deve-se ter um conhecimento do material para escolher as melhores condições de tratamento [23].

\section{Técnicas físico-químicas}

\section{Distribuição de tamanho de partículas}

A distribuição de tamanho de partículas ou de aglomerados de particulas pode ser obtida pela técnica de espalhamento laser. Nesse caso, é adicionado um líquido dispersante adequado seguido de desaglomeração em ultra-som, na tentativa de manter máxima a distância média entre partículas. Esta técnica tem como principio a passagem de feixes de raios laser através do meio líquido contendo as partículas dispersas. Quando o feixe atinge uma partícula, ocorrem os processos de transmissão, absorção e espalhamento. O feixe espalhado depende do indice de refração relativo ao meio de suspensão das partículas. Os detectores medem a intensidade e o ângulo da luz espalhada, sendo esse sinal convertido em 
informações a respeito da distribuição do tamanho de partículas. O tamanho médio de partículas dos sólidos é um parâmetro importante para o processamento de materiais cerâmicos obtidos por mistura de pós quando se pretende uma alta densificação do produto final [24].

\section{Termogravimetria (TG)}

$\mathrm{Na}$ termogravimetria a massa de uma substância é determinada em função da temperatura, enquanto a substância é submetida a uma programação controlada de temperatura [25]. A perda e o ganho de massa estão associados a processos de redução e de oxidação, respectivamente, permitindo a caracterização de materiais e seu comportamento sob aquecimento ou resfriamento. Os resultados podem ser influenciados por fatores instrumentais e fatores relacionados às caracteristicas da amostra. Entre os instrumentais podem ser citadas a taxa de aquecimento, a atmosfera do forno e a sensibilidade do mecanismo de coleta de dados. Em relação às caracteristicas da amostra, podem ser citados a quantidade de amostra analisada, o tamanho médio das partículas e sua condutividade térmica [25].

\section{Fluorescência de raios $X(F R X)$}

Pode ser classificada como uma técnica de emissão atômica, fundamentada no efeito fotoelétrico; quando um átomo é exposto a raios $X$, pode ser excitado por meio de ejeção de elétrons das camadas eletrônicas internas. Para estabilização desta forma excitada, elétrons das camadas eletrônicas mais externas ocupam as posições vazias, liberando a diferença de energia existente entre os dois niveis envolvidos. Como este processo envolve níveis de energia que são característicos de cada elemento, a radiação emitida para cada transição é também caracteristica. Desta maneira, a energia da radiação emitida pode ser diretamente utilizada na identificação da espécie sendo analisada. Por outro lado, como a intensidade da radiação emitida é diretamente proporcional à concentração da espécie, a técnica também fornece informações que podem ser utilizadas para fins quantitativos [26].

\section{Difração de raios $X(D R X)$}

$A$ análise por difração de raios $X$ baseia-se no fato dos raios $X$ serem radiação eletromagnética com comprimento de onda da ordem de $1 \AA$ e que podem ser 
difratados. A condição para interferência construtiva da radiação $X$ difratada pelos planos cristalinos de um material é $2 d \cdot \operatorname{sen} \theta=n . \lambda$, lei fundamental da cristalografia de raios $X$, lei de Bragg. Nesta relação fica evidente que para um comprimento de onda $\lambda$ a radiação será difratada nos ângulos $\theta$ para que seja satisfeita a relação de Bragg. Desta forma, o feixe difratado apresenta picos de máximos, produzidos por conjuntos de planos separados por uma distância interplanar d [27].

\section{Microscopia eletrônica de varredura (MEV)}

Uma etapa importante no processamento de pós cerâmicos é a determinação da composição quimica, qualitativa e quantitativa, que pode ser feita por microscopia eletrônica de varredura, assim como o estudo da morfologia do pó e da distribuição do tamanho de particulas. Esta é uma técnica muito versátil ao permitir a análise de superficies rugosas e lisas; dependendo do equipamento empregado, podem se obter aumentos altos com excelente resolução de imagem. O principio da microscopia eletrônica de varredura consiste em incidir na amostra um feixe de elétrons de alta energia e se obter uma imagem. Considerando que o feixe eletrônico pode sofrer uma interação inelástica com a amostra, com uma pequena mudança de direção e conseqüente perda de energia, origina-se um sinal de imagens por elétrons secundários (ES). Outro tipo de interação permitida entre os elétrons e a amostra também ocasiona mudança de direção sem, no entanto, perda de energia. Esta interação elástica dá origem à imagem por elétrons retroespalhados. Por fim, a interação inelástica produz raios $X$, que podem ser utilizados para a identificação analítica. A imagem por ES é mais utilizada por fornecer maior resolução e uma grande profundidade de campo, sendo também de mais fácil interpretação. Para que possa ser analisada, uma amostra deve ser sólida, seca e preferencialmente composta por material condutor; caso contrário deve ser feito um recobrimento com ouro ou carbono [28].

\section{Medidas elétricas}

Existem vários métodos que podem ser usados para a determinação da resistividade elétrica. Conhecendo as dimensões do material, pode ser feita uma medida direta de sua resistência elétrica medindo a corrente elétrica que flui através da amostra sob a ação de um campo elétrico dc. É possivel obter o valor da 
resistividade de acordo com a equação apresentada a seguir. O cálculo da resistividade elétrica é feito com os valores da corrente elétrica medida, da tensão elétrica aplicada e das dimensões da amostra [29]: $\rho=\mathbf{R}$. ( S/e ), $\rho$ é a resistividade elétrica (expressa geralmente em $\Omega . c m$ ), $R$ a resistência elétrica $(\Omega), S$ a área $\left(\mathrm{cm}^{2}\right)$, e e a espessura $(\mathrm{cm})$.

\section{Objetivo geral}

Preparar termistores cerâmicos tipo NTC formados por soluções sólidas de misturas de óxidos de manganês, de níquel e de cobalto por meio da técnica de mistura de óxidos seguida de compactação e sinterização.

Analisar o comportamento elétrico dos termistores para possibilitar o projeto de fabricação de termistores a partir da relação entre resistividade elétrica e temperatura.

\section{Objetivos específicos}

- montagem e calibração de uma câmara porta-amostra para a medida de resistência elétrica na faixa de temperatura entre temperatura ambiente e $180^{\circ} \mathrm{C}$;

- caracterização dos materiais de partida e dos termistores por diferentes técnicas analíticas;

- análise de composições com
(a) variação da concentração de $\mathrm{MnO} 2$, de $\mathrm{NiO}$ e de $\mathrm{Co} 3 \mathrm{O} 4$
(b) variação da concentração de $\mathrm{MnO} 2$
(c) uso de ligante na compactação
(d) diferentes perfis de temperatura e tempo de sinterização
(e) sinterizações sucessivas; $\mathrm{e}$
(f) estudo da reprodutibilidade do sinal a $50^{\circ} \mathrm{C}$ 


\section{MATERIAIS E MÉTODOS}

\subsection{Matérias-primas}

Caracterização dos óxidos precursores.

A Tabela 1 mostra os óxidos precursores e demais materiais usados para a obtenção de cerâmicas termistoras, seus fornecedores e teores de pureza especificados.

Tabela 1: Reagentes para a preparação das cerâmicas termistoras.

\begin{tabular}{llll}
\hline Materiais & Fórmula & Fornecedor & Pureza \% \\
\hline Óxido de níquel & $\mathrm{NiO}$ & JB Química & 99 \\
Óxido de manganês & $\mathrm{MnO}_{2}$ & JB Química & 92 \\
Óxido de cobalto & $\mathrm{CO}_{3} \mathrm{O}_{4}$ & JB Química & 99 \\
Acido esteárico & $\mathrm{C}_{18} \mathrm{H}_{36} \mathrm{O}_{2}$ & - & - \\
Polietilenoglicol (400) & $\mathrm{HO}_{\left(\mathrm{CH}_{2} \mathrm{CH}_{2}\right)_{n} \mathrm{H}}$ & CAAL & 99 \\
Acetona técnica & $\left(\mathrm{CH}_{3}\right)_{2} \mathrm{CO}$ & Synth & - \\
\hline
\end{tabular}

A necessidade de controle estequiométrico para a obtenção de cerâmicas termistoras e sua reprodutibilidade requerem a caracterização dos materiais precursores. Esta caracterização foi feita segundo diferentes técnicas, tentando uma melhor resposta para cada um dos componentes das misturas.

Distribuição de tamanho de partículas

Medidas de distribuição de tamanho de partículas/aglomerados de dispersões dos óxidos foram feitas pela técnica de espalhamento laser em um granulômetro Cilas modelo 1064 de 0,1 a $500 \mu \mathrm{m}$. As dispersões foram preparadas em ultra-som (Vibracell Sonics \& Materials) por $3 \mathrm{~min}$ com água deionizada e defloculante pirofosfato de sódio.

\section{Fluorescência de raios $X$}

Foram feitas análises semi-quantitativas para determinar o teor dos elementos em amostras de pós cerâmicos dos óxidos de manganês, de níquel e de cobalto e em compactos sinterizados de misturas desses óxidos em um espectrômetro de 
fluorescência de raios $X$ de energia dispersiva Jordan Valley EX-2600. O tubo de raios $\mathrm{X}$, com catodo de ródio, foi operado a $12 \mathrm{kV}$ e $100 \mathrm{~mA}$, com 3 medidas para cada amostra. As amostras sinterizadas foram analisadas a $40 \mathrm{kV}$ e $100 \mathrm{~mA}$, com tempo de exposição de $30 \mathrm{~s}$.

\section{Termogravimetria}

Os ensaios termogravimétricos foram feitos para os óxidos precursores em pó. As amostras foram pesadas em balança analítica Mettler ALW 220D e os experimentos feitos em equipamento Shimadzu TG-51, em cadinhos de alumina. Foram obtidas as curvas TG/DTG dos óxidos de niquel, de cobalto e de manganês sob três diferentes atmosferas dinâmicas (ar, $\mathrm{N}_{2}$ e mistura $\mathrm{N}_{2} / \mathrm{H}_{2}$ ), em quatro diferentes vazões $\left(50 \mathrm{~mL} / \mathrm{min}, 100 \mathrm{~mL} / \mathrm{min}\right.$ sob atmosfera de ar, $50 \mathrm{~mL} / \mathrm{min}$ sob $\mathrm{N}_{2}$ e $25 \mathrm{~mL} / \mathrm{min}\left(\mathrm{N}_{2}\right)$ com $75 \mathrm{~mL} / \mathrm{min}\left(\mathrm{H}_{2}\right)$, todas com taxa de aquecimento $10^{\circ} \mathrm{C} / \mathrm{min}$ até $1250^{\circ} \mathrm{C}\left(1000{ }^{\circ} \mathrm{C}\right.$ sob atmosfera redutora) e com resfriamento sem controle até a temperatura ambiente. A massa em cada experimento foi $\sim 40 \mathrm{mg}$. Em todas as figuras de termogravimetria deste trabalho a temperatura é apresentada na abscissa em graus centígrados e nas ordenadas TGA significa a massa e DrTGA a derivada da massa em relação ao tempo em minutos, para taxa de aquecimento de $10^{\circ} \mathrm{C} / \mathrm{min}$.

\subsection{Preparação das amostras}

As cerâmicas foram preparadas por meio das misturas de pós dos óxidos de níquel, de manganês e de cobalto em diferentes concentrações.

Os óxidos precursores foram colocados em estufa a $100^{\circ} \mathrm{C} / 2 \mathrm{~h}$, pesados em balança analítica (Mettler Toledo $A B$ ), misturados e homogeneizados em almofariz de ágata, com adição de $1 \%$ em massa de ácido esteárico.

As misturas de pós cerâmicos foram compactadas uniaxialmente em matriz metálica a $100 \mathrm{MPa}$ na forma de cilindros de diâmetro $10 \mathrm{~mm}$ e espessura $2 \mathrm{~mm}$, e sinterizadas ao ar em forno resistivo a $1250{ }^{\circ} \mathrm{C} / 2 \mathrm{~h}$, com taxa de aquecimento e de resfriamento $10^{\circ} \mathrm{C} / \mathrm{min}$. Para o estudo do comportamento elétrico, foi depositado eletrodo de prata nas faces paralelas das amostras.

A descrição da preparação das amostras, dependendo da finalidade, está a seguir: 


\subsubsection{Diferentes concentrações de óxidos de manganês, de niquel e de cobalto}

Foram preparadas diferentes composições, mostradas na Tabela 2, com sinterização ao ar a $1250^{\circ} \mathrm{C} / 2 \mathrm{~h}$.

Tabela 2: Concentração em massa dos óxidos adicionados na mistura

\begin{tabular}{llll}
\hline Amostras & $\% \mathrm{NiO}$ & $\% \mathrm{MnO}_{2}$ & $\% \mathrm{Co}_{3} \mathrm{O}_{4}$ \\
\hline A1 & 50,1 & 49,9 & 0 \\
A2 & 50,3 & 0 & 49,7 \\
A3 & 0 & 50,4 & 49,6 \\
A4 & 31,8 & 33,3 & 34,9 \\
A5 & 49,2 & 25,4 & 25,4 \\
A6 & 26,2 & 48,4 & 25,4 \\
A7 & 25,2 & 25,3 & 49,5 \\
\hline
\end{tabular}

Para facilidade de leitura, neste trabalho usaremos as seguintes porcentagens na descrição das composições: $50 \%, 33,3 \%$ e $25 \%$.

\subsubsection{Diferentes concentrações de óxido de manganês}

Os estudos de variação das concentrações de óxidos, efeito do plastificante e rotas de sinterização, permitiram optar por quatro concentrações diferentes na tentativa de obter melhor comportamento termistor. Foram então preparadas quatro amostras, $\left(50 \% \mathrm{NiO}-50 \% \mathrm{Co}_{3} \mathrm{O}_{4}\right)_{1-x}\left(\mathrm{MnO}_{2}\right)_{x}$, com $\mathrm{x}=0,0,1,0,2$ e $0,3 \mathrm{~mol}$, denominadas 1D, 2D, 3D e 4D, respectivamente.

\subsubsection{Uso de ligante na compactação (polietileno glicol)}

Foram preparadas duas amostras de mesma composiçăo (33,3\% NiO - 33,3\% $\mathrm{MnO}_{2}-33,3 \% \mathrm{Co}_{3} \mathrm{O}_{4}$ ) com e sem ligante polietileno glicol (PEG 400). A compactação e a sinterização foram feitas como descrito acima.

\subsubsection{Diferentes perfis de temperatura/tempo de sinterização}

Foram preparadas duas amostras de mesma composição (33,3\% NiO - 33,3\% $\left.\mathrm{MnO}_{2}-33,3 \% \mathrm{Co}_{3} \mathrm{O}_{4}\right)$, denominadas 1B e 2B. A amostra 1B foi sinterizada a 1250 ${ }^{\circ} \mathrm{C} / 2 \mathrm{~h}$, com taxa de aquecimento e resfriamento de $10^{\circ} \mathrm{C} / \mathrm{min}$. A amostra $2 \mathrm{~B}$ tratada termicamente a $600^{\circ} \mathrm{C} / 2 \mathrm{~h}$ com taxa de aquecimento de $5{ }^{\circ} \mathrm{C} / \mathrm{min}$, seguido de 1250 ${ }^{\circ} \mathrm{C} / 1 \mathrm{~h}$ com taxa de aquecimento e resfriamento $10^{\circ} \mathrm{C} / \mathrm{min}$. 


\subsubsection{Sinterizações sucessivas}

Foram preparadas quatro amostras de mesma composição $(33,3 \% \mathrm{NiO}$ $33,3 \% \mathrm{MnO}_{2}-33,3 \% \mathrm{Co}_{3} \mathrm{O}_{4}$ ). As amostras, denominadas $1 \mathrm{C}, 2 \mathrm{C}, 3 \mathrm{C}$ e $4 \mathrm{C}$, foram sinterizadas a $1250^{\circ} \mathrm{C} / 2 \mathrm{~h} \mathrm{com}$ taxa de aquecimento e resfriamento $10^{\circ} \mathrm{C} / \mathrm{min}$. As amostras $2 \mathrm{C}$ e $3 \mathrm{C}$ foram trituradas, compactadas e sinterizadas a $1250^{\circ} \mathrm{C} / 2 \mathrm{~h}$. A amostra $3 \mathrm{C}$ foi triturada e novamente homogeneizada em almofariz de ágata, compactada e sinterizada a $1250^{\circ} \mathrm{C} / 2 \mathrm{~h}$.

\subsubsection{Estudo da dependência da resistividade elétrica com a ciclagem térmica a $50^{\circ} \mathrm{C}$ (reprodutibilidade do sinal)}

Foram preparadas como descrito acima no item 2.2.2.

\subsection{Medidas elétricas}

As medidas elétricas foram feitas em uma câmara porta-amostra, apresentada esquematicamente na Figura 1, constituida por ferro de solda como aquecedor, eletrodo de solda como contato elétrico, variac para aplicação de tensão (0-100 V), termopar de cobre-constantan, e um multímetro digital Hewlett Packard 974A para a avaliação dos valores de resistência elétrica e força eletromotriz do termopar.

\subsection{Difração de raios $X$}

Os experimentos de difração de raios $X$ foram feitos, em amostras na forma de pós e em pastilhas, em um difratômetro Bruker-AXS modelo D8 Advance em configuração de Bragg-Brentano $\theta-2 \theta$ com radiação Cu-ka na faixa de $2 \theta 20-80^{\circ}$, com passo de $0,05^{\circ}$ e tempo por passo de $5 \mathrm{~s}$. As análises de difração de raios $X$ foram qualitativas por causa da fluorescência produzida pelos metais da amostra, principalmente o manganês, que produz alta radiação de fundo no detector de estado sólido (de cintilação de Nal:Tl). 


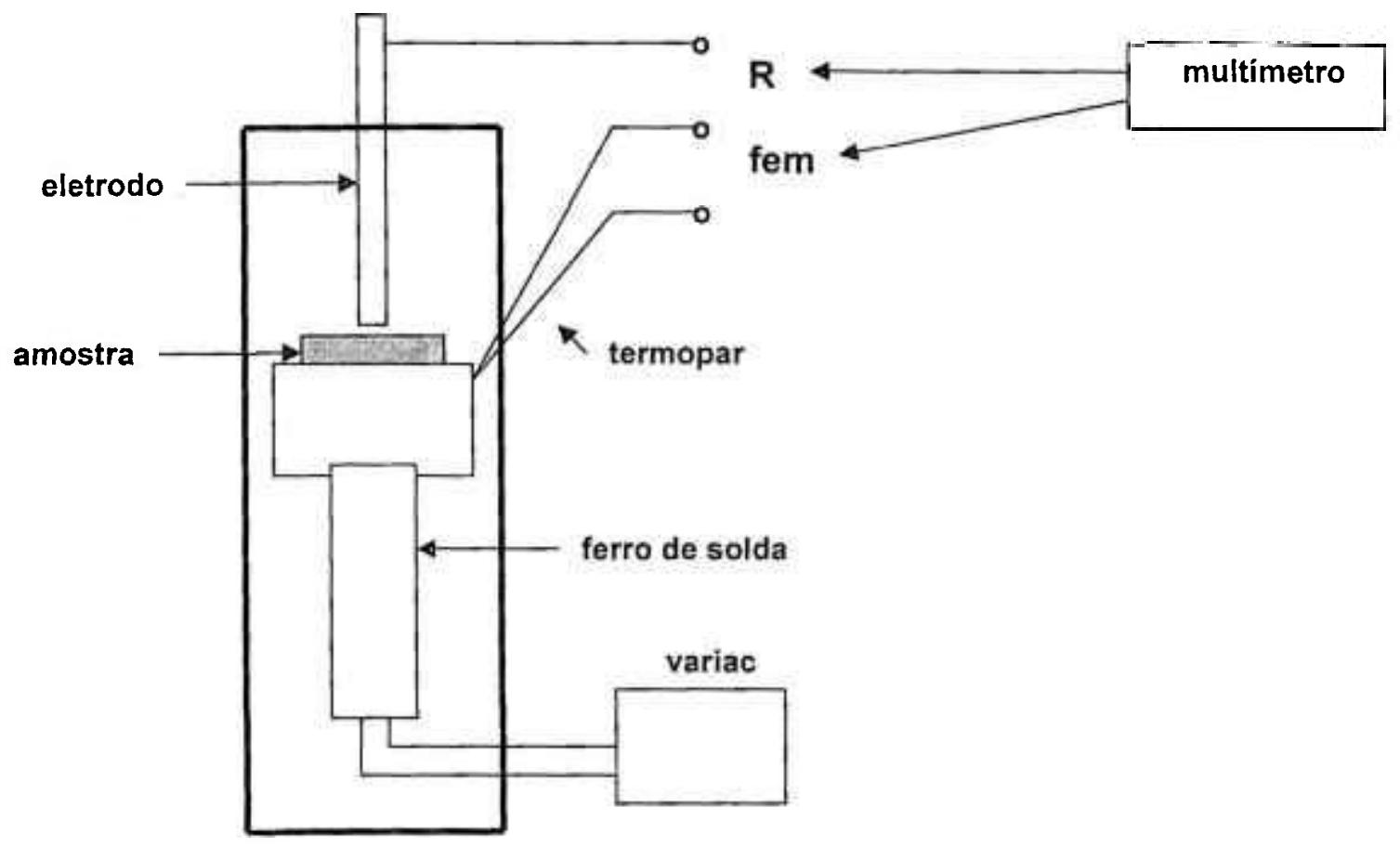

Figura 1: Representação esquemática do conjunto para medidas de resistência elétrica.

Foram feitas medidas de temperatura em função da tensão $(0-100 \mathrm{~V})$ para a aferição da temperatura da câmara. Após a calibração da câmara de medidas, foram feitas medidas de valores de resistência elétrica em função da temperatura nos vários tipos de amostras preparadas. Foram também feitas medidas da resistência elétrica a $50{ }^{\circ} \mathrm{C}$ em função do tempo durante 6 meses, para a determinação da reprodutibilidade e estabilidade do termistor. Nesse caso, a câmara é mantida a 50 ${ }^{\circ} \mathrm{C}$ e as amostras de termistores cerâmicos são introduzidas na câmara para a aferição da resistência elétrica e retiradas para armazenamento à temperatura ambiente até a próxima aferição. Esta série de experimentos foi feita para verificar se algumas das composições atendiam um dos requisitos para uso em veículos automotivos, a ciclagem térmica. Ao ligar, desligar e religar o motor do veículo, não pode haver deterioração do sinal do termistor cerâmico. 


\section{RESULTADOS E DISCUSSÃO}

\section{Caracterização dos óxidos precursores}

Os resultados dos teores de pureza das matérias-primas determinados por meio de análise semi-quantitativa por fluorescência de raios $X$ foram: $99,99 \%$ para o óxido de níquel ( $99 \%$ segundo o fornecedor), $89,3 \%$ para o di-óxido de manganês (90\%) e $99 \%$ para o tri-óxido de cobalto $(97 \%)$. O objetivo neste trabalho foi usar óxidos de baixo custo disponiveis no mercado nacional para possibilitar a posterior fabricação de termistores cerâmicos com baixa relação custo/benefício.

\section{Distribuição de tamanho de partículas}

Os pós dos óxidos precursores foram submetidos a experimentos, como recebidos, em um granulômetro a laser.

O pós de óxido de níquel apresentam distribuição bimodal com diâmetro médio equivalente das partículas $1,6 \mu \mathrm{m}$, sendo que $50 \%$ das partículas tem diâmetro equivalente inferior $\mathrm{a} \sim 1,6 \mu \mathrm{m}$ e $10 \%$ inferior $\mathrm{a} \sim 0,5 \mu \mathrm{m}$.

Os pós de dióxido de manganês apresentam distribuição bimodal com diâmetro médio equivalente das partículas $\sim 2,1 \mu \mathrm{m}$, sendo que $90 \%$ das partículas possuem diâmetro equivalente inferior $\mathrm{a} \sim 4,5 \mu \mathrm{m}$.

Os pós de trióxido de cobalto apresentam distribuição bimodal com diâmetro médio equivalente das particulas $0,7 \mu \mathrm{m}$, sendo que $90 \%$ das particulas possuem diâmetro equivalente inferior a 2,0 $\mu \mathrm{m}$ tamanho.

Os valores encontrados para o diâmetro médio equivalente das particulas dos óxidos de niquel $(\sim 1,6 \mu \mathrm{m})$, de manganês $(\sim 2,1 \mu \mathrm{m})$ e de cobalto $(\sim 0,7 \mu \mathrm{m})$ são próximos e adequados para a preparação por mistura de óxidos durante o processo de mistura e compactação.

\section{Termogravimetria}

Nesta parte do trabalho apresentamos os resultados de ensaio termogravimétrico das matérias-primas. Os óxidos precursores podem apresentar diferentes números de oxidação: níquel $\left(\mathrm{Ni}^{\circ}, \mathrm{NiO}, \mathrm{Ni}_{2} \mathrm{O}_{3}\right)$, cobalto $\left(\mathrm{Co}^{\circ}, \mathrm{CoO}, \mathrm{CO}_{2} \mathrm{O}_{3}\right.$, $\mathrm{Co}_{3} \mathrm{O}_{4}$ ) e manganês $\left(\mathrm{Mn}^{\circ}, \mathrm{MnO}\right.$ e $\mathrm{MnO}_{2}$ ). Os ensaios termogravimétricos foram feitos para caracterizar termicamente os óxidos precursores, simulando o processo de 
sinterização. Experimentos com diferentes atmosferas e vazões foram feitos para favorecer eventos com perdas e/ou ganhos de massa em diferentes etapas. O estudo da redução e da oxidação de ions metálicos possibilita a caracterização do estado de oxidação. No apêndice no fim desta Dissertação são identificados os eventos e apresentados os valores de temperatura em que ocorrem e as correspondentes perdas de massa.

As curvas TG/DTG do óxido de níquel apresentadas na Figuras $2 a$ e $2 b$ foram obtidas com duas atmosferas dinâmicas e nas seguintes vazões: a) $\mathrm{N}_{2}$ com vazão de $50 \mathrm{~mL} / \mathrm{min}$ ou ar (100 mL/min) e b) $\mathrm{N}_{2} / \mathrm{H}_{2}$ com $25 \mathrm{~mL} / \mathrm{min}$ de $\mathrm{N}_{2}$ e $75 \mathrm{~mL} / \mathrm{min}$ de $\mathrm{H}_{2}$.
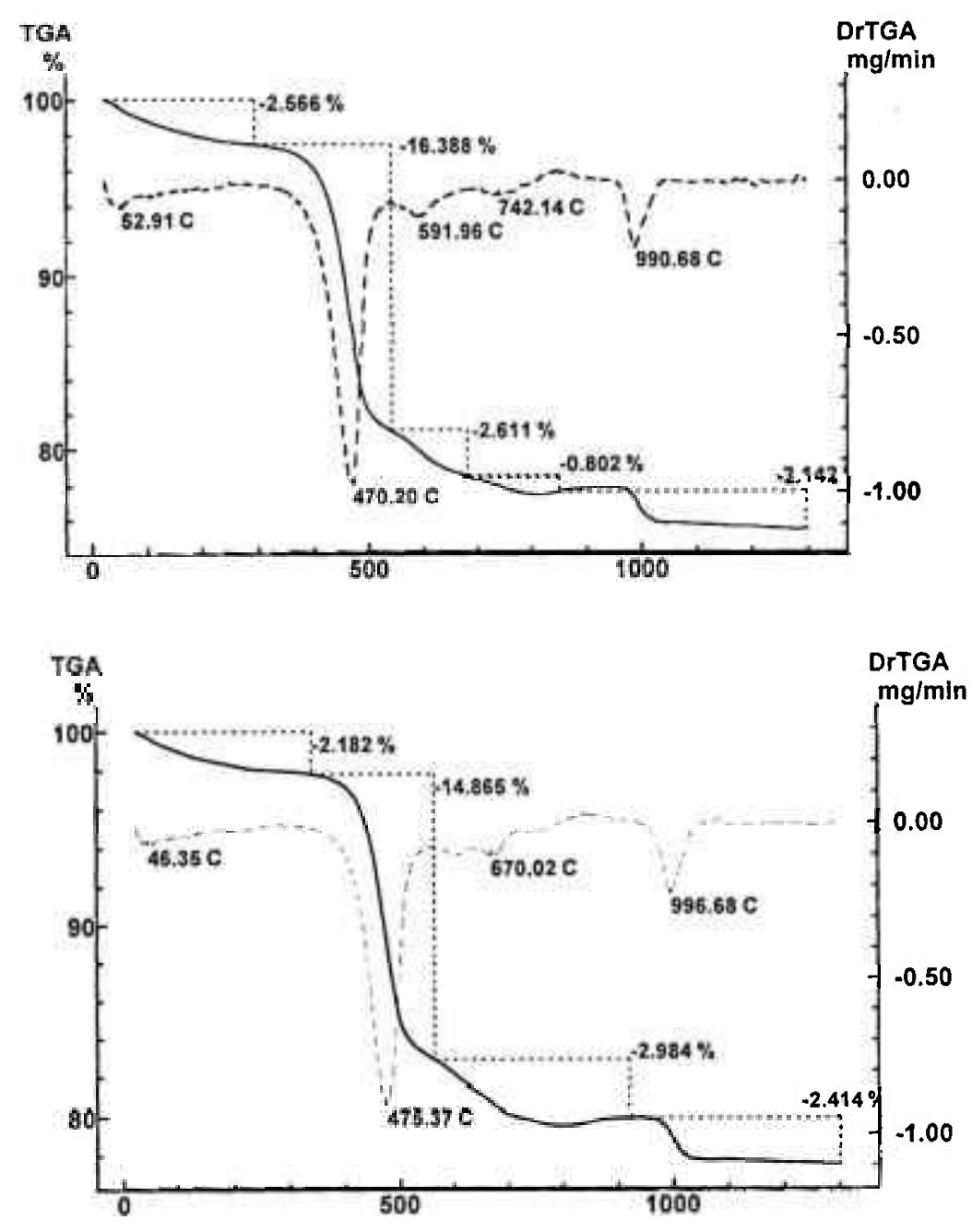

Temperatura $\left({ }^{\circ} \mathrm{C}\right)$

Figura 2: Curvas TG/DTG do óxido de niquel: a) sob atmosfera dinâmica de $\mathrm{N}_{2}$ (50 $\mathrm{mL} / \mathrm{min}$ ); b) $\mathrm{N}_{2}, 25 \mathrm{~mL} / \mathrm{min}$ e $\mathrm{H}_{2}, 75 \mathrm{~mL} / \mathrm{min}$. 
No óxido de níquel o elemento níquel apresenta número de oxidação $\mathrm{Ni}^{2+}$, tendo o óxido a fórmula geral NiO. O teor de pureza elou de $\mathrm{Ni}^{2+}$ reduzido a $\mathrm{Ni}^{0}$ foi $98 \%$, com um desvio de $1 \%$ do valor fornecido pelo fabricante.

A Figura 3 apresenta as curvas TG/DTG do óxido de manganês obtidas sob atmosferas dinâmicas oxidante (ar, $100 \mathrm{~mL} / \mathrm{min}$ ) e redutora $\left(\mathrm{N}_{2}, 25 \mathrm{~mL} / \mathrm{min}\right.$ e $\mathrm{H}_{2}, 75$ $\mathrm{mL} / \mathrm{min})$.
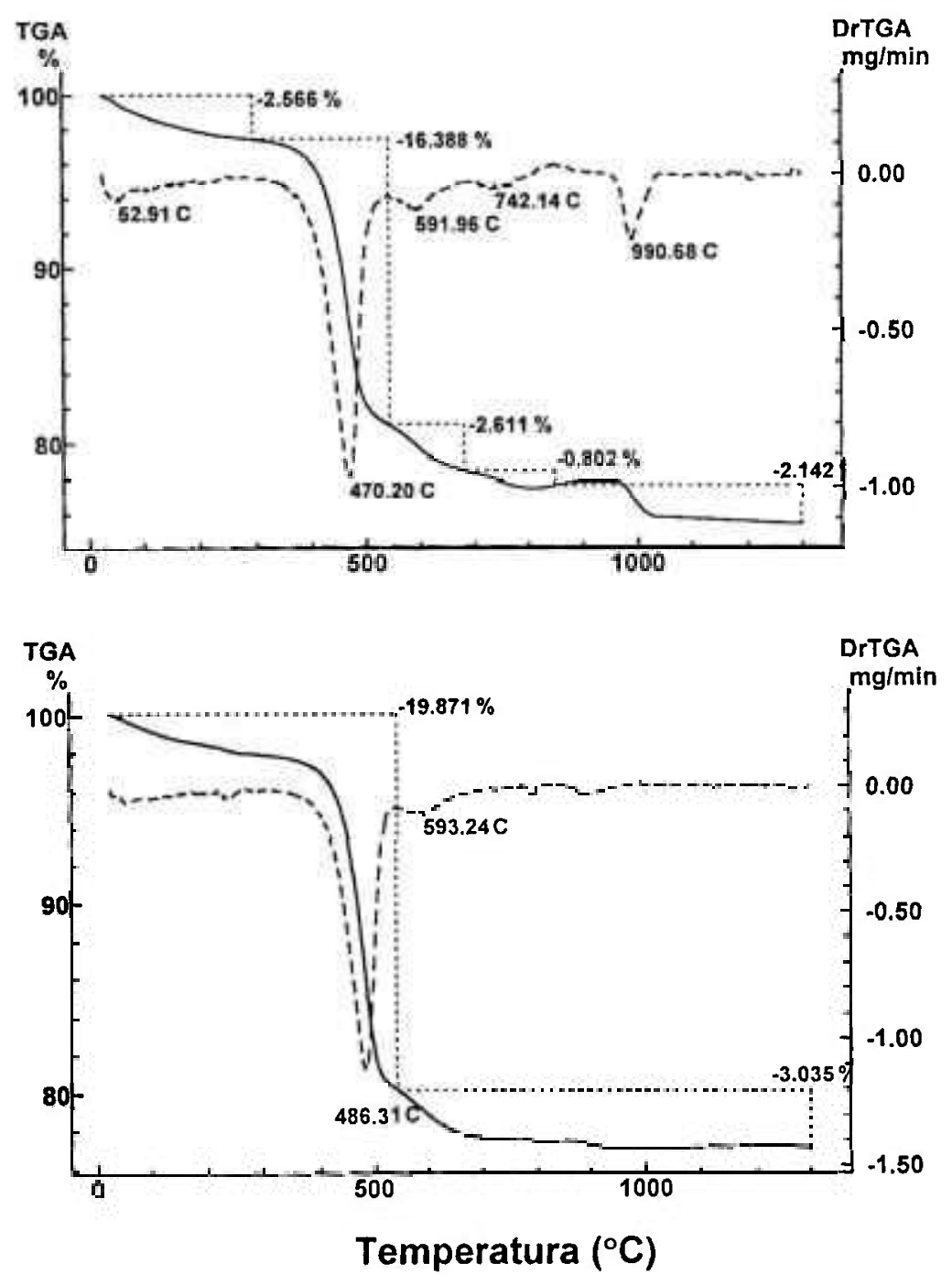

Figura 3: Curvas TG/DTG do óxido de manganês: a) sob atmosfera dinâmica de ar a $100 \mathrm{~mL} / \mathrm{min}$; b) $\mathrm{N}_{2}, 25 \mathrm{~mL} / \mathrm{min}$ e $\mathrm{H}_{2}, 75 \mathrm{~mL} / \mathrm{min}$.

o elemento manganês apresenta número de oxidaçāo $\mathrm{Mn}^{4+}$, sendo utilizado como óxido de fórmula geral $\mathrm{MnO}_{2}$. 
A Figura 4 mostra as curvas TG/DTG do óxido de cobalto obtidas sob atmosferas oxidante (ar com vazão $100 \mathrm{~mL} / \mathrm{min}$ ) e redutora $\left(\mathrm{N}_{2}, 25 \mathrm{~mL} / \mathrm{min}\right.$ e $\mathrm{H}_{2}, 75$ $\mathrm{mL} / \mathrm{min})$.
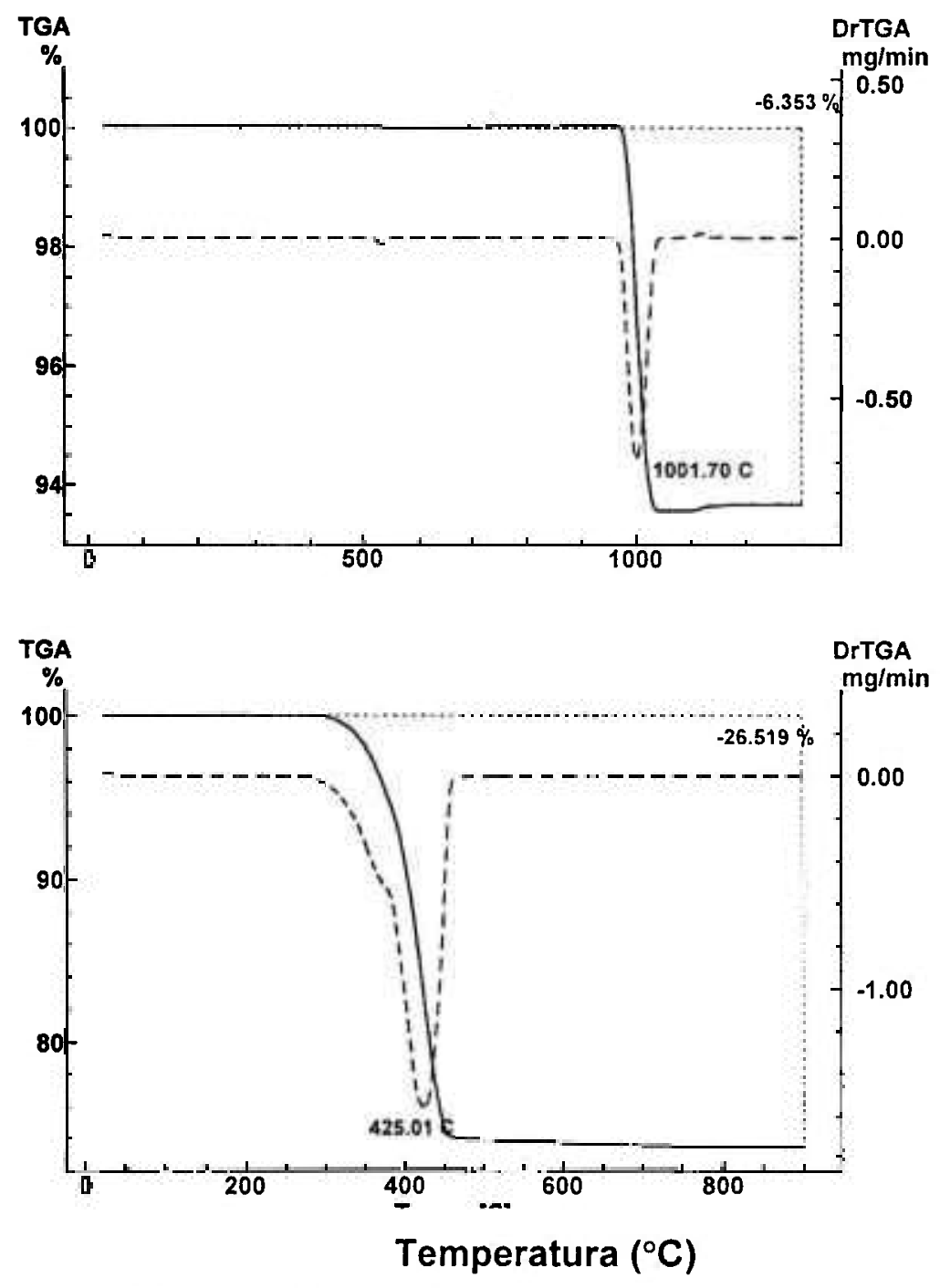

Figura 4: Curvas TG/DTG do óxido de cobalto: a) sob atmosfera dinâmica de ar a $100 \mathrm{~mL} / \mathrm{min}$ e b) $\mathrm{N}_{2}, 25 \mathrm{~mL} / \mathrm{min}$ e $\mathrm{H}_{2}, 75 \mathrm{~mL} / \mathrm{min}$.

As curvas TG/DTG mostram que o óxido de cobalto é uma mistura estequiométrica na razão $1: 1$ de $\mathrm{Co}_{2} \mathrm{O}_{3}$ e $\mathrm{CoO}$ com pureza $99 \%$.

O estudo térmico dos três diferentes óxidos utilizados como precursores de cerâmicas termistoras do tipo NTC mostra que os materiais de partida seguem as concentrações fornecidas pelo fabricante e que as estequiometrias desejadas podem ser obtidas tendo estes valores como referência. 


\subsection{Diferentes concentrações de óxidos de manganês, de níquel e de cobalto}

Os compactos cerâmicos obtidos foram analisados por fluorescência de raios $X$. Cada amostra cilindrica teve suas duas faces paralelas analisadas e os valores de concentração apresentados são médias das duas medidas. Os resultados são mostrados na Tabela 3.

Tabela 3: Valores das concentrações de $\mathrm{NiO}, \mathrm{MnO}_{2}$ e $\mathrm{Co}_{3} \mathrm{O}_{4}$ adicionados e os obtidos por fluorescência de raios $X$ (entre parêntesis).

\begin{tabular}{llll}
\hline $\begin{array}{l}\text { número da } \\
\text { amostra }\end{array}$ & $\begin{array}{l}\% \mathrm{NiO} \\
\text { adicionado } \\
\text { (FRX) }\end{array}$ & $\begin{array}{l}\% \mathrm{MnO}_{2} \\
\text { adicionado } \\
\text { (FRX) }\end{array}$ & $\begin{array}{l}\% \mathrm{Co}_{3} \mathrm{O}_{4} \\
\text { adicionado } \\
\text { (FRX) }\end{array}$ \\
\hline 1 & 50,1 & 49.9 & 0 \\
& $(49,2)$ & $(50,8)$ & \\
2 & 50,3 & 0 & 49,7 \\
& $(49,9)$ & & $(50,1)$ \\
3 & 0 & 50,4 & 49,6 \\
& & $(50,1)$ & $(49,9)$ \\
4 & 31,8 & 33,3 & 34,9 \\
& $(32,0)$ & $(33,2)$ & $(34,8)$ \\
5 & 49,2 & 25,4 & 25,4 \\
& $(49,5)$ & $(25,3)$ & $(25,5)$ \\
6 & 26,2 & 48,4 & 25,4 \\
& $(26,0)$ & $(48,7)$ & $(26,3)$ \\
7 & 25,2 & 25,3 & 49,5 \\
& $(24,8)$ & $(25,3)$ & $(49,9)$ \\
\hline
\end{tabular}

A comparação entre os valores adicionados e os obtidos por fluorescência de raios $\mathrm{X}$ evidencia que as amostras apresentam estequiometria próxima à desejada.

A seguir foram obtidas curvas TG/DTG das misturas dos óxidos em diferentes concentrações, atmosfera e vazão. As amostras analisadas foram nomeadas A1 $\left(50 \% \mathrm{NiO}-50 \% \mathrm{MnO}_{2}\right), \mathrm{A} 2\left(50 \% \mathrm{NiO}-50 \% \mathrm{Co}_{3} \mathrm{O}_{4}\right), \mathrm{A} 3\left(50 \% \mathrm{MnO}_{2}-50 \% \mathrm{Co}_{3} \mathrm{O}_{4}\right)$ e A4 (33,3\% $\left.\mathrm{NiO}-33,3 \% \mathrm{MnO}_{2}-33,3 \% \mathrm{Co}_{3} \mathrm{O}_{4}\right)$.

\section{Termogravimetria}

A Figura 5 mostra as curvas TG/DTG da composição $50 \% \mathrm{NiO}-50 \% \mathrm{MnO}_{2}$ sob atmosferas oxidante e redutora. 

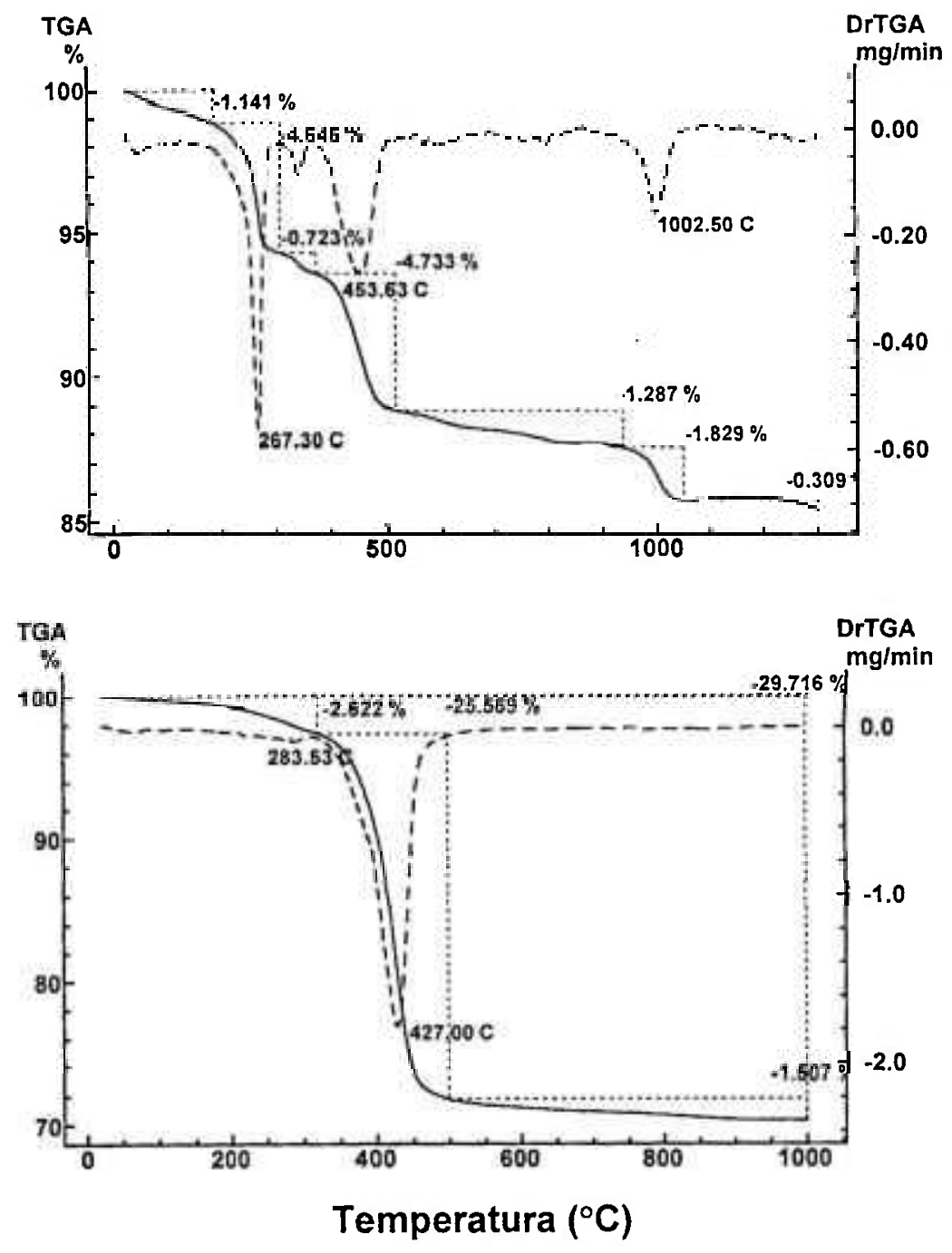

Figura 5: Curvas TG/DTG da mistura $50 \% \mathrm{NiO}-50 \%$ de $\mathrm{MnO}_{2}$ : a) sob atmosfera dinâmica (ar), $20 \mathrm{~mL} / \mathrm{min}$; b) $\mathrm{N}_{2}, 25 \mathrm{~mL} / \mathrm{min}$ e $\mathrm{H}_{2}, 75 \mathrm{~mL} / \mathrm{min}$.

A Figura 6 mostra curvas TG/DTG da composição $50 \% \mathrm{NiO}-50 \% \mathrm{Co}_{3} \mathrm{O}_{4}$ sob atmosferas oxidante e redutora. 

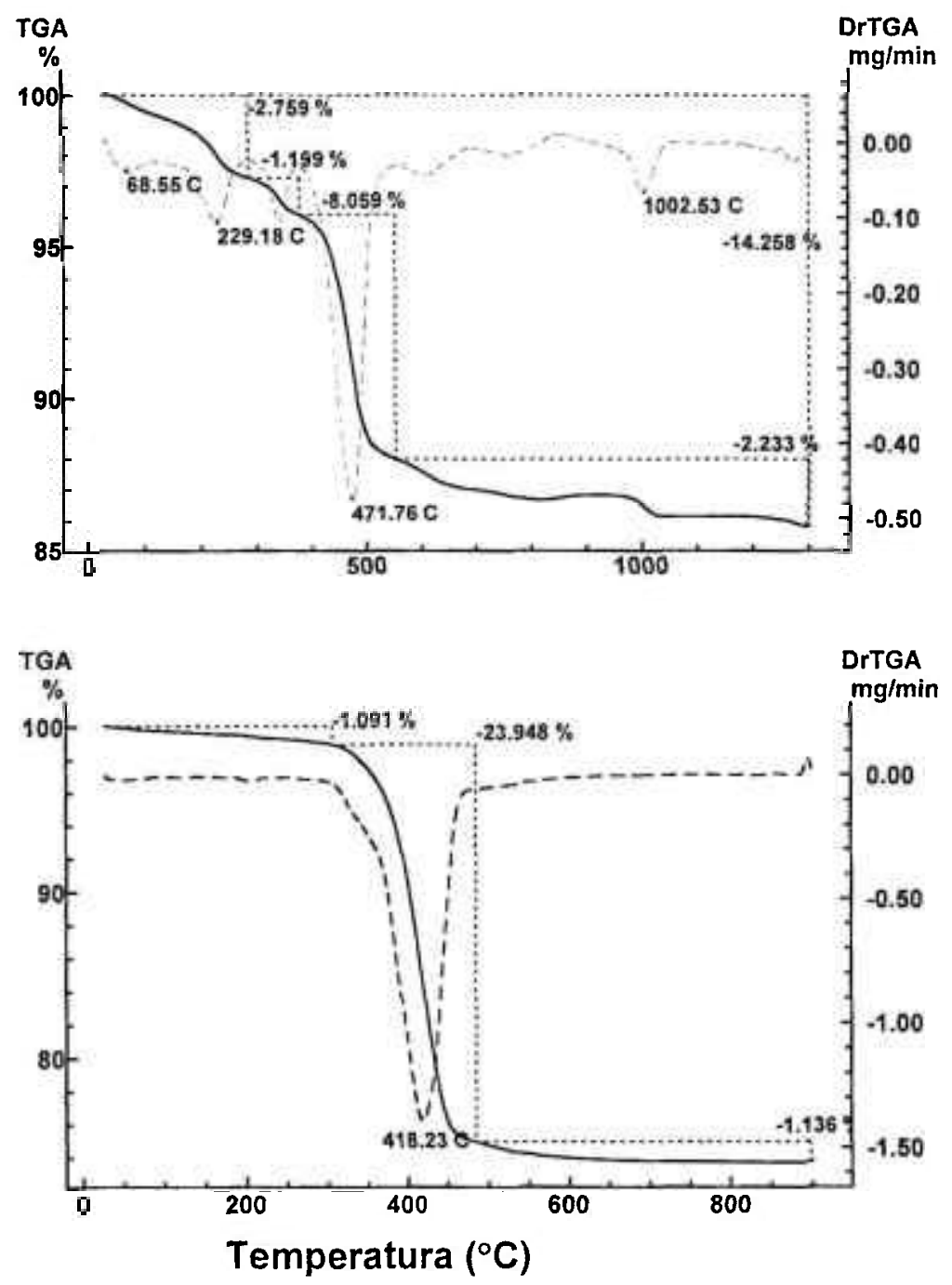

Figura 6: Curvas TG/DTG da mistura $50 \% \mathrm{NiO}-50 \% \quad \mathrm{Co}_{3} \mathrm{O}_{4}$ : a) sob atmosfera dinâmica (ar), $100 \mathrm{~mL} / \mathrm{min}$; b) $\mathrm{N}_{2}, 25 \mathrm{~mL} / \mathrm{min} \mathrm{e} \mathrm{H}_{2}, 75 \mathrm{~mL} / \mathrm{min}$.

A Figura 7 mostra curvas TG/DTG da composição $50 \% \mathrm{MnO}_{2}-50 \% \mathrm{Co}_{3} \mathrm{O}_{4}$ sob atmosferas oxidante e redutora. 

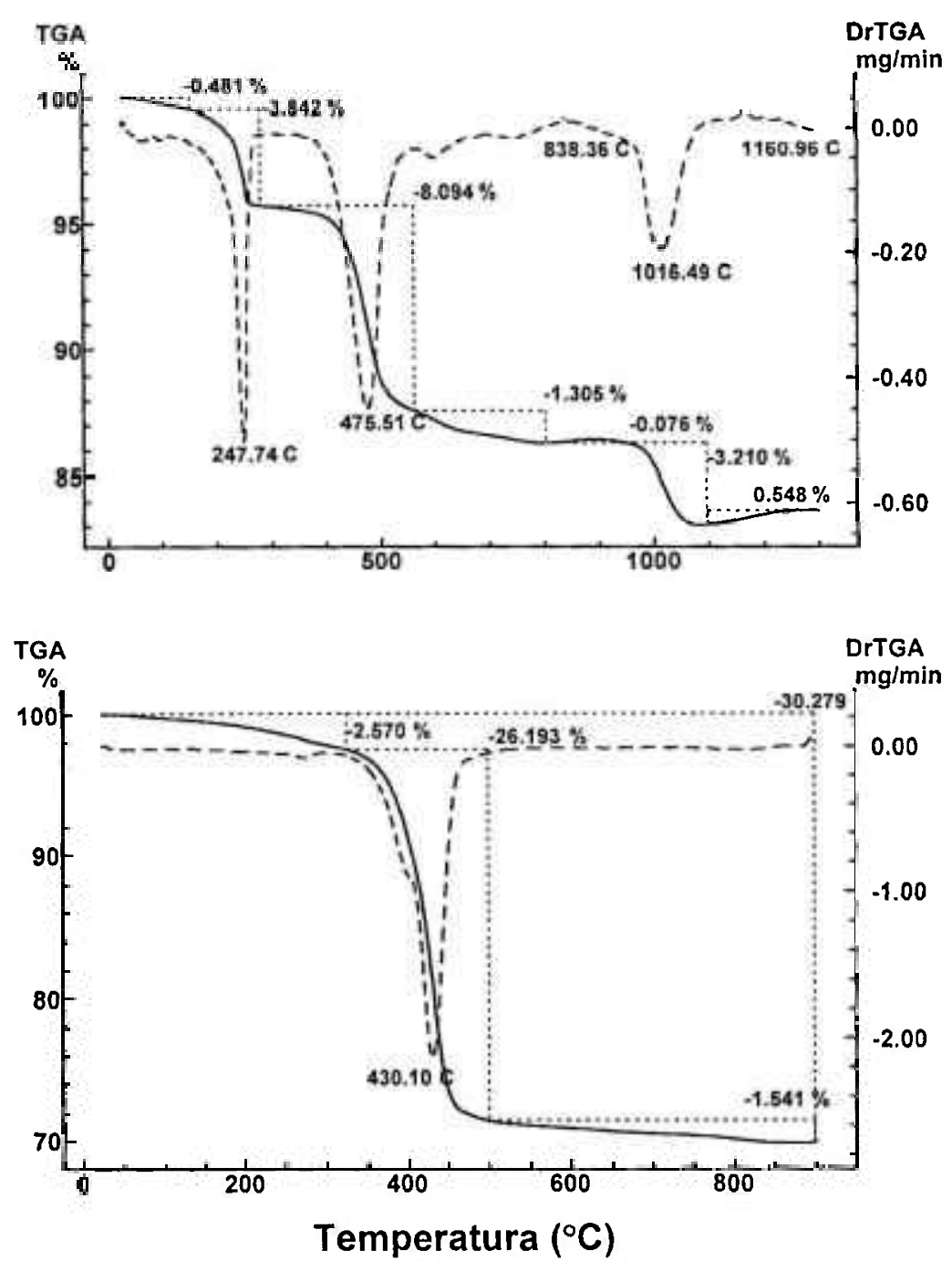

Figura 7: Curvas TG/DTG da mistura $50 \% \mathrm{MnO}_{2}-50 \% \mathrm{Co}_{3} \mathrm{O}_{4}$ : a) sob atmosfera dinâmica (ar), $100 \mathrm{~mL} / \mathrm{min}$; b) $\mathrm{N}_{2}, 25 \mathrm{~mL} / \mathrm{min}$ e $\mathrm{H}_{2}, 75 \mathrm{~mL} / \mathrm{min}$.

A Figura 8 mostra curvas TG/DTG da composição $33,3 \% \mathrm{NiO}-33,3 \% \mathrm{MnO}_{2}$ $33,3 \% \mathrm{Co}_{3} \mathrm{O}_{4}$ sob atmosferas oxidante e redutora. 

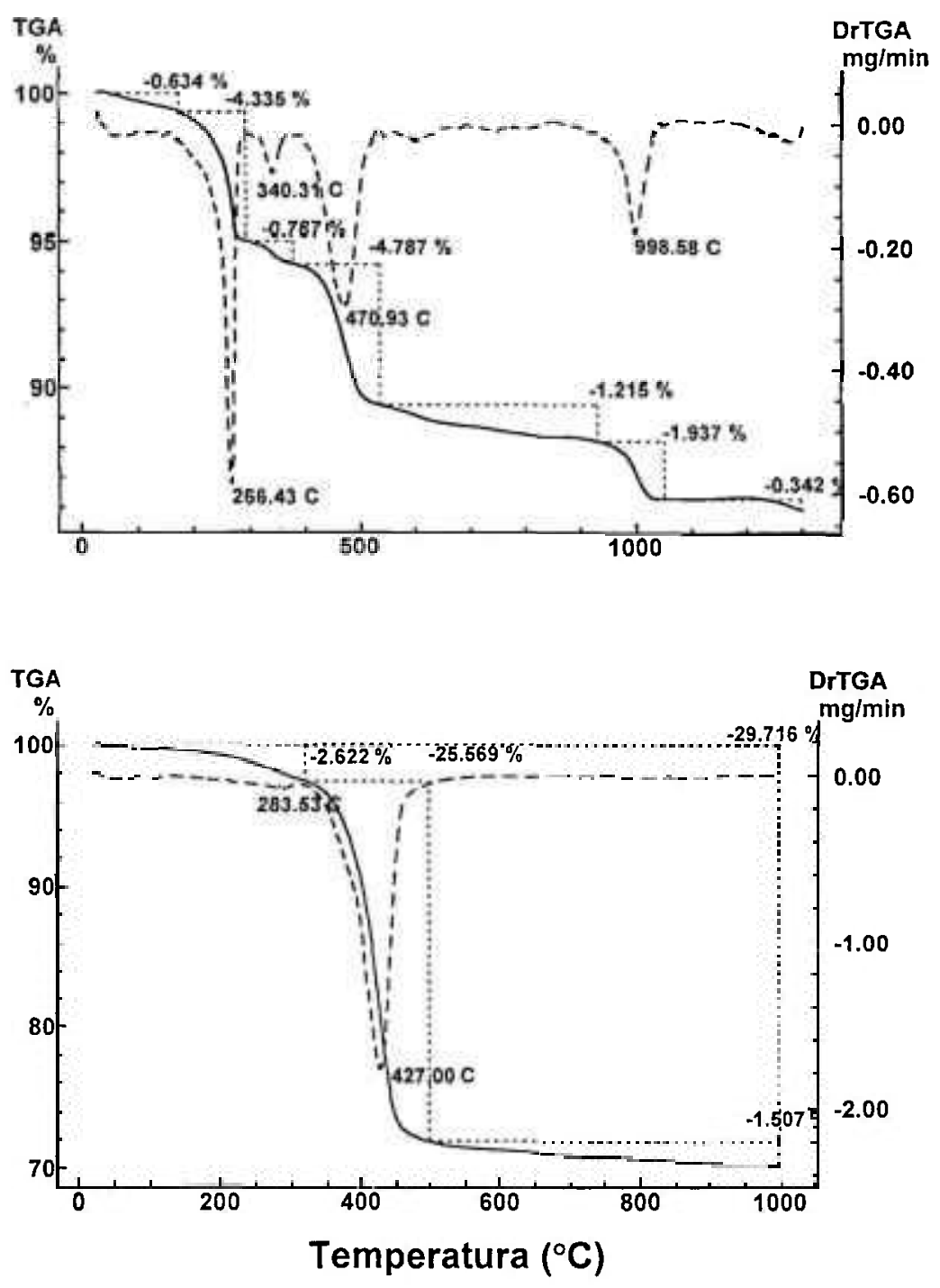

Figura 8: Curvas TG/DTG da mistura $33,3 \% \mathrm{NiO}-33,3 \% \mathrm{MnO}_{2}-33,3 \% \mathrm{Co}_{3} \mathrm{O}_{4}$ sob atmosfera dinâmica (ar), $100 \mathrm{~mL} / \mathrm{min}$.

A perda de massa, que ocorre principalmente em três etapas na preparação dos termistores por mistura de óxidos metálicos com diferentes concentrações e sob diferentes atmosferas, mostra que durante o processo de sinterização a ordem dos eventos é sempre a mesma, com a redução acontecendo como se os óxidos estivessem reagindo individualmente e com ordem preferencial de redução segundo o potencial padrão de redução de cada ín metálico $\left(\mathrm{Mn}^{4+}-\mathrm{Mn}^{3+}-\mathrm{Mn}^{2+}-\mathrm{Mn}^{0}, \mathrm{Ni}^{2+}-\mathrm{Ni}^{0}, \mathrm{Co}^{3+}-\mathrm{Co}^{2+}-\mathrm{Co}^{\circ}\right)$. A difusão e a possivel formação de novas fases não foram evidenciadas devido à necessidade de maior quantidade de energia para a promoção de tais processos, o que justifica o valor utilizado para a temperatura de sinterização, $1250^{\circ} \mathrm{C}$ com patamar de $2 \mathrm{~h}$ e taxa de aquecimento/resfriamento de $10^{\circ} \mathrm{C} / \mathrm{min}$. 


\section{Microscopia eletrônica de varredura}

As amostras com sete diferentes composições (Cf. Tabela 5) foram fraturadas e analisadas por microscopia eletrônica de varredura. Para cada composição foram obtidas micrografias com os respectivos aumentos e regiões: aumento de 250 vezes em uma região típica, 500 vezes em uma região mais densa e 1000 vezes em um grão. A seguir são apresentadas nas Figuras 9,10 e 11 as micrografias da amostra de composição $50 \% \mathrm{NiO}-50 \% \mathrm{MnO}_{2}$.

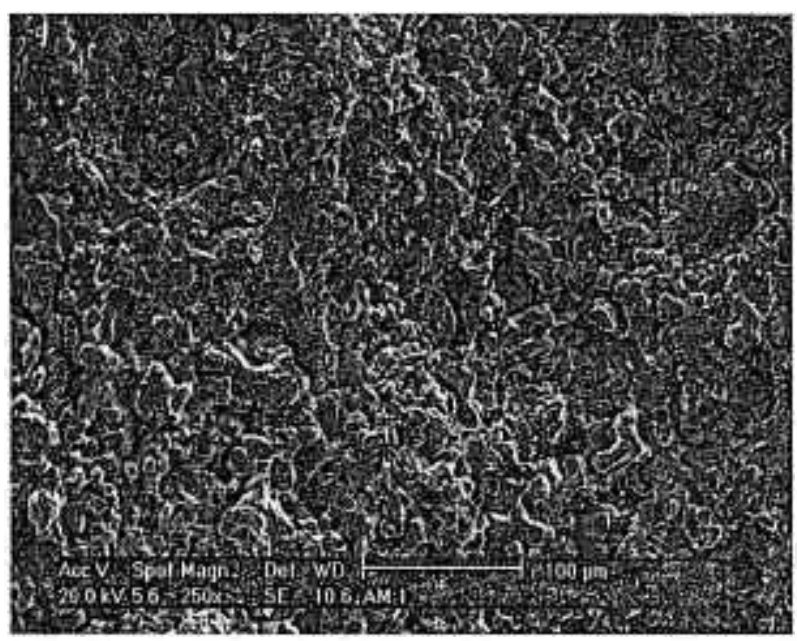

Figura 9: Micrografia de superfície de fratura obtida em microscópio eletrônico de varredura da cerâmica de composição $50 \% \mathrm{NiO}-50 \% \mathrm{MnO}_{2}$; região típica.

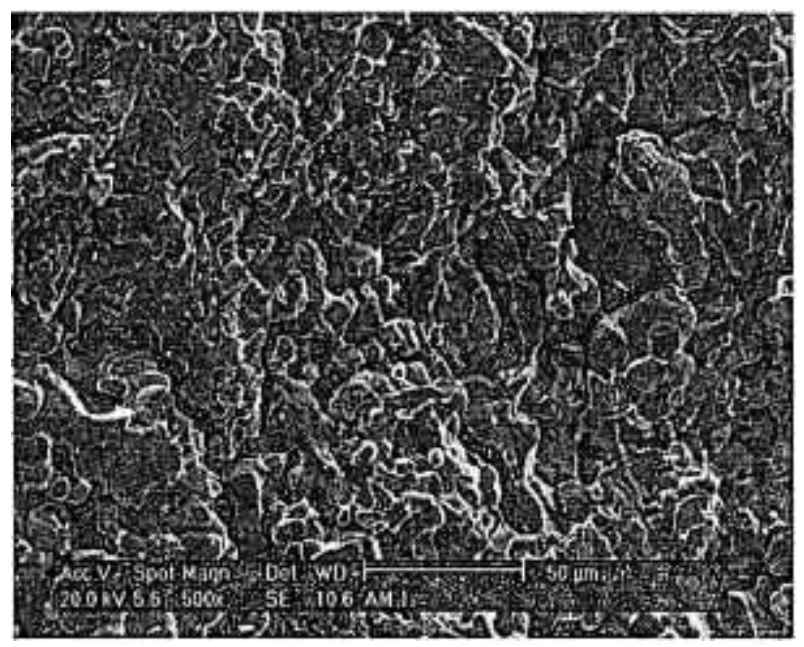

Figura 10: Micrografia de superfície de fratura obtida em microscópio eletrônico de varredura da cerâmica de composição $50 \% \mathrm{NiO}-50 \% \quad \mathrm{MnO}_{2}$; região de maior densidade. 


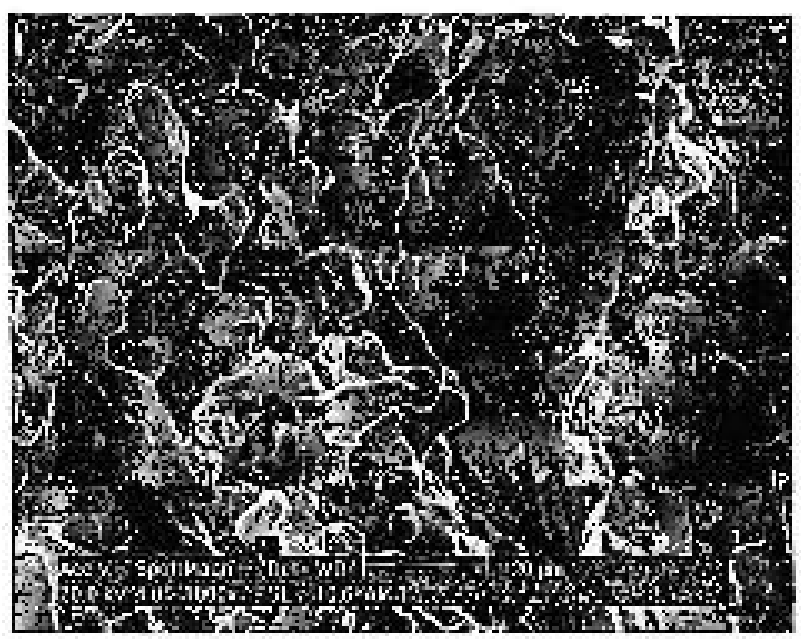

Figura 11: Micrografia de superfície de fratura obtida em microscópio eletrônico de varredura da cerâmica de composição $50 \% \mathrm{NiO}-50 \% \mathrm{MnO}_{2}$; região do grão.

Essa cerâmica apresenta aparentemente uma única fase com distribuição de porosidade intergranular em toda extensão.

As Figuras 12 a 14 apresentam micrografias da amostra de composição $50 \%$ $\mathrm{NiO}-50 \% \mathrm{CO}_{3} \mathrm{O}_{4}$ com diferentes ampliações.

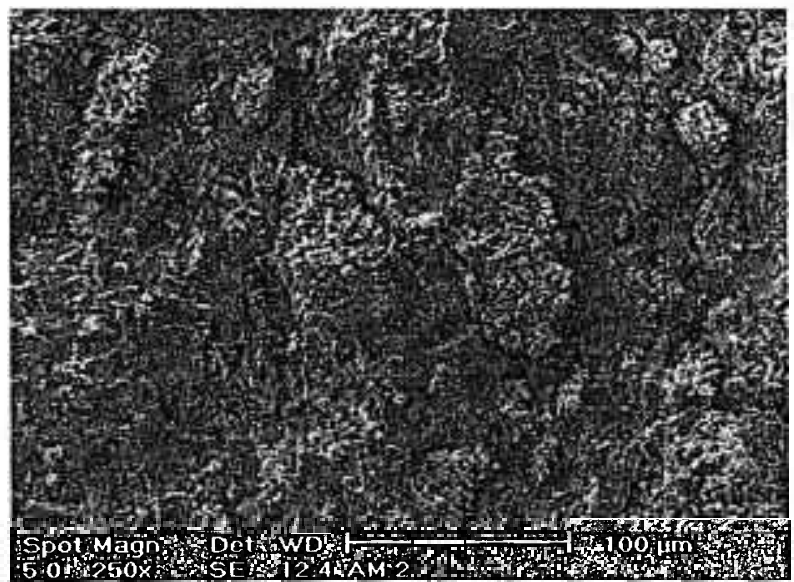

Figura 12: Micrografia de superfície de fratura obtida em microscópio eletrônico de varredura da cerâmica de composição $50 \% \mathrm{NiO}-50 \% \mathrm{Co}_{3} \mathrm{O}_{4}$; região típica. 


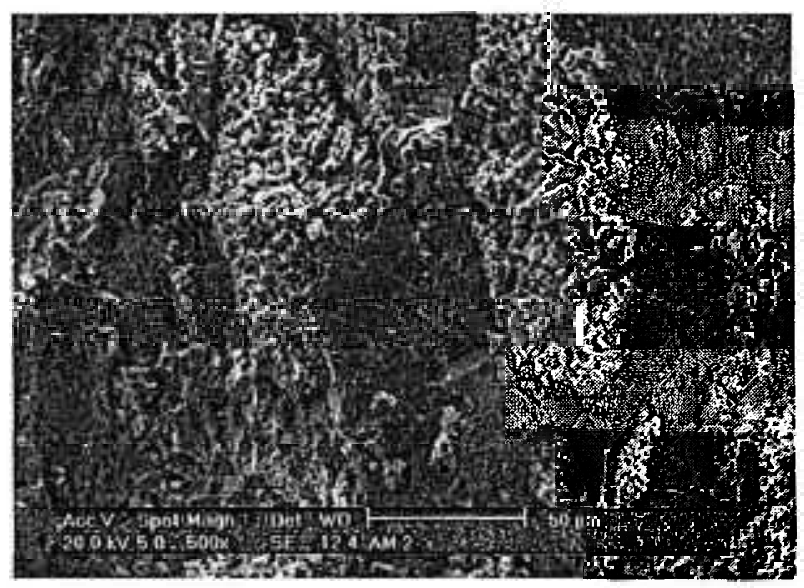

Figura 13: Micrografia de superfície de fratura obtida em microscópio eletrônico de varredura da cerâmica de composição $50 \% \mathrm{NiO}-50 \% \mathrm{Co}_{3} \mathrm{O}_{4}$; região mais densa.

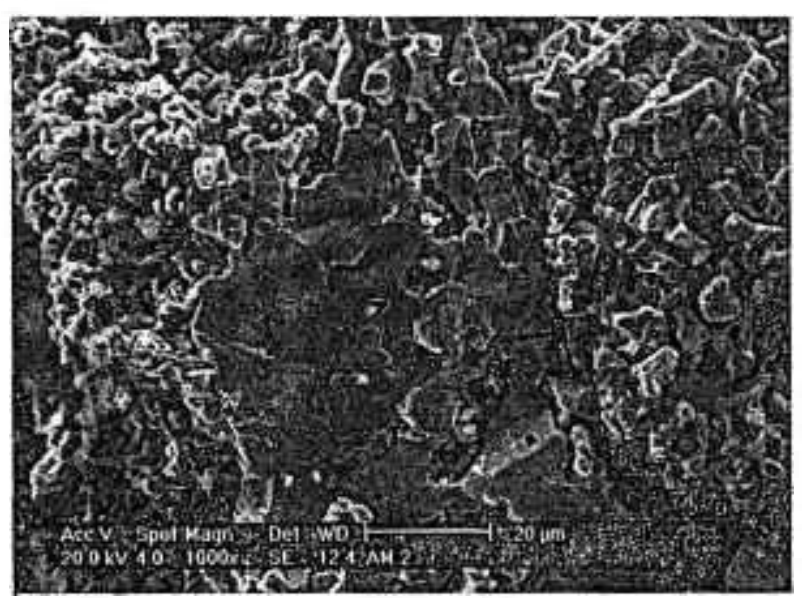

Figura 14: Micrografia de superfície de fratura obtida em microscópio eletrônico de varredura da cerâmica de composição $50 \%$ de $\mathrm{NiO}-50 \% \mathrm{Co}_{3} \mathrm{O}_{4}$; região do grão.

É possível observar a formação de regiōes com diferentes densificações com poros intergranulares e intergranulares, com duas fases bem distintas.

As Figuras 15 a 17 apresentam micrografias da amostra de composição 50\% $\mathrm{MnO}_{2}-50 \% \mathrm{Co}_{3} \mathrm{O}_{4}$ com diferentes ampliações. 


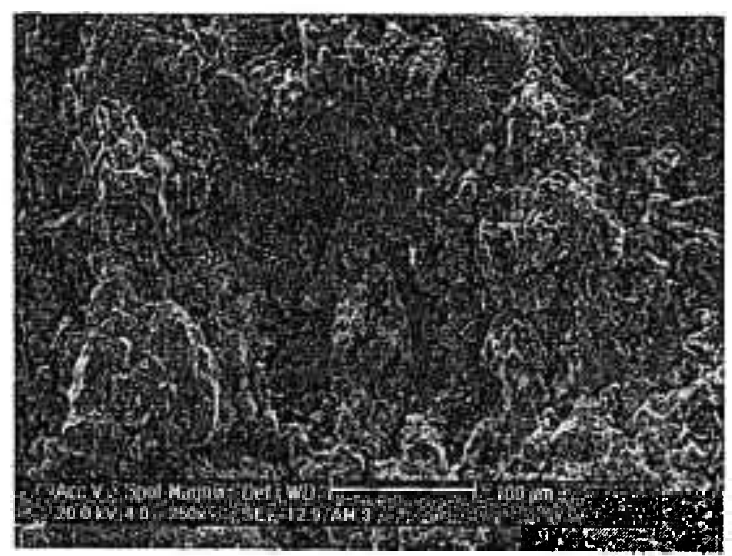

Figura 15: Micrografia de superfície de fratura obtida em microscópio eletrônico de varredura da cerâmica de composição $50 \% \mathrm{MnO}_{2}-50 \% \mathrm{Co}_{3} \mathrm{O}_{4}$; região típica.

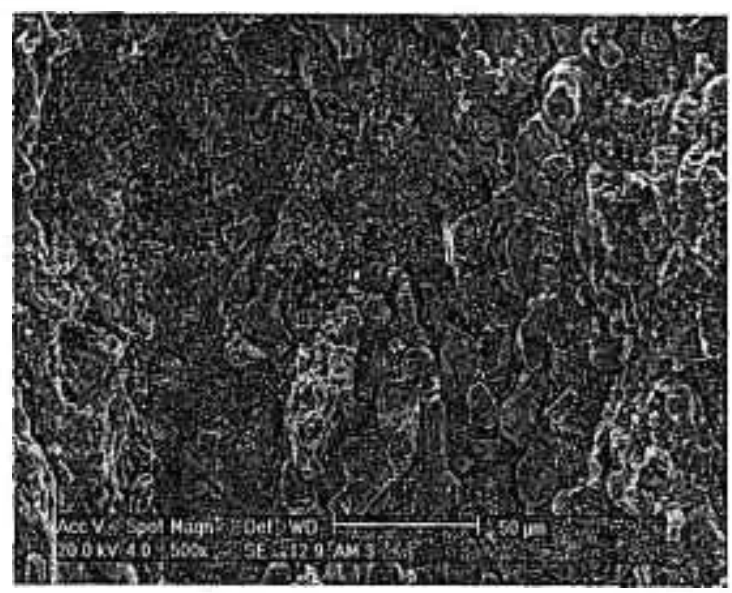

Figura 16: Micrografia de superfície de fratura obtida em microscópio eletrônico de varredura da cerâmica de composição $50 \% \mathrm{MnO}_{2}-50 \% \mathrm{Co}_{3} \mathrm{O}_{4}$; região mais densa.

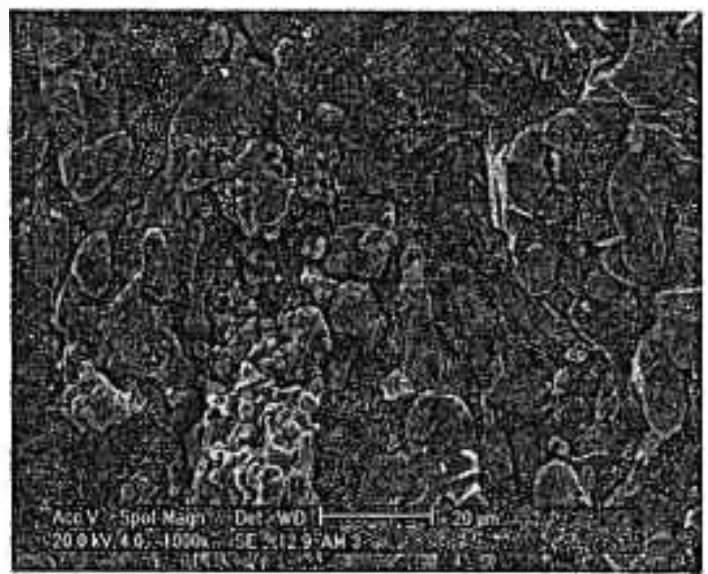

Figura 17: Micrografia de superficie de fratura obtida em microscópio eletrônico de varredura da cerâmica de composição $50 \% \mathrm{MnO}_{2}-50 \% \mathrm{Co}_{3} \mathrm{O}_{4}$; região do grão. 
Essas micrografias mostram regiões com grande número de grãos pequenos, alguns deles com geometria de ângulos bem definidos.

As Figuras 18 a 20 apresentam micrografias da amostra de composição $33,3 \% \mathrm{NiO}-33,3 \% \mathrm{MnO}_{2}-33,3 \% \mathrm{Co}_{3} \mathrm{O}_{4}$ com diferentes ampliações.

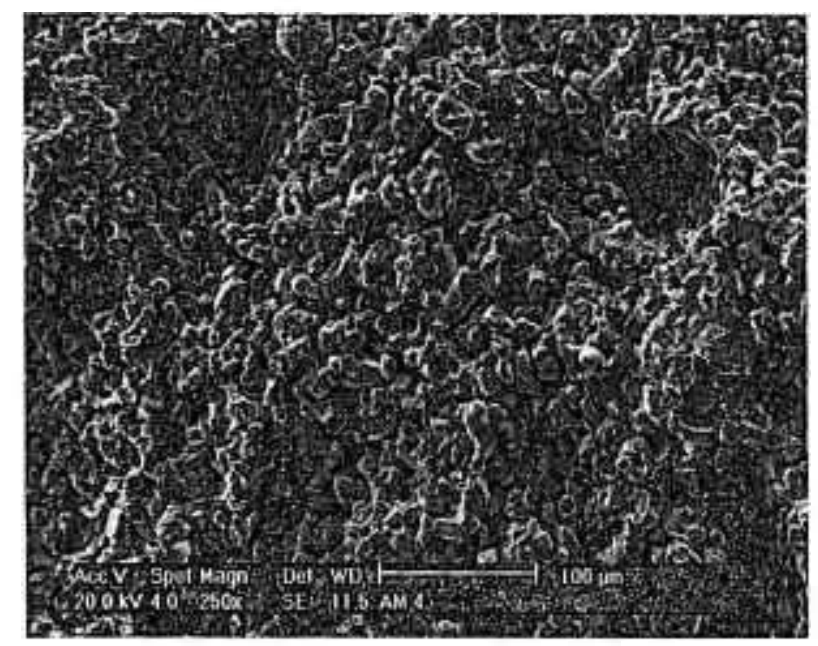

Figura 18: Micrografia da cerâmica termistora de composição 33,3\% NiO - 33,3\% $\mathrm{MnO}_{2}-33,3 \% \mathrm{Co}_{3} \mathrm{O}_{4} ;$ região típica

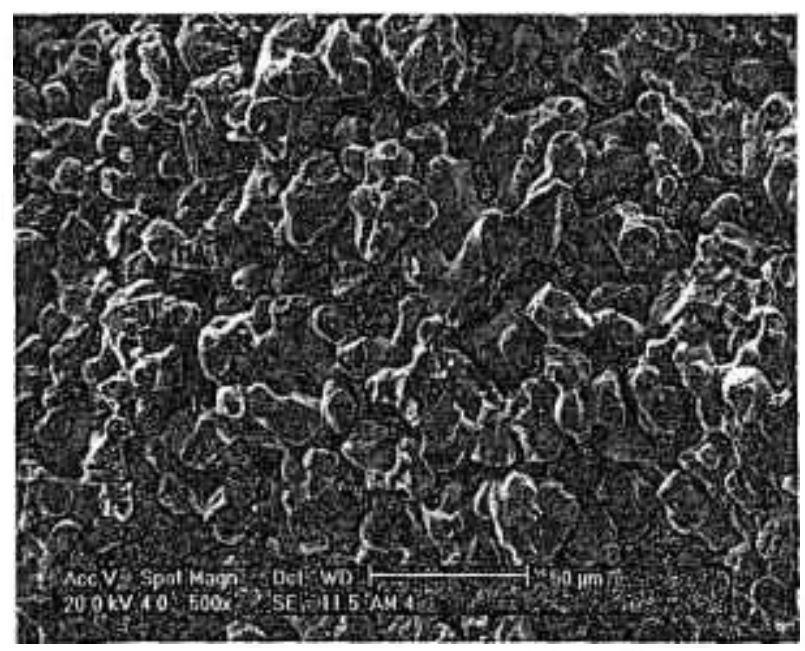

Figura 19: Micrografia da cerâmica de composição $33,3 \% \mathrm{NiO}-33,3 \% \mathrm{MnO}_{2}-33,3 \%$ $\mathrm{CO}_{3} \mathrm{O}_{4}$; região mais densa. 


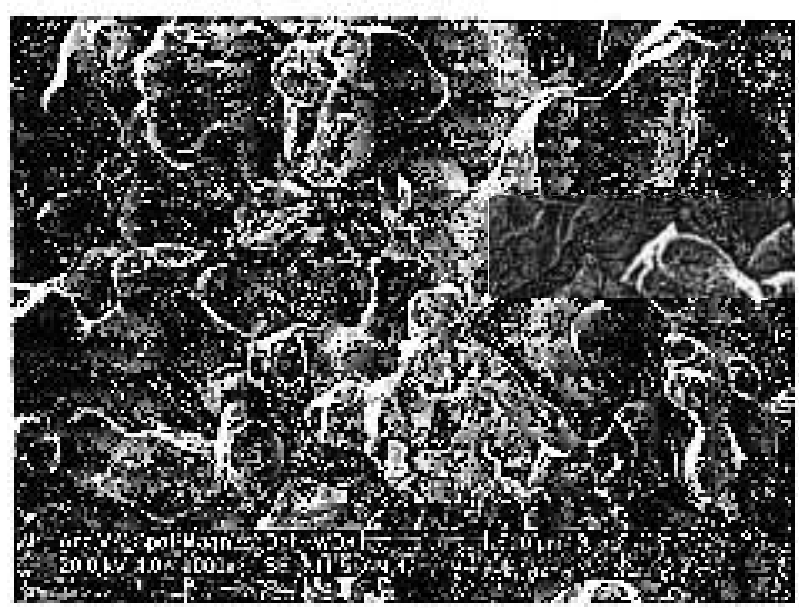

Figura 20: Micrografia da cerâmica de composição 33,3\% $\mathrm{NiO}-33,3 \% \mathrm{MnO}_{2}-33,3 \%$ $\mathrm{Co}_{3} \mathrm{O}_{4}$; região do grão.

As micrografias mostram uma distribuição homogênea dos tamanhos de grão com uma porosidade relativamente alta, sem regiōes com grande densificação. Também é possivel observar a formação de pescoço intergranular evidenciando a sinterização.

As Figuras 21 a 23 apresentam micrografias da amostra de composição $50 \%$ $\mathrm{NiO}-25 \% \mathrm{MnO}_{2}-25 \% \mathrm{Co}_{3} \mathrm{O}_{4}$.

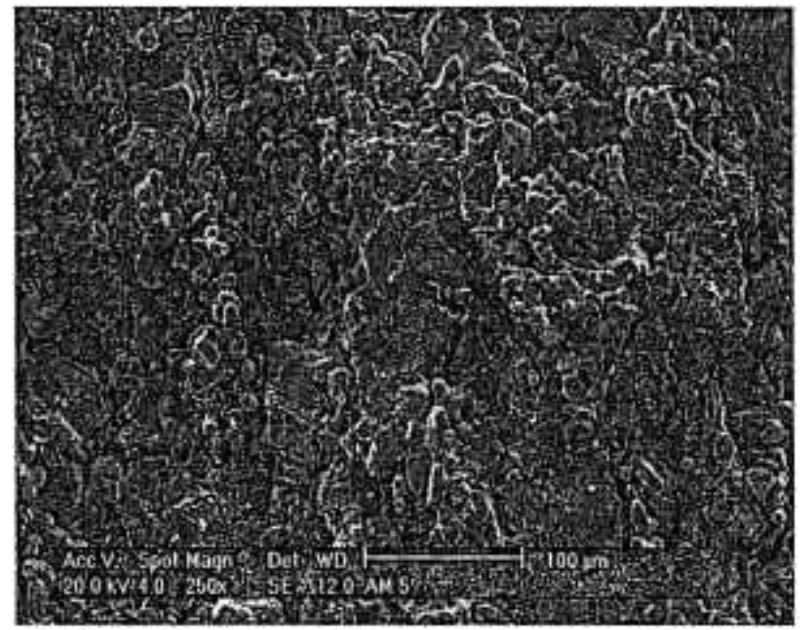

Figura 21: Micrografia da cerâmica de composição $50 \% \mathrm{NiO}-25 \% \mathrm{MnO}_{2}-25 \%$ $\mathrm{Co}_{3} \mathrm{O}_{4}$; regiāo típica. 


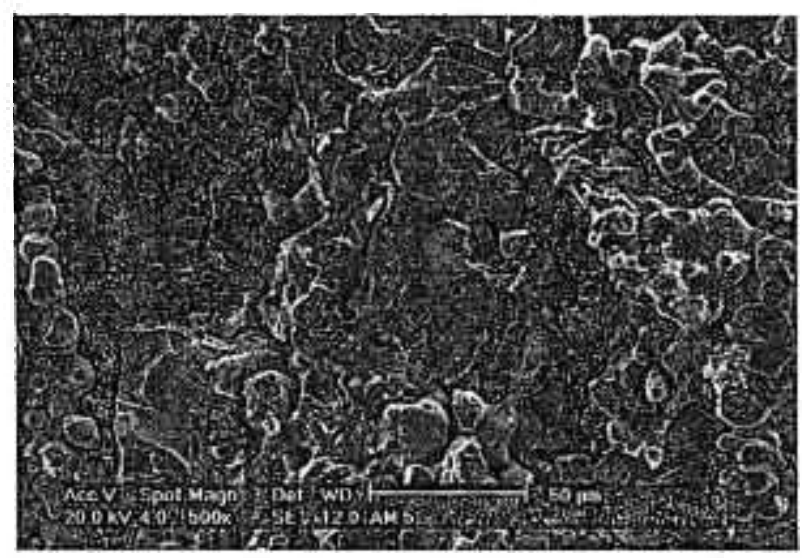

Figura 22: Micrografia da cerâmica de composição $50 \% \mathrm{NiO}-25 \% \mathrm{MnO}_{2}-25 \%$ $\mathrm{Co}_{3} \mathrm{O}_{4}$; região mais densa.

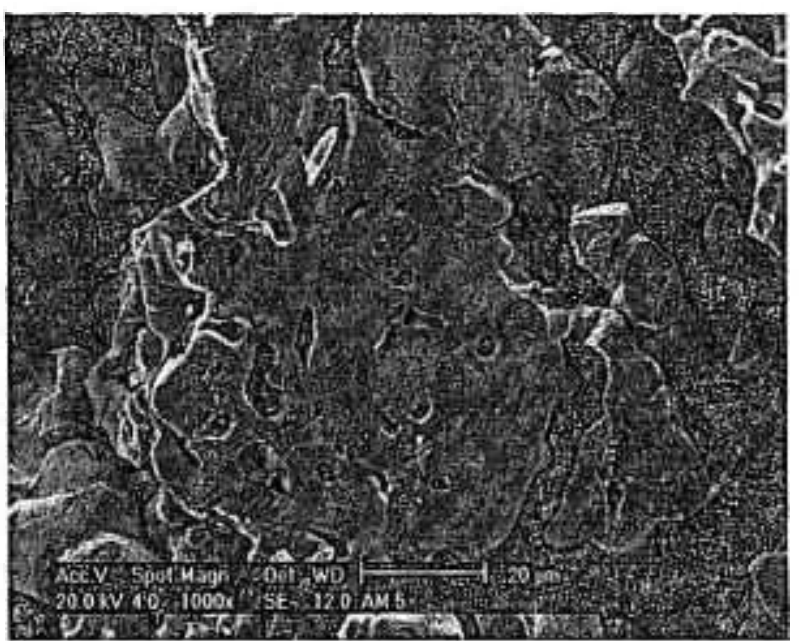

Figura 23: Micrografia da cerâmica de composição $50 \% \mathrm{NiO}-25 \% \mathrm{MnO}_{2}-25 \%$ $\mathrm{Co}_{3} \mathrm{O}_{4} ;$ região do grão.

Há duas diferentes fases com regiōes de densidade e porosidade diferentes, tanto intragranular como intergranular. Também é possivel observar grãos grandes e porosos.

As Figuras 24 a 26 apresentam micrografias da amostra de composição $25 \%$ $\mathrm{NiO}-50 \% \mathrm{MnO}_{2}-25 \% \mathrm{Co}_{3} \mathrm{O}_{4}$ com diferentes ampliações. 


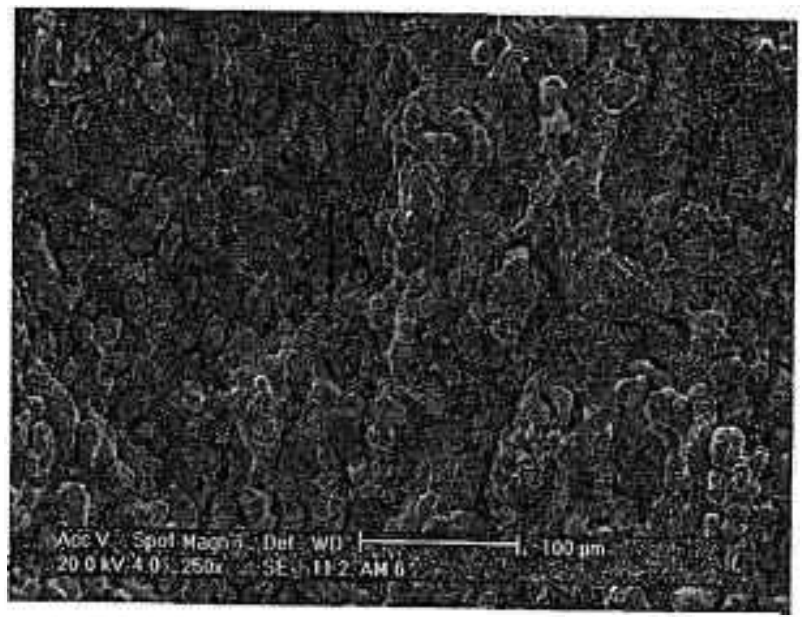

Figura 24: Micrografia da cerâmica de composição $25 \% \mathrm{NiO}-50 \% \mathrm{MnO}_{2}-25 \%$ $\mathrm{Co}_{3} \mathrm{O}_{4}$; região típica.

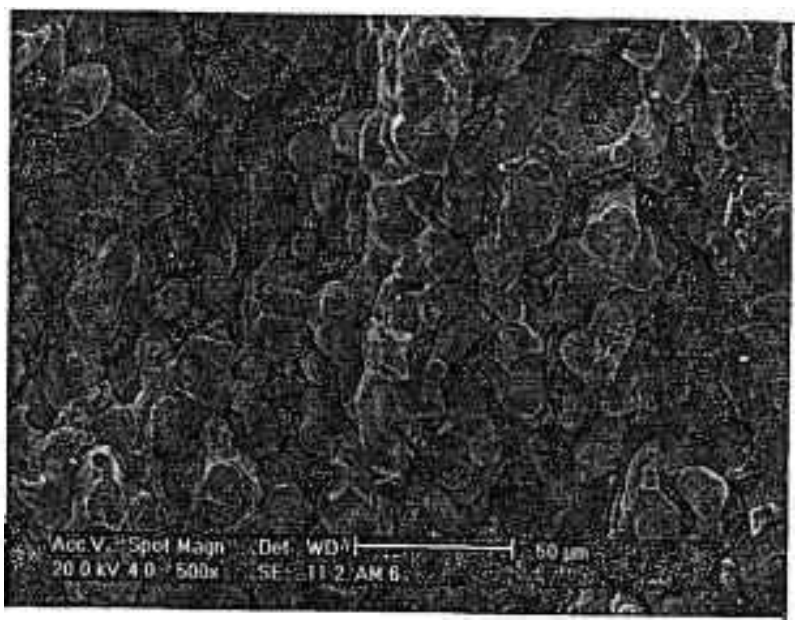

Figura 25: Micrografia da cerâmica de composição $25 \% \mathrm{NiO}-50 \% \mathrm{MnO}_{2}-25 \%$ $\mathrm{Co}_{3} \mathrm{O}_{4} ;$ região mais densa.

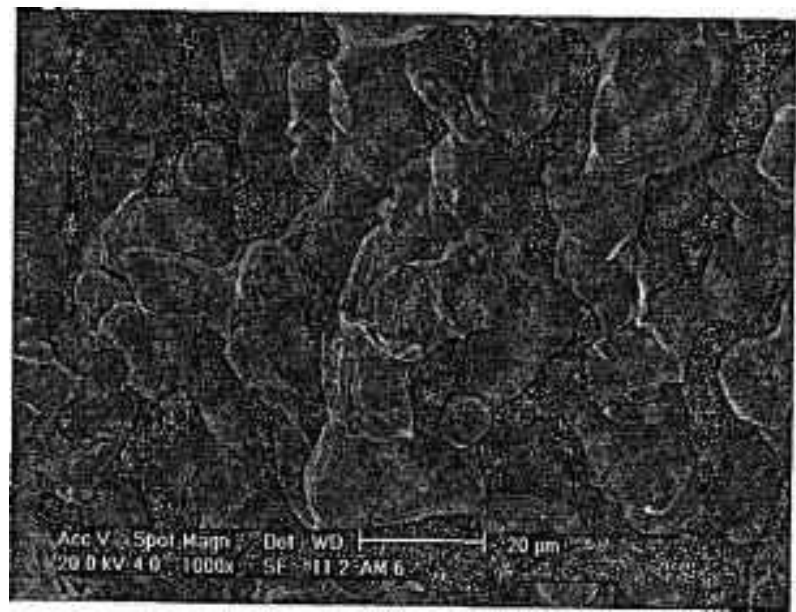

Figura 26: Micrografia da cerâmica de composição $25 \% \mathrm{NiO}-50 \% \mathrm{MnO}_{2}-25 \%$ $\mathrm{Co}_{3} \mathrm{O}_{4}$; região do grão. 
Há regiōes com diferente densificação, com grão grandes e pequenos bem distribuídos. Há poros intergranulares por toda a extensão. Também é possivel observar a formação de pescoço intergranular em várias regiōes.

As Figuras 27 a 29 apresentam micrografias da amostra de composição $25 \%$ $\mathrm{NiO}-55 \% \mathrm{MnO}_{2}-50 \% \mathrm{Co}_{3} \mathrm{O}_{4}$ com diferentes ampliações.

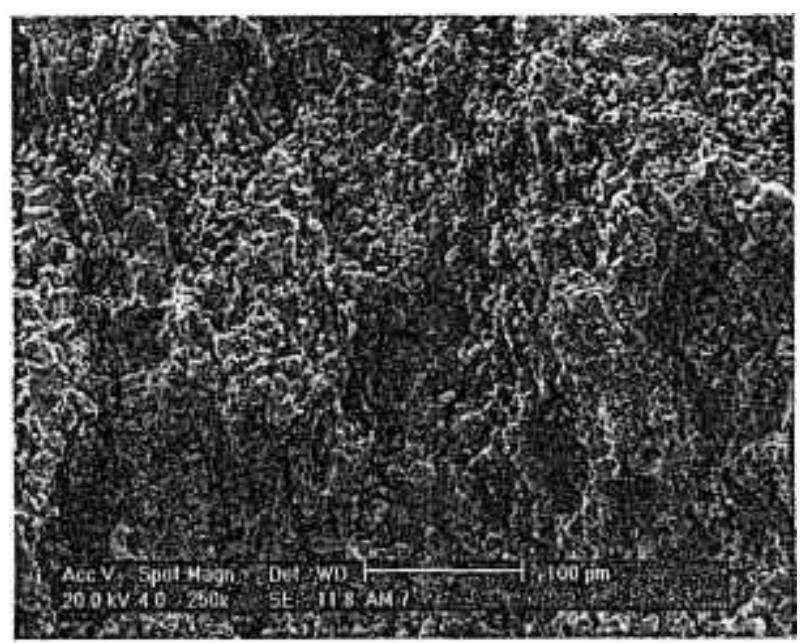

Figura 27: Micrografia da cerâmica de composição $25 \% \mathrm{NiO}-25 \% \mathrm{MnO}_{2}-50 \%$ $\mathrm{Co}_{3} \mathrm{O}_{4} ;$ região típica.

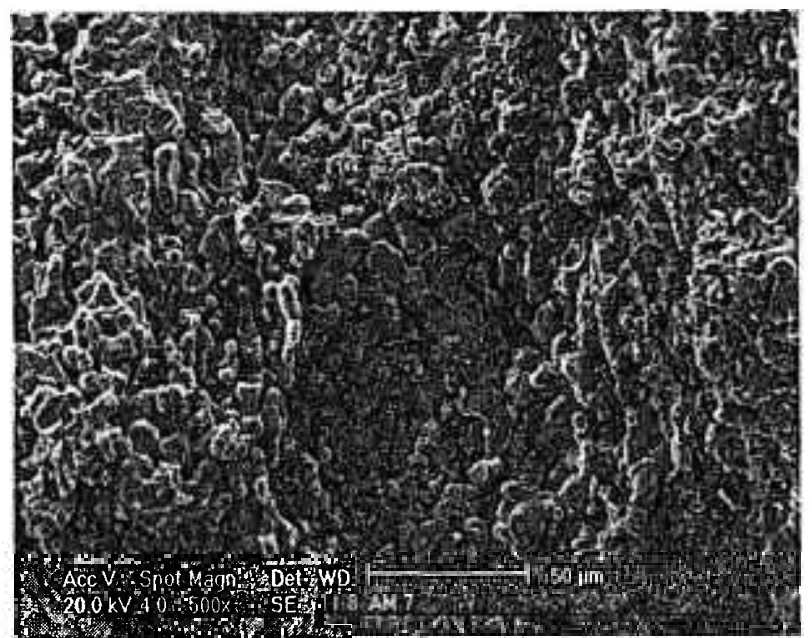

Figura 28: Micrografia da cerâmica de composição 25\% $\mathrm{NiO}-25 \% \mathrm{MnO}_{2}-50 \%$ $\mathrm{Co}_{3} \mathrm{O}_{4}$; região mais densa. 


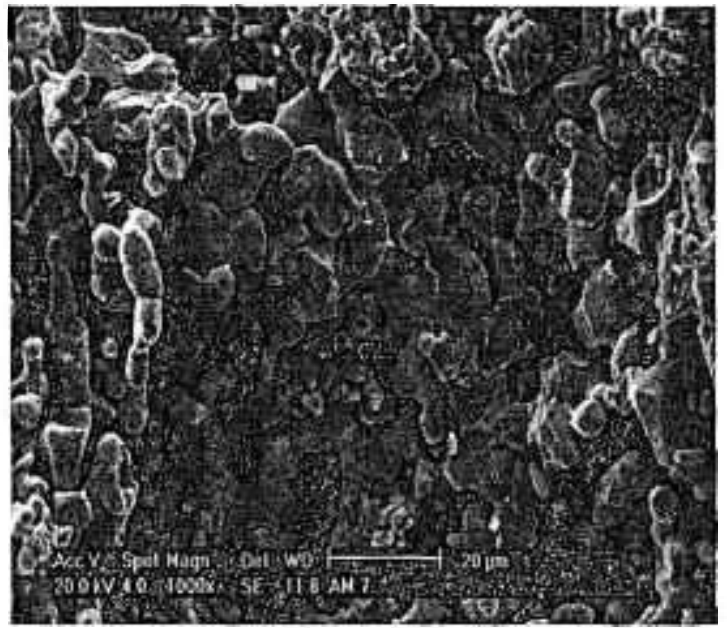

Figura 29: Micrografia da cerâmica de composição $25 \% \mathrm{NiO}-25 \% \mathrm{MnO}_{2}-50 \%$ $\mathrm{Co}_{3} \mathrm{O}_{4}$; região do grão.

Há regiōes distintas com grãos micrométricos e poros intragranulares pequenos, relativamente ao tamanho médio dos grãos.

Foram determinados, por análise EDS, valores de concentrações de $\mathrm{Ni}, \mathrm{Mn}$ e Co em diferentes regióes das amostras, evidenciando a difusão durante o processo de sinterização. As regiões analisadas foram: uma, denominada típica, com ampliação de 250 vezes, uma região mais densa (500 vezes) e uma última região localizada em um grão (1000 vezes).

$\mathrm{Na}$ maioria das regiões analisadas em diferentes amostras, a concentração determinada esteve próximo da adicionada na preparação do termistor. Entretanto, na análise de concentração no grão e nas regiões mais densas aparecem valores mais altos para alguns metais, provavelmente devido a uma preferência de ocupação de sitios na estrutura cristalina durante o processo de sinterização. A Tabela 4 mostra os valores obtidos por EDS para as sete diferentes composições de cerâmicas termistoras em três diferentes regiões. 
Tabela 4: Valores obtidos por EDS para as sete diferentes composições de cerâmicas termistoras em três diferentes regiões.

\begin{tabular}{|c|c|c|c|c|c|c|c|c|}
\hline $\begin{array}{l}\text { região } \\
\text { analisada }\end{array}$ & $\begin{array}{l}\text { amostras } \\
\text { metais (\%) }\end{array}$ & A1 & A2 & $A 3$ & $\overline{\mathrm{A} 4}$ & $\overline{A 5}$ & $\overline{A 6}$ & $\overline{A 7}$ \\
\hline Tipica & $\begin{array}{l}\mathrm{Ni} \\
\mathrm{Mn} \\
\mathrm{Co}\end{array}$ & $\begin{array}{l}46,6 \\
53,4\end{array}$ & $\begin{array}{l}42,6 \\
57,4\end{array}$ & $\begin{array}{l}49,8 \\
50,2\end{array}$ & $\begin{array}{l}41,7 \\
23,8 \\
34,5\end{array}$ & $\begin{array}{l}32,8 \\
37,7 \\
29,5\end{array}$ & $\begin{array}{r}32,2 \\
5,6 \\
61,2\end{array}$ & $\begin{array}{l}51,4 \\
18,9 \\
29,7\end{array}$ \\
\hline Densa & $\begin{array}{l}\mathrm{Ni} \\
\mathrm{Mn} \\
\mathrm{Co}\end{array}$ & & & $\begin{array}{l}60,3 \\
39,7\end{array}$ & & & $\begin{array}{r}9,3 \\
45,1 \\
45,6\end{array}$ & $\begin{array}{l}46,4 \\
18,8 \\
34,8\end{array}$ \\
\hline No grão & $\begin{array}{l}\mathrm{Ni} \\
\mathrm{Mn} \\
\mathrm{Co}\end{array}$ & $\begin{array}{l}77,5 \\
22,5\end{array}$ & $\begin{array}{l}38,9 \\
61,1\end{array}$ & $\begin{array}{l}48,6 \\
51,4\end{array}$ & $\begin{array}{r}60,4 \\
8,2 \\
31,4\end{array}$ & $\begin{array}{l}49,7 \\
12,4 \\
37,9\end{array}$ & $\begin{array}{r}33,2 \\
5,6 \\
61,2\end{array}$ & $\begin{array}{c}64,7 \\
6,3 \\
29,0\end{array}$ \\
\hline
\end{tabular}

Difração de raios $X$

A Figura 30 mostra os difratogramas de raios $X$ das sete composições (Cf. Tabela 2).

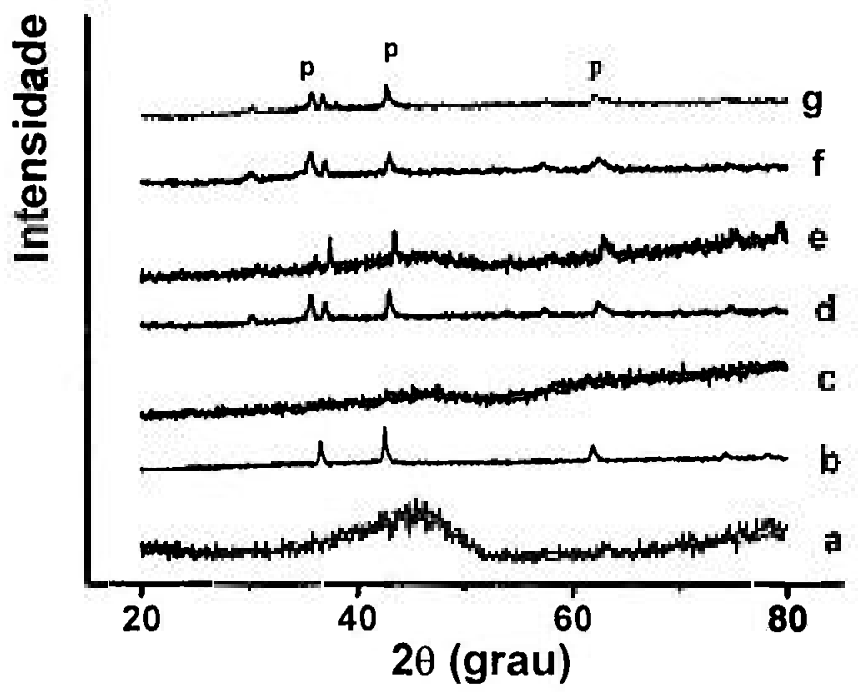

Figura 30: Difratogramas de raios $\mathrm{X}$ das composiçōes: a) $50 \% \mathrm{NiO}-50 \% \mathrm{MnO}_{2}$; b) $50 \% \mathrm{NiO}-50 \% \mathrm{Co}_{3} \mathrm{O}_{4} ;$ c) $50 \% \mathrm{MnO}_{2}-50 \% \mathrm{Co}_{3} \mathrm{O}_{4}$; d) $33,3 \% \mathrm{NiO}-33,3 \% \mathrm{MnO}_{2}-$ $33,3 \% \mathrm{Co}_{3} \mathrm{O}_{4}$; e) $50 \% \mathrm{MnO}_{2}-25 \% \mathrm{NiO}-25 \% \mathrm{Co}_{3} \mathrm{O}_{4} ;$ f) $50 \% \mathrm{NiO}-25 \% \mathrm{MnO}_{2}-$ $\mathrm{Co}_{3} \mathrm{O}_{4} ;$ g) $50 \% \mathrm{Co}_{3} \mathrm{O}_{4}-25 \% \mathrm{NiO}-25 \% \mathrm{MnO}_{2}$. A letra $\mathrm{p}$ indica as principais raias de difração da fase perovskita cúbica. 
Os difratogramas das composições $50 \% \mathrm{NiO}$ - $50 \% \mathrm{MnO}_{2}, 50 \% \mathrm{MnO}_{2}$ $50 \% \mathrm{Co}_{3} \mathrm{O}_{4}$ e $50 \% \mathrm{MnO}_{2}-25 \% \mathrm{NiO}-25 \% \mathrm{Co}_{3} \mathrm{O}_{4}$ indicam que estes materiais estão na fase amorfa, sendo que as demais estão cristalinas, evidenciadas pelas reflexōes marcadas com $p$.

Dos três óxidos utilizados, o $\mathrm{MnO}_{2}$ é o que possui menor ponto de fusão, 535 ${ }^{\circ} \mathrm{C}$. Como a temperatura de sinterização $\left(1250^{\circ} \mathrm{C}\right)$ é maior que seu ponto de fusão o óxido de manganês funde durante o processo de sinterização. Consequentemente, as amostras com maior teor de manganês apresentam fase amorfa. As demais amostras cristalinas possuem estrutura espinélio característica de cerâmicas termistoras.

\section{Análise do comportamento elétrico}

Em todas as figuras de resistividade elétrica em função da temperatura, apresentadas a seguir, o traço contínuo foi determinado pelo melhor ajuste segundo a equação [1], página 6 .

As Figuras 31 a 37 mostram a dependência da resistividade elétrica com a temperatura para todas as sete composições (Cf. Tabela 2).

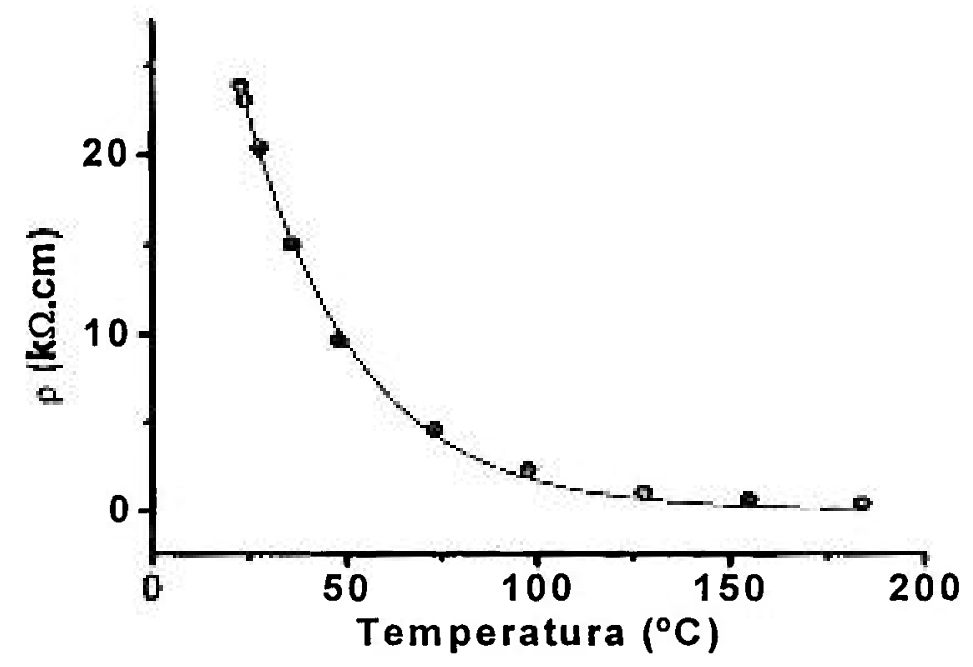

Figura 31: Resistividade elétrica em função da temperatura da composição $50 \% \mathrm{NiO}$ $-50 \% \mathrm{MnO}_{2}$ sinterizada a $1250^{\circ} \mathrm{C} / 2 \mathrm{~h}$. 


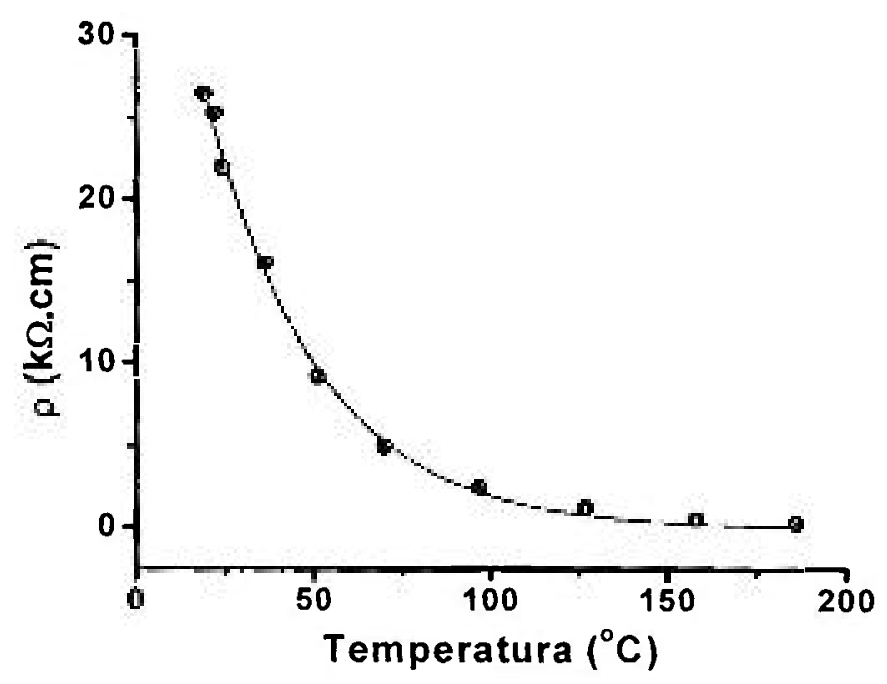

Figura 32: Resistividade elétrica em função da temperatura composição $50 \% \mathrm{NiO}$ $50 \% \mathrm{Co}_{3} \mathrm{O}_{4}$ sinterizada a $1250^{\circ} \mathrm{C} / 2 \mathrm{~h}$.

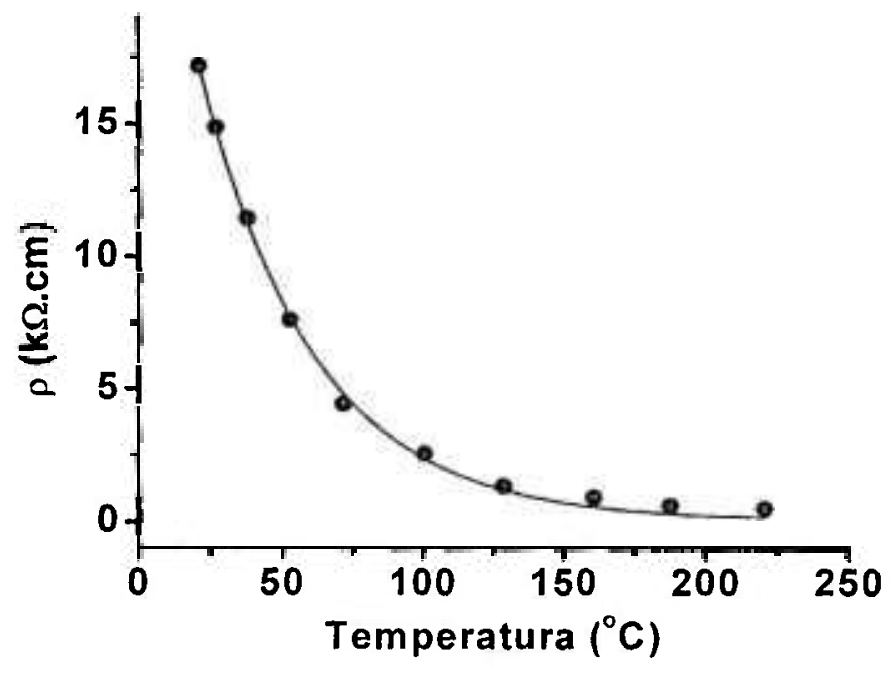

Figura 33: Resistividade elétrica em função da temperatura da composição $50 \%$ $\mathrm{MnO}_{2}-50 \% \mathrm{Co}_{3} \mathrm{O}_{4}$ sinterizada $1250^{\circ} \mathrm{C} / 2 \mathrm{~h}$. 


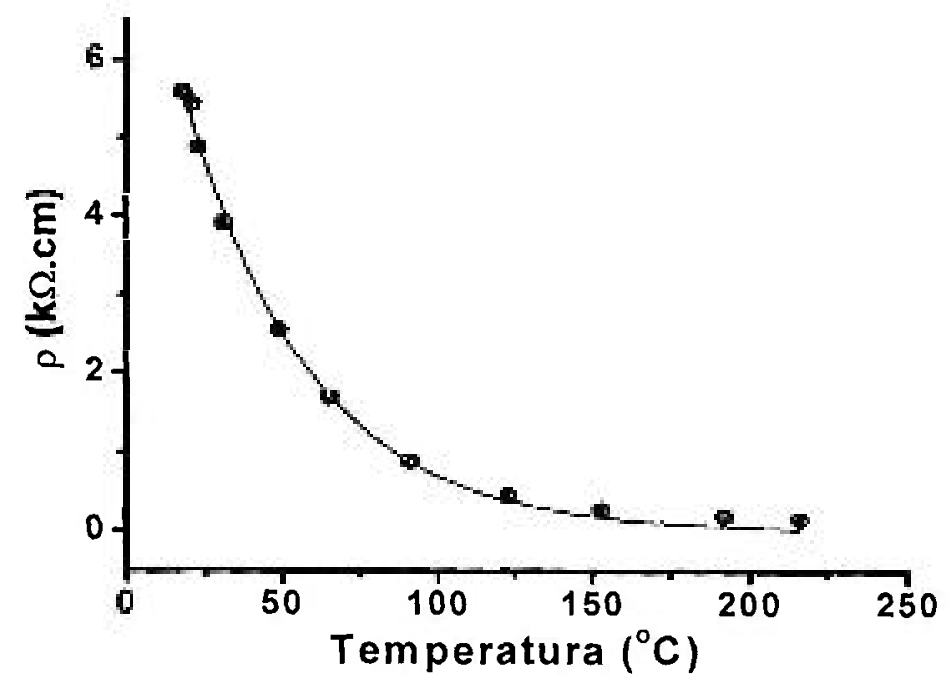

Figura 34: Resistividade elétrica em função da temperatura composição $33,3 \% \mathrm{NiO}$ $33,3 \% \mathrm{MnO}_{2}-33,3 \% \mathrm{Co}_{3} \mathrm{O}_{4}$ sinterizada a $1250^{\circ} \mathrm{C} / 2 \mathrm{~h}$.

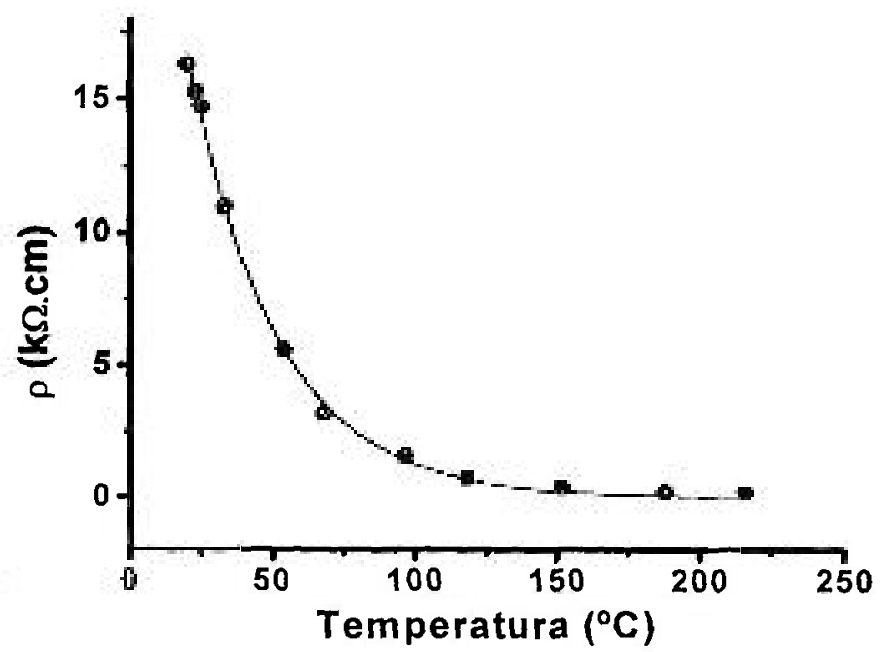

Figura 35: Resistividade elétrica em função da temperatura da composição $50 \% \mathrm{NiO}$ $-25 \% \mathrm{MnO}_{2}-25 \% \mathrm{Co}_{3} \mathrm{O}_{4}$ sinterizada a $1250^{\circ} \mathrm{C}$. 


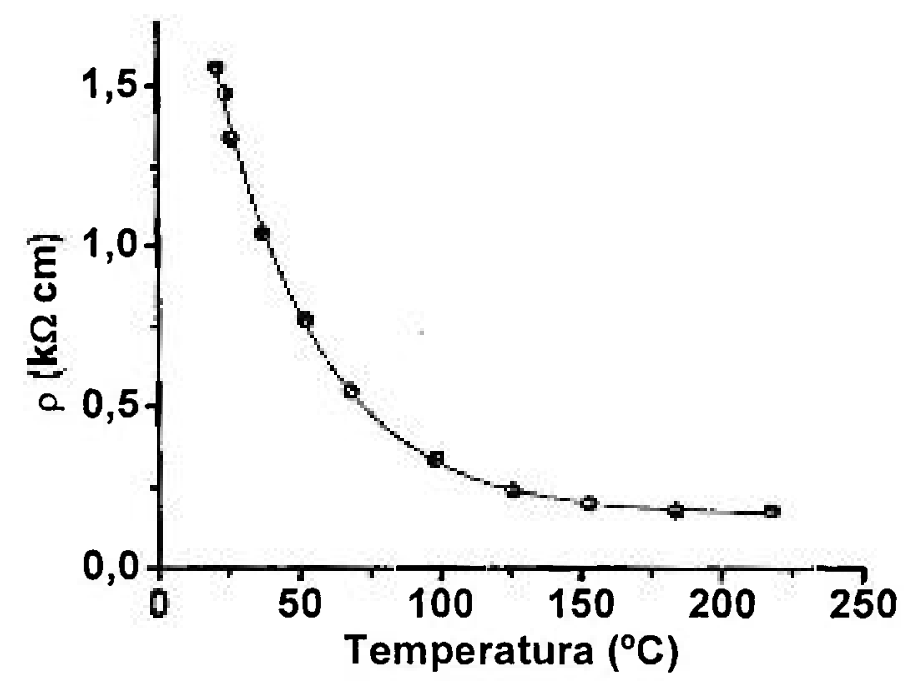

Figura 36: Resistividade elétrica em função da temperatura composição $25,2 \% \mathrm{NiO}$ $48,7 \% \mathrm{MnO}_{2}-26,1 \% \mathrm{Co}_{3} \mathrm{O}_{4}$ sinterizada a $1250^{\circ} \mathrm{C}$.

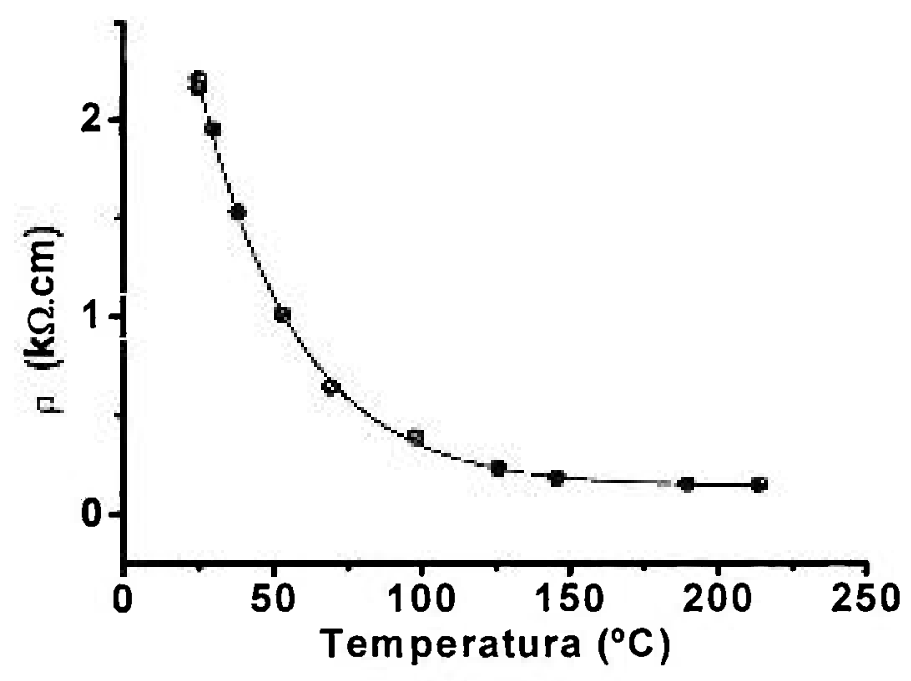

Figura 37: Resistividade elétrica em função da temperatura da composição $24,8 \%$ $\mathrm{NiO}-25,3 \% \mathrm{MnO}_{2}-49,9 \% \mathrm{Co}_{3} \mathrm{O}_{4}$ sinterizada a $1250^{\circ} \mathrm{C}$.

A Tabela 5 apresenta os valores de resistividade a $50^{\circ} \mathrm{C}$ e os fatores $\beta$ e $\alpha$ determinados para todas as composições (medidas) de termistores preparadas. 
Tabela 5: Resistividade elétrica $\rho$ a $50^{\circ} \mathrm{C}$ e os parâmetros $\alpha$ e $\beta$.

\begin{tabular}{|c|c|c|c|c|}
\hline Amostra & Composição & $\begin{array}{c}\text { pa } 50^{\circ} \mathrm{C} \\
\text { (kOhm.cm) }\end{array}$ & $\alpha(\% / K)$ & $\beta(K)$ \\
\hline A1 & $\begin{array}{c}49,2 \% \mathrm{NiO} \\
50,8 \% \mathrm{MnO}_{2}\end{array}$ & 9,48 & $-10,2$ & 3816 \\
\hline A2 & $\begin{array}{c}48,7 \% \mathrm{NiO} \\
51,3 \% \mathrm{Co}_{3} \mathrm{O}_{4}\end{array}$ & 10,0 & $-8,2$ & 3049 \\
\hline A3 & $\begin{array}{l}47,3 \% \mathrm{MnO}_{2} \\
52,7 \% \mathrm{Co}_{3} \mathrm{O}_{4}\end{array}$ & 8,37 & $-7,6$ & 2830 \\
\hline A4 & $\begin{array}{c}32,9 \% \mathrm{NiO} \\
33,2 \% \mathrm{MnO}_{2} \\
33,9 \% \mathrm{Co}_{3} \mathrm{O}_{4}\end{array}$ & 2,51 & $-7,5$ & 2804 \\
\hline A5 & $\begin{array}{c}49,2 \% \mathrm{NiO} \\
25,3 \mathrm{MnO}_{2} \\
25,5 \% \mathrm{Co}_{3} \mathrm{O}_{4}\end{array}$ & 6,4 & $-9,5$ & 3584 \\
\hline $\mathrm{A} 6$ & $\begin{array}{c}25,2 \% \mathrm{NiO} \\
48,7 \% \mathrm{MnO}_{2} \\
26,1 \% \mathrm{Co}_{3} \mathrm{O}_{4}\end{array}$ & 0,78 & $-4,1$ & 1521 \\
\hline A7 & $\begin{array}{c}24,8 \% \mathrm{NiO} \\
25,3 \% \mathrm{MnO}_{2} \\
49,9 \% \mathrm{Co}_{3} \mathrm{O}_{4}\end{array}$ & 1,09 & $-7,4$ & 2767 \\
\hline
\end{tabular}

A análise do comportamento elétrico das sete composições evidencia que à exceção da amostra A6, todas as demais apresentam comportamento termistor adequado (alto valor de $\beta$ ) para uso em dispositivos para se aferir a temperatura.

Fica evidente que a diminuição da concentração de NiO leva a uma diminuição da resistividade elétrica e que o aumento da concentração de $\mathrm{Co}_{3} \mathrm{O}_{4}$ leva a um aumento da resistividade elétrica, provavelmente pelas modificações promovidas na microestrutura.

Na Figura 38 estão agrupadas as curvas de resistividade elétrica em função da temperatura para as sete composições. 


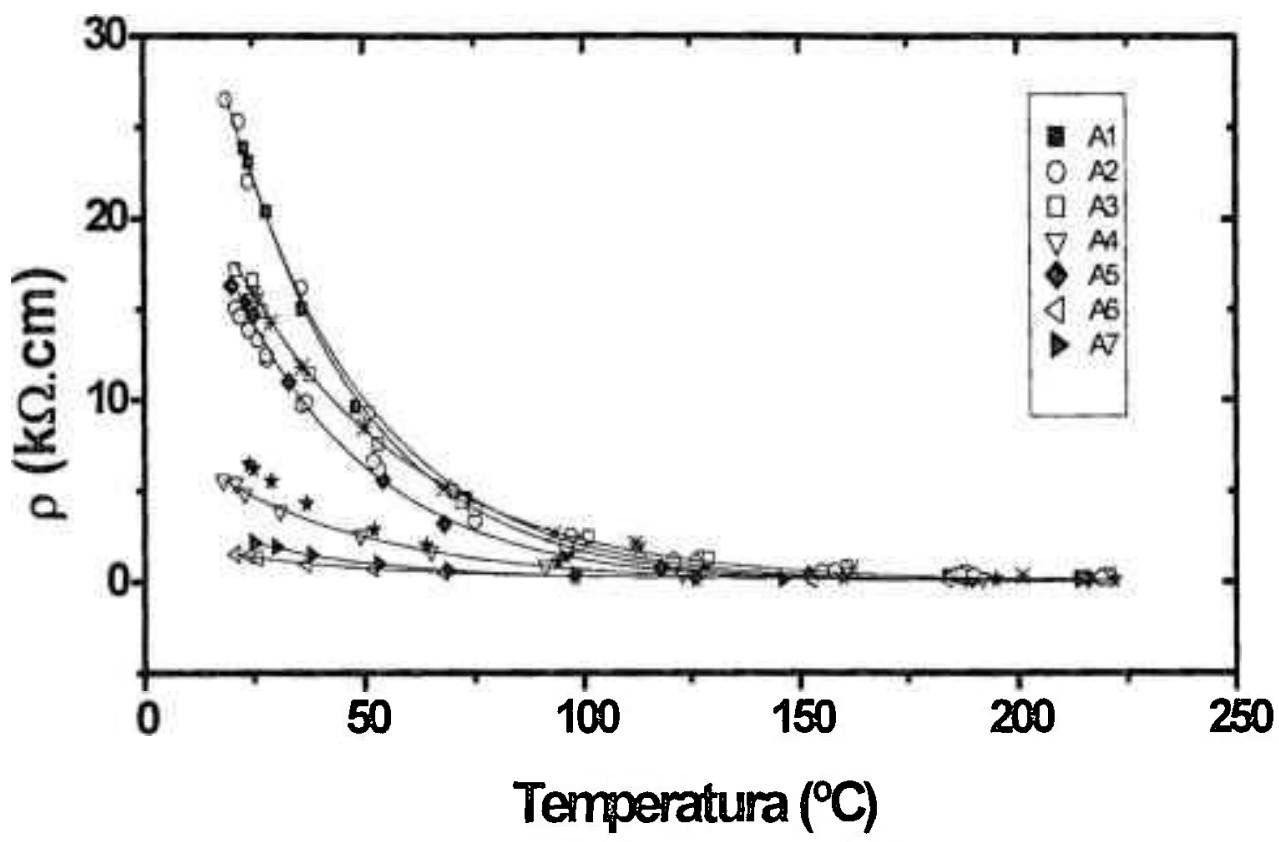

Figura 38: Resistividade elétrica em função da temperatura para sete composiçōes de termistores (Cf. Tabela 2).

Há uma relação direta entre a concentração de $\mathrm{MnO}_{2}$ e o aumento da resistência elétrica. Consequentemente foi analisado o comportamento elétrico de quatro amostras com diferentes teores relativos de $\mathrm{MnO}_{2}$, fixados iguais teores relativos de $\mathrm{NiO}$ e de $\mathrm{Co}_{3} \mathrm{O}_{4}:\left(50 \% \mathrm{NiO}-50 \% \mathrm{Co}_{3} \mathrm{O}_{4}\right)_{1-x}\left(\mathrm{MnO}_{2}\right)_{x}, \operatorname{com} \mathrm{x}=0,0,1,0,2 \mathrm{e}$ $0,3 \mathrm{~mol}$.

\subsection{Diferentes concentrações de óxido de manganês}

Foram preparadas quatro composições de $\left(50 \% \mathrm{NiO}-50 \% \mathrm{Co}_{3} \mathrm{O}_{4}\right)_{1-\mathrm{x}}\left(\mathrm{MnO}_{2}\right)_{\mathrm{x}}$, $x=0,0,1,0,2$ e $0,3 \mathrm{~mol}$. As composições foram caracterizadas por fluorescência de raios $X$ e por difração de raios $X$. Foram determinados os valores de resistência elétrica em diferentes temperaturas.

As Figuras 39 a 46 mostram os difratogramas das composições com diferentes teores de $\mathrm{MnO}_{2}$, seguidos dos resultados de comportamento elétrico em função da temperatura. 


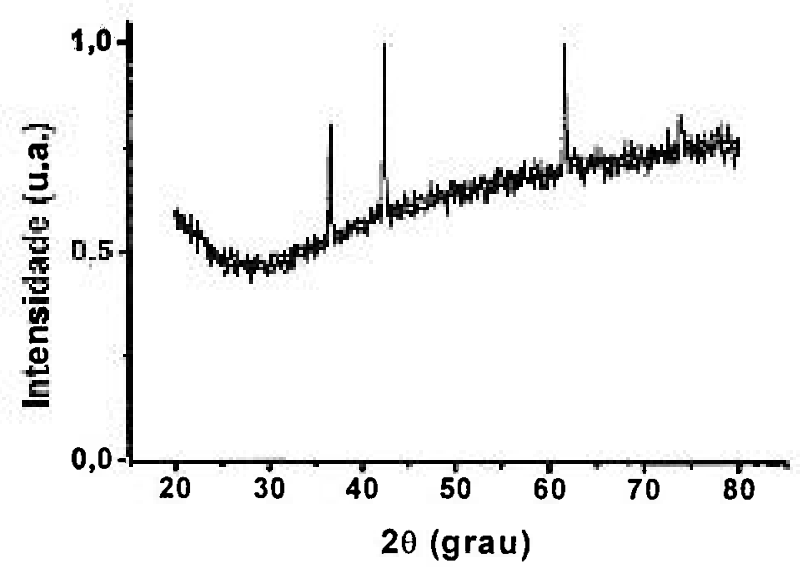

Figura 39: Difratograma de raios $X$ da composição $50 \% \mathrm{NiO}-50 \% \mathrm{Co}_{3} \mathrm{O}_{4}$.

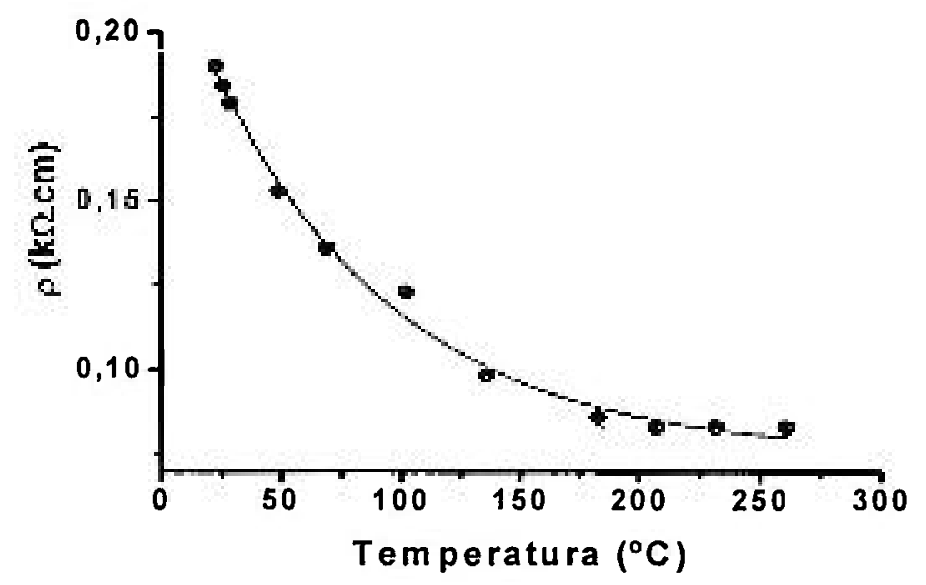

Figura 40: Resistividade elétrica em função da temperatura da composição $50 \% \mathrm{NiO}$ $-50 \% \mathrm{Co}_{3} \mathrm{O}_{4}$.

A composição $50 \% \mathrm{NiO}-50 \% \mathrm{Co}_{3} \mathrm{O}_{4}$ apresenta comportamento termistor NTC com resistividade elétrica de $0,15 \mathrm{k} \Omega . \mathrm{cm}$ a $50^{\circ} \mathrm{C}$, fator $\beta_{25 / 100} 601 \mathrm{~K}$ e coeficiente de temperatura $\alpha=-1,6 \% / \mathrm{K}$. 


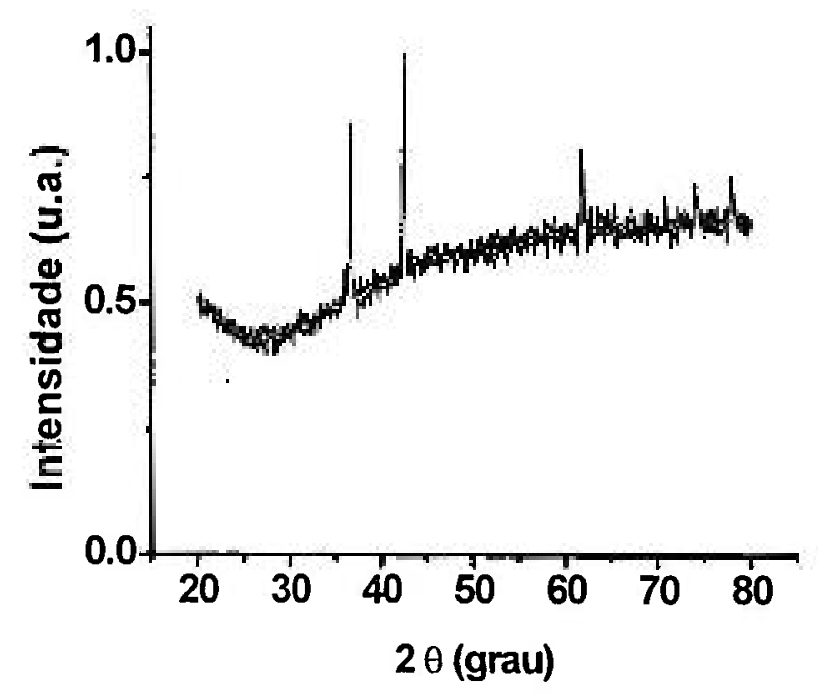

Figura 41: Difratograma da composição $45 \% \mathrm{NiO}-45 \% \mathrm{Co}_{3} \mathrm{O}_{4}-10 \% \mathrm{MnO}_{2}$.

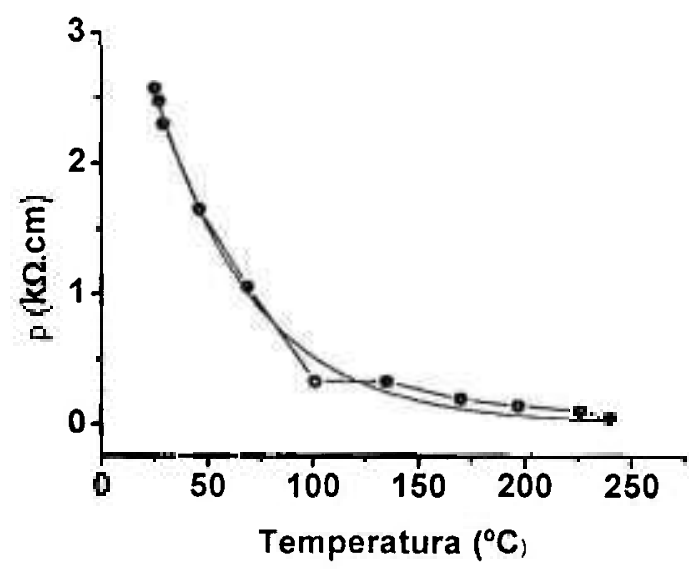

Figura 42: Resistividade elétrica em função da temperatura da composição $45 \%$ NiO $-45 \% \mathrm{Co}_{3} \mathrm{O}_{4}-10 \% \mathrm{MnO}_{2}$.

A composição $45 \% \mathrm{NiO}-45 \% \mathrm{Co}_{3} \mathrm{O}_{4}-10 \% \mathrm{MnO}_{2}$ apresenta comportamento termistor NTC e sua resistividade elétrica a $50^{\circ} \mathrm{C}$ é $1,56 \mathrm{k} \Omega \mathrm{cm}$, o fator $\beta_{25 / 100}$ é 615 $\Omega$ e o coeficiente de temperatura $a-1,6 \% / K$, valores de termistores de coeficiente negativo com qualidade inferior. 


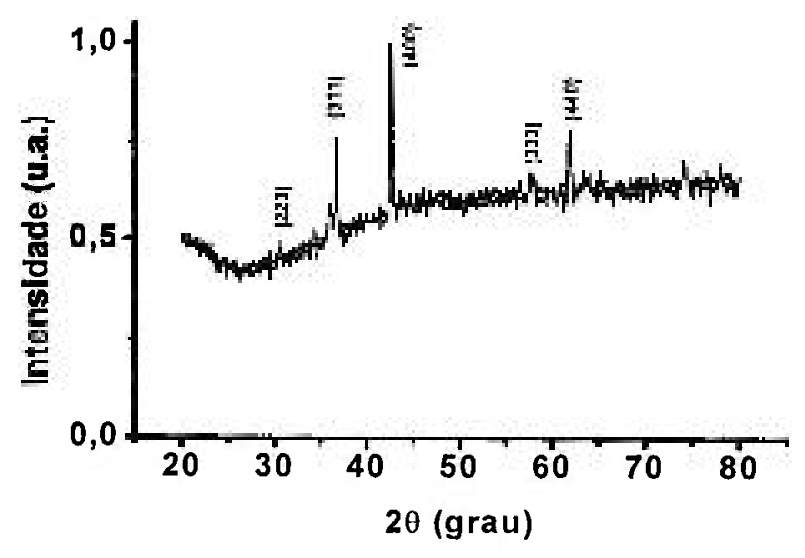

Figura 43: Difratograma da composição $40 \% \mathrm{NiO}-40 \% \mathrm{Co}_{3} \mathrm{O}_{4}-20 \% \mathrm{MnO}_{2}$. Indexação segundo a referência [30].

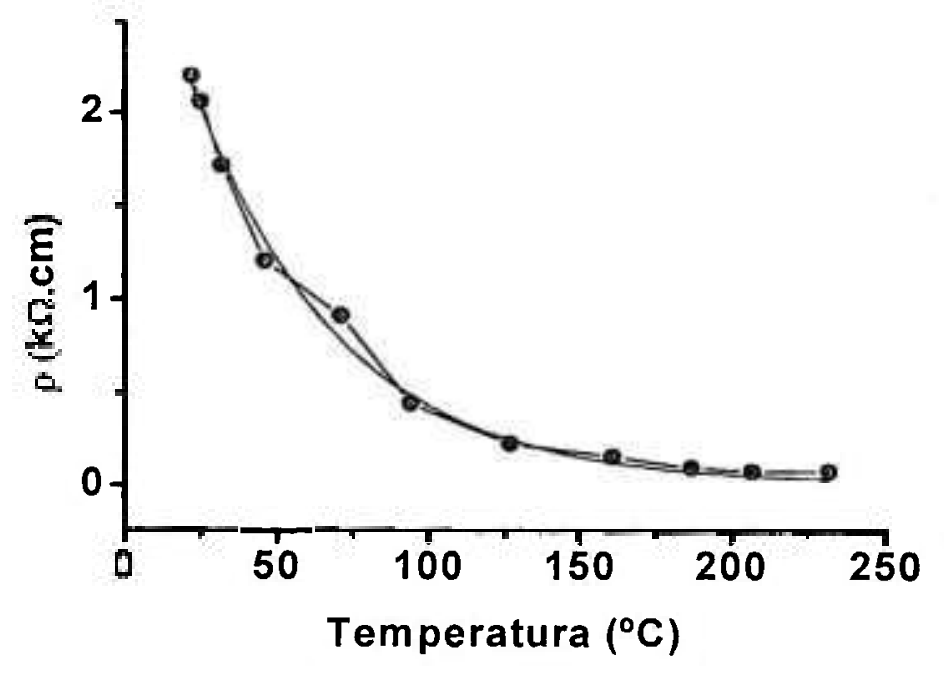

Figura 44: Resistividade elétrica em função da temperatura da composição $40 \% \mathrm{NiO}$ $-40 \% \mathrm{Co}_{3} \mathrm{O}_{4}-20 \% \mathrm{MnO}_{2}$.

Esses resultados mostram que as composições $40 \% \mathrm{NiO}-40 \% \mathrm{Co}_{3} \mathrm{O}_{4}-20 \%$ $\mathrm{MnO}_{2}$ apresentam comportamento termistor NTC com resistividade elétrica de 1,21 $\mathrm{k} \Omega . \mathrm{cm}$ a $50^{\circ} \mathrm{C}$, fator $\beta_{25 / 100} 2204 \mathrm{~K}$ e coeficiente de temperatura $\alpha=-5,9 \% / \mathrm{K}$. Esta composição resulta em termistores de coeficiente negativo de boa qualidade. 


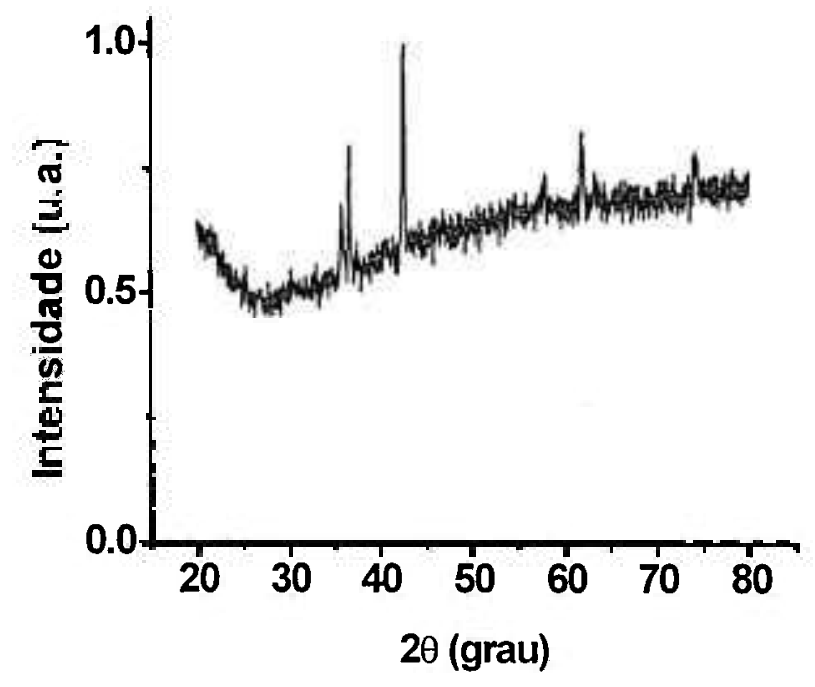

Figura 45: Difratograma da composição $35 \% \mathrm{NiO}-35 \% \mathrm{Co}_{3} \mathrm{O}_{4}-30 \% \mathrm{MnO}_{2}$.

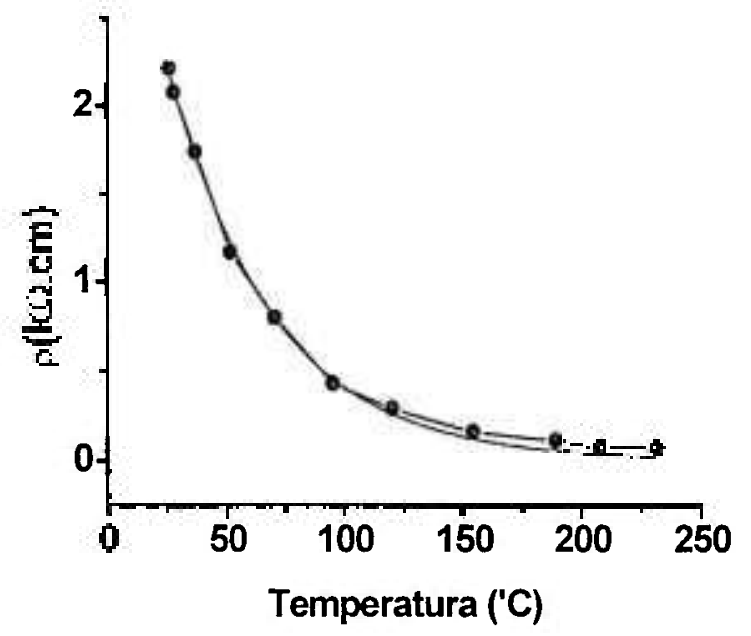

Figura 46: Resistividade elétrica em função da temperatura da composição $35 \% \mathrm{NiO}$ $-35 \% \mathrm{Co}_{3} \mathrm{O}_{4}-30 \% \mathrm{MnO}_{2}$.

A composição $35 \% \mathrm{NiO}-35 \% \mathrm{CO}_{3} \mathrm{O}_{4}-30 \% \mathrm{MnO}_{2}$ apresenta comportamento NTC com resistividade elétrica $1,28 \mathrm{k} \Omega . \mathrm{cm}$ a $50^{\circ} \mathrm{C}$, fator $\beta_{25 / 100} 2577 \mathrm{~K}$ e coeficiente de temperatura $\alpha=-6,4 \% / \mathrm{K}$. Esta composição tem comportamento termistor de coeficiente negativo adequado. 
A Figura 47 mostra valores de resistividade elétrica em função da temperatura na faixa de temperatura entre ambiente e $240^{\circ} \mathrm{C}$ para as diferentes concentrações de $\mathrm{MnO}_{2}$, agrupados em uma única figura.

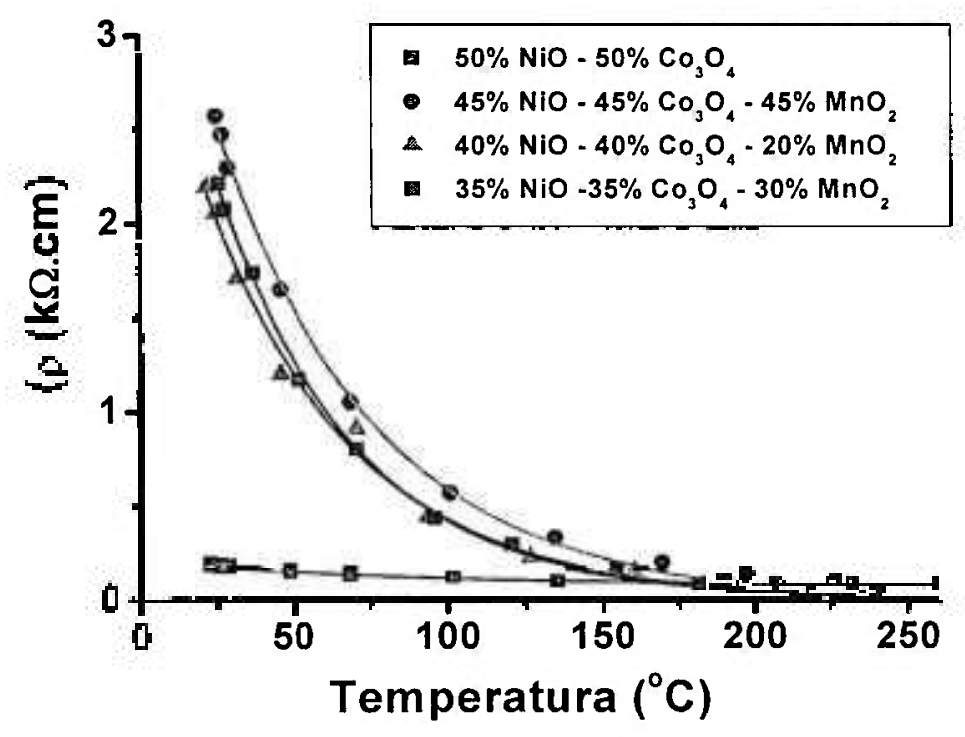

Figura 47: Resistividade em função da temperatura para quatro composições $50 \%$ $\mathrm{NiO}-50 \% \mathrm{Co}_{3} \mathrm{O}_{4}, 45 \% \mathrm{NiO}-45 \% \mathrm{Co}_{3} \mathrm{O}_{4}-10 \% \mathrm{MnO}_{2}, 40 \% \mathrm{NiO}-40 \% \mathrm{Co}_{3} \mathrm{O}_{4}-20 \%$ $\mathrm{MnO}_{2}$ e $35 \% \mathrm{NiO}-35 \% \mathrm{Co}_{3} \mathrm{O}_{4}-30 \% \mathrm{MnO}_{2}$.

$A$ adição de $\mathrm{MnO}_{2}$ à composição $\mathrm{NiO}-\mathrm{Co}_{3} \mathrm{O}_{4}$ promove um aumento significativo da resistividade elétrica.

\subsection{Uso de ligante na compactação (polietileno glicol)}

Foi analisado o comportamento elétrico de duas amostras de mesma composição $\left(33,3 \% \mathrm{NiO}-33,3 \% \mathrm{MnO}_{2}-33,3 \% \mathrm{Co}_{3} \mathrm{O}_{4}\right)$, preparadas com e sem ligante orgânico (polietileno glicol). Os resultados estão nas Figuras 48 e 49. 


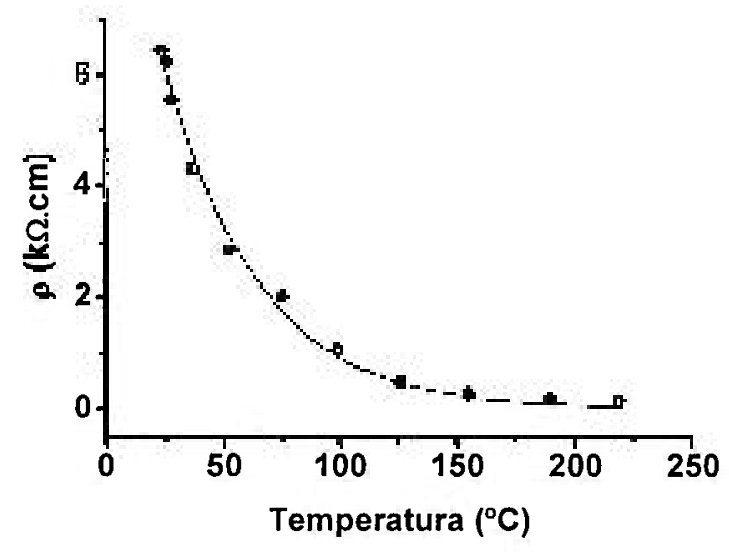

Figura 48: Resistividade elétrica em função da temperatura da composição $33,3 \%$ $\mathrm{NiO}-33,3 \% \mathrm{MnO}_{2}-33,3 \% \mathrm{Co}_{3} \mathrm{O}_{4}$ com ligante, sinterizada a $1250{ }^{\circ} \mathrm{C}$.

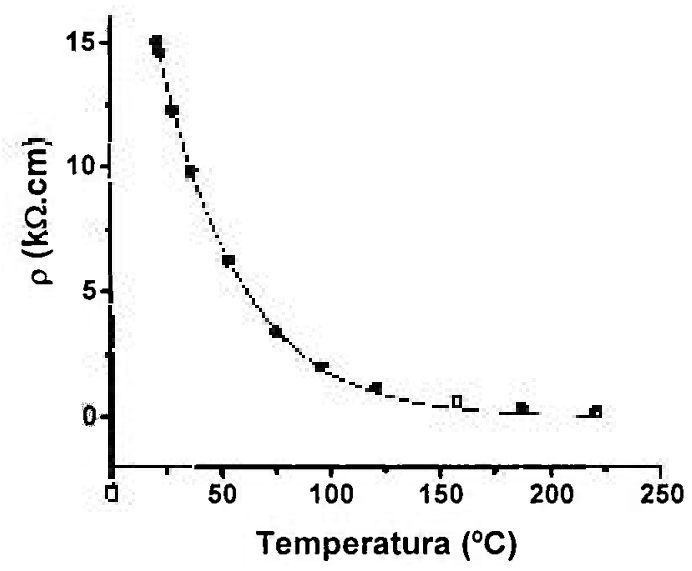

Figura 49: Resistividade elétrica em função da temperatura da composição $33,3 \%$ $\mathrm{NiO}-33,3 \% \mathrm{MnO}_{2}-33,3 \% \mathrm{Co}_{3} \mathrm{O}_{4}$ sem ligante, sinterizados a $1250^{\circ} \mathrm{C}$.

A amostra preparada sem ligante possui maior valor de resistividade elétrica que a preparada com ligante, mostrando que o ligante permite densificar melhor a cerâmica, diminuindo o volume relativo de poros e diminuindo, conseqüentemente a resistividade elétrica. 


\subsection{Diferentes perfis de temperatura/tempo de sinterização}

A composição $33,3 \% \mathrm{NiO}-33,3 \% \mathrm{MnO}_{2}-33,3 \% \mathrm{Co}_{3} \mathrm{O}_{4}$ foi sinterizada a 1250 ${ }^{\circ} \mathrm{C} / 1 \mathrm{~h}$ com taxa de aquecimento e resfriamento de $10^{\circ} \mathrm{C} / \mathrm{min}$ (rota 1). Outra, de mesma composição, foi sinterizada a $1250^{\circ} \mathrm{C} / 1 \mathrm{~h}$ com prévia queima a $600^{\circ} \mathrm{C} / 1 \mathrm{~h}$ (rota 2). A rota 2 teve como objetivo promover uma fusão do óxido de manganês

Os difratogramas para as amostras preparadas segundo as diferentes rotas de sinterização são mostrados na Figura 50.

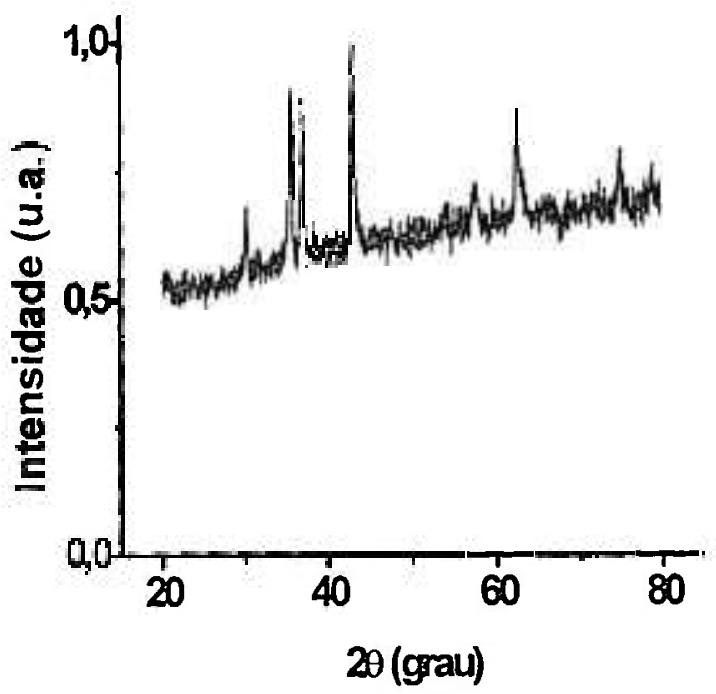

(a)

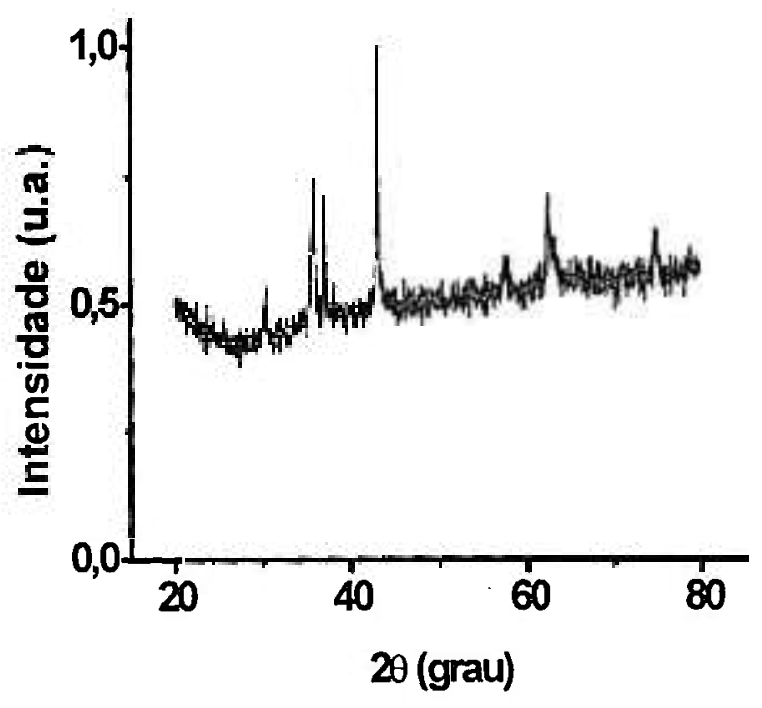

(b)

Figura 50: Difratogramas de raios $\mathrm{X}$ da composição $33,3 \% \mathrm{NiO}-33,3 \% \mathrm{MnO}_{2}-$ $33,3 \% \mathrm{Co}_{3} \mathrm{O}_{4}$ : (a) sinterizada a $1250^{\circ} \mathrm{C} / 1 \mathrm{~h}$; (b) com prévia queima a $600^{\circ} \mathrm{C}$.

Os difratogramas apresentam estrutura espinélio caracteristica de cerâmicas termistoras à base de óxidos de niquel, de cobalto e de manganês.

A Figura 51 mostra os resultados de medidas de resistividade elétrica em função da temperatura. 


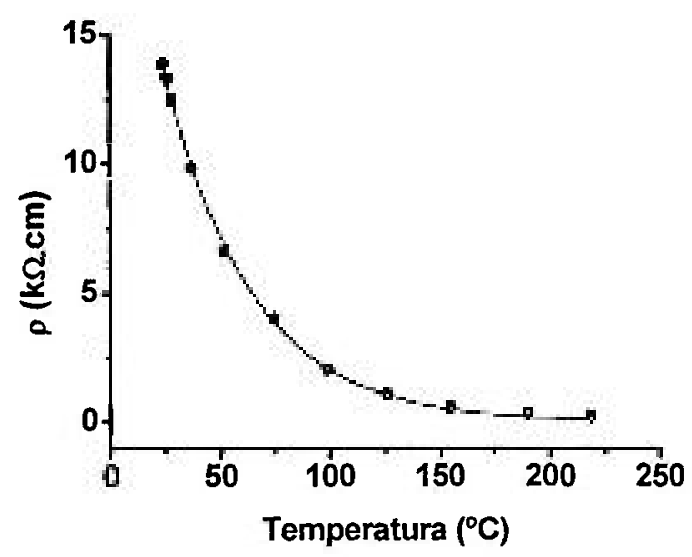

(a)

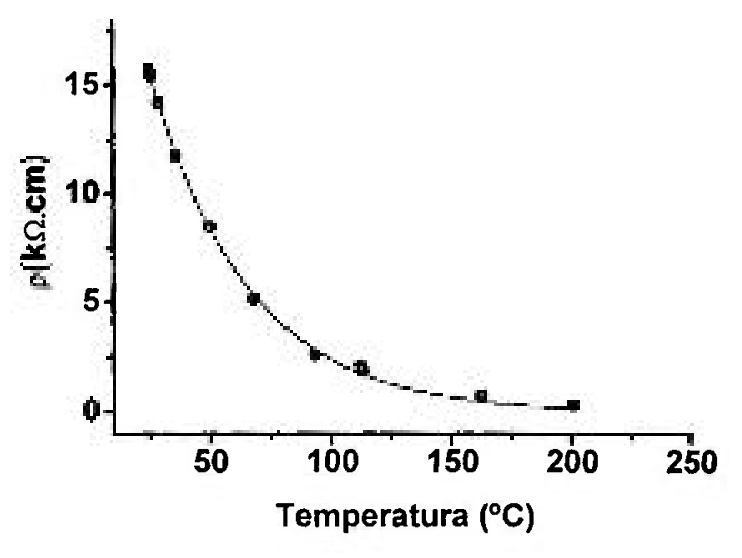

(b)

Figura 51: Resistividade elétrica em função da temperatura da composição $33,3 \%$ $\mathrm{NiO}-33,3 \% \mathrm{MnO}_{2}-33,3 \% \mathrm{Co}_{3} \mathrm{O}_{4}$ : (a) sinterizada a $1250{ }^{\circ} \mathrm{C} / 1 \mathrm{~h}$; (b) com prévia queima a $600^{\circ} \mathrm{C}$.

As amostras apresentam comportamento elétrico semelhante com fator $\beta_{25 / 100} 2676 K$ e coeficiente de temperatura $\alpha=-7,2 \% / K$, mostrando não ser necessária a queima a $600^{\circ} \mathrm{C}$ antes da sinterização.

\subsection{Sinterizações sucessivas}

As amostras foram obtidas por meio de sinterização e re-sinterização após cominuição com o objetivo de se procurar uma melhor homogeneização das composições. Foram preparadas quatro amostras de mesma composição (33,3\% $\left.\mathrm{NiO}-33,3 \% \mathrm{MnO}_{2}-33,3 \% \mathrm{Co}_{3} \mathrm{O}_{4}\right)$. As amostras foram sinterizadas a $1250^{\circ} \mathrm{C} / 2 \mathrm{~h}$ com taxa de aquecimento e resfriamento $10^{\circ} \mathrm{C} / \mathrm{min}$. As amostras $2 \mathrm{C}$ e $3 \mathrm{C}$ foram trituradas e novamente homogeneizadas em almofariz de ágata, compactadas e sinterizadas a $1250^{\circ} \mathrm{C} / 2 \mathrm{~h}$. A amostra $3 \mathrm{C}$ foi triturada, compactada e sinterizada a $1250^{\circ} \mathrm{C} / 2 \mathrm{~h}$.

A Figura 52 mostra os difratogramas de raios $X$ destas composições. 


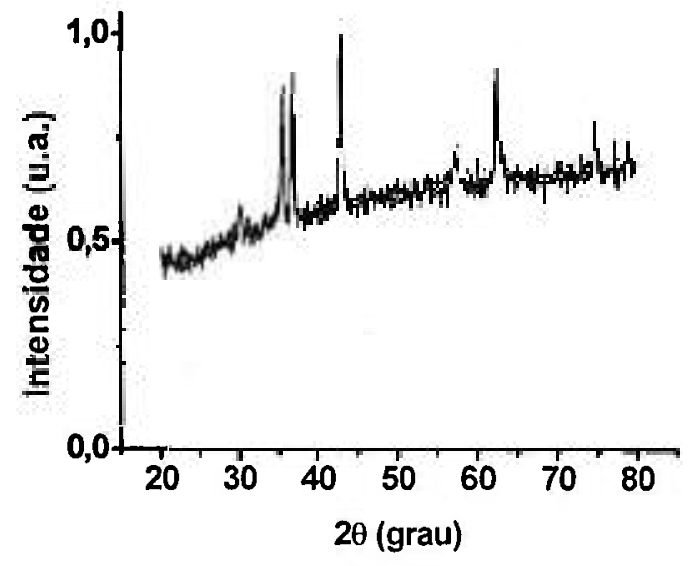

(a)

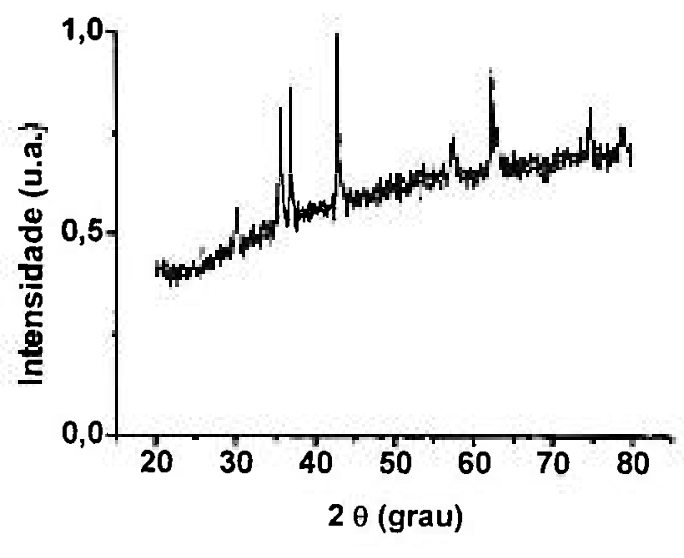

(b)

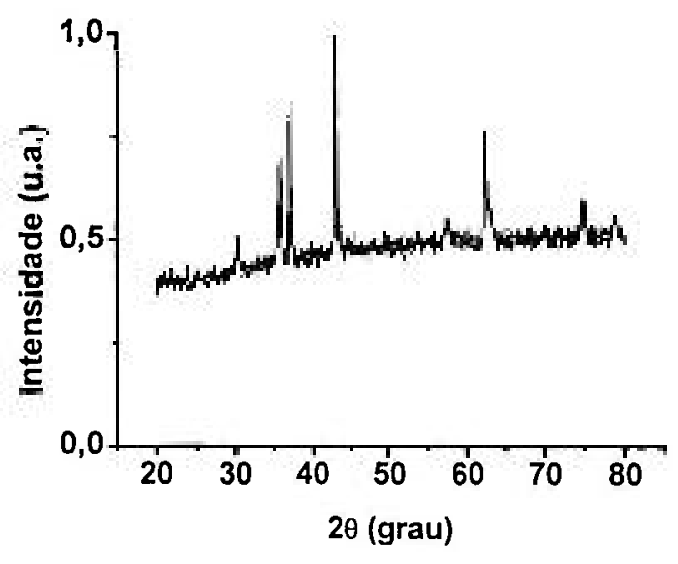

(c)

Figura 52: Difratogramas da composição $33,3 \% \mathrm{NiO}-33,3 \% \mathrm{MnO}_{2}-33,3 \% \mathrm{Co}_{3} \mathrm{O}_{4}$ sinterizada a $1250^{\circ} \mathrm{C} / 2 \mathrm{~h}$ : a) uma sinterização, b) duas e c) três.

Após uma e duas sinterizações as amostras apresentam difratogramas semelhantes com alto teor de cristalinidade. $O$ difratograma de raios $X$ da amostra com três tratamentos térmicos de sinterização tem picos mais definidos, correspondentes à estrutura espinélio.

A Figura 53 mostra o resultado da análise do comportamento elétrico destas três composições. 


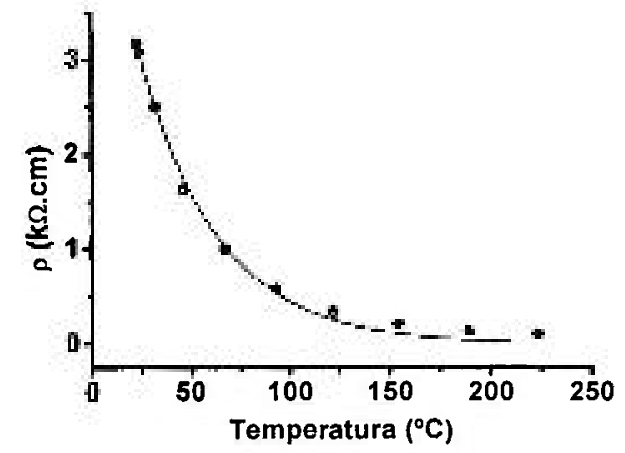

(a)

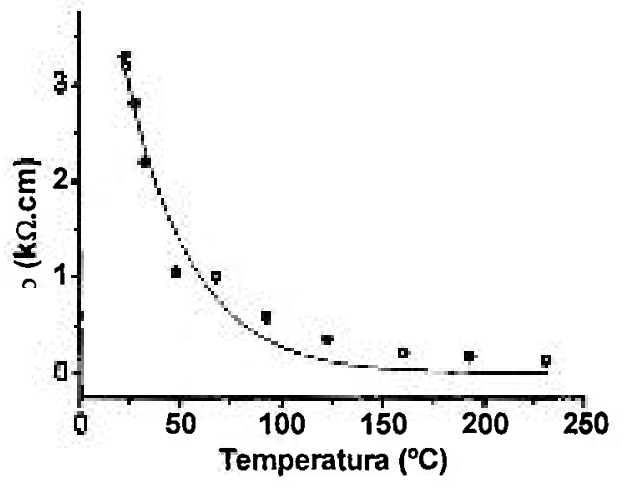

(b)

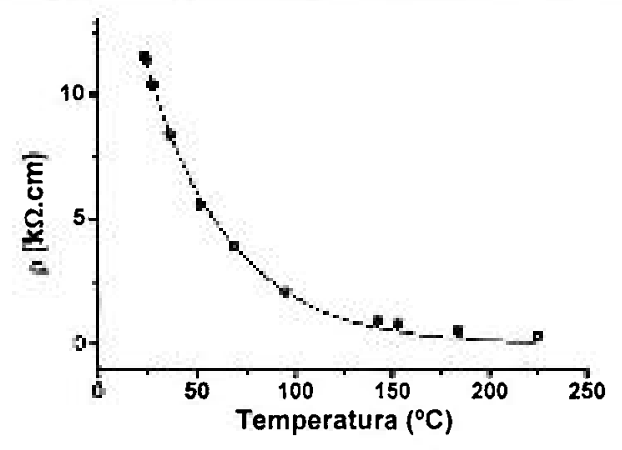

(c)

Figuras 53: Resistividade elétrica da composição 33,3\% $\mathrm{NiO}-33,3 \% \mathrm{MnO}_{2}-33,3 \%$ $\mathrm{Co}_{3} \mathrm{O}_{4}$ a $1250^{\circ} \mathrm{C} / 2 \mathrm{~h}$ submetida a sucessivos tratamentos térmicos de sinterização: a) um b) dois e c) três.

Os valores para os fatores $\beta_{25 / 100}$ e a foram 2844 e $-7,6 \% / K, 3472$ e $-9,3 \% / K$, 2653 e $-7,1 \% / K$ para uma, duas e três sinterizaçōes. Os compactos cerâmicos sinterizados duas vezes apresentam comportamento termistor mais adequado, mesmo com a amostra sinterizada três vezes apresentando uma estrutura cristalina mais definida.

3.6 Estudo da dependência da resistividade elétrica com a ciclagem térmica a $50^{\circ} \mathrm{C}$ (reprodutibilidade do sinal).

Foi feito o estudo da reprodutibilidade do valor de resistividade elétrica com a ciclagem térmica entre a temperatura ambiente e $50^{\circ} \mathrm{C}$, das composições $45 \% \mathrm{NiO}$ $45 \% \mathrm{Co}_{3} \mathrm{O}_{4}-10 \% \mathrm{MnO}_{2}, 40 \% \mathrm{NiO}-40 \% \mathrm{Co}_{3} \mathrm{O}_{4}-20 \% \mathrm{MnO}_{2}, 35 \% \mathrm{NiO}-35 \% \mathrm{Co}_{3} \mathrm{O}_{4}$ - $30 \% \mathrm{MnO}_{2}$ e $50 \% \mathrm{NiO}-50 \% \mathrm{Co}_{3} \mathrm{O}_{4}$. 
As medidas da resistência elétrica foram feitas ao longo de 3480 horas (145 dias) a intervalos variados de tempo. As Figuras 54 a 57 mostram os resultados.

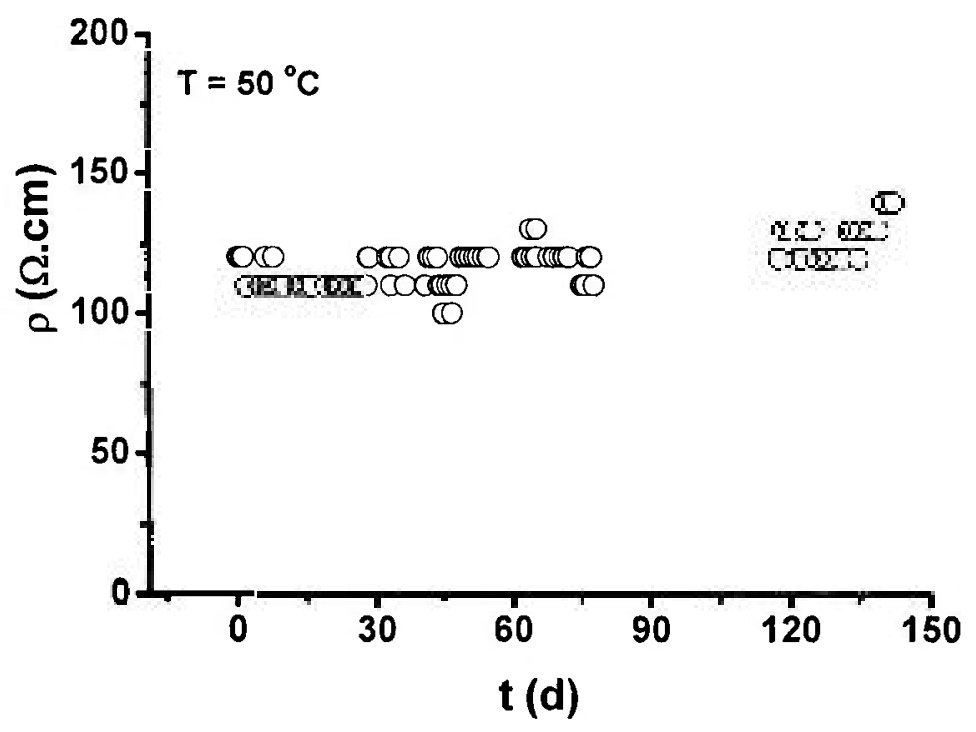

Figura 54: Resistividade elétrica da composição $50 \% \mathrm{NiO}-50 \% \quad \mathrm{Co}_{3} \mathrm{O}_{4}$ após ciclagem térmica a $50^{\circ} \mathrm{C}$.

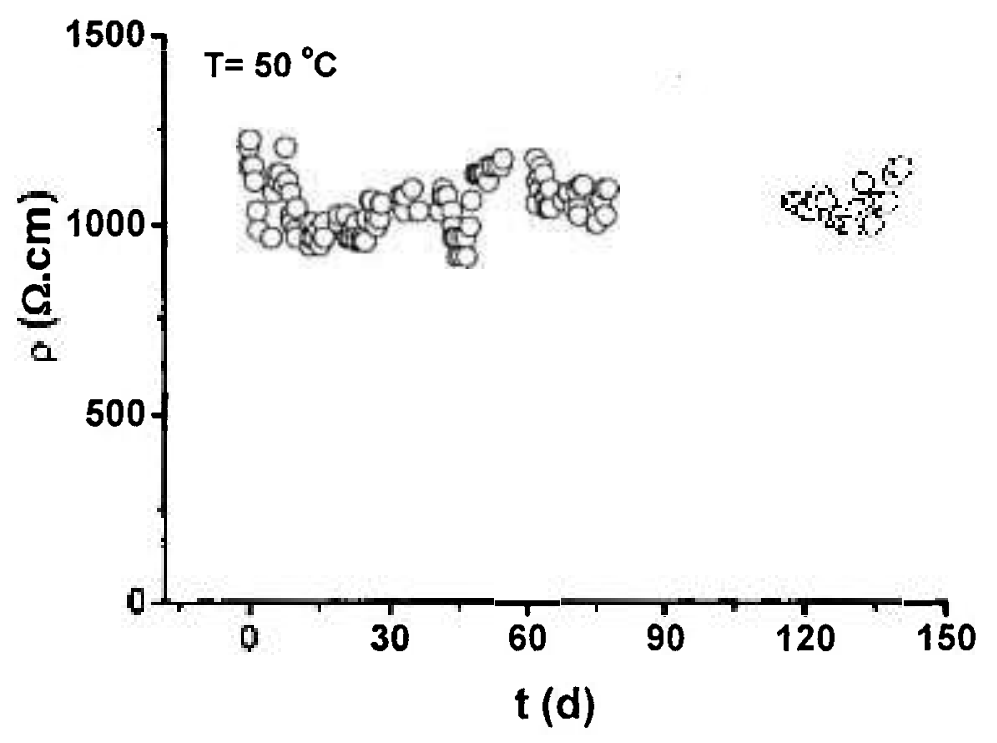

Figura 55: Resistividade elétrica da composição $45 \% \mathrm{NiO}-45 \% \mathrm{Co}_{3} \mathrm{O}_{4}-10 \% \mathrm{MnO}_{2}$ após ciclagem térmica a $50^{\circ} \mathrm{C}$. 


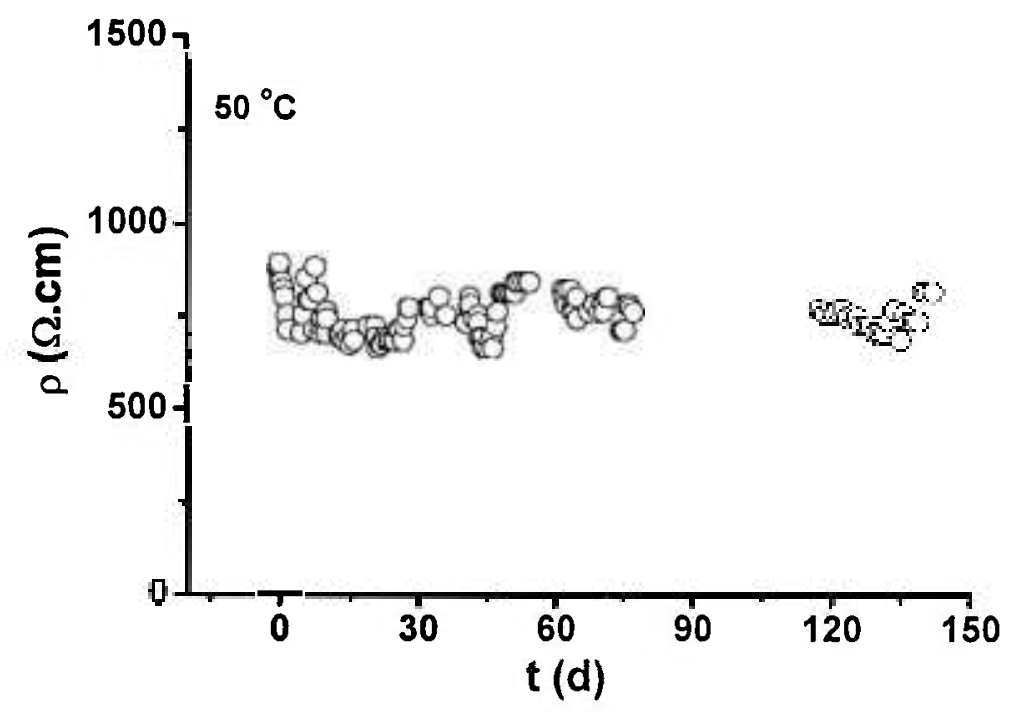

Figura 56: Resistividade elétrica da composição $40 \% \mathrm{NiO}-40 \% \mathrm{Co}_{3} \mathrm{O}_{4}-20 \% \mathrm{MnO}_{2}$ após ciclagem térmica a $50^{\circ} \mathrm{C}$.

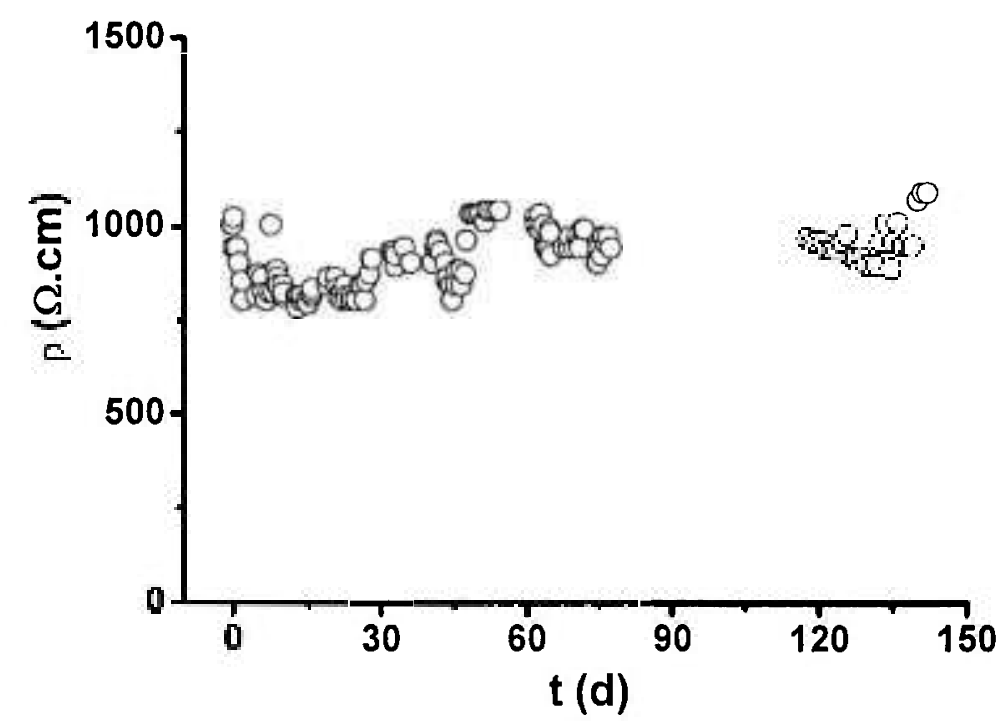

Figura 57: Resistividade elétrica da composição 35\% NiO - 35\% $\mathrm{Co}_{3} \mathrm{O}_{4}-30 \% \mathrm{MnO}_{2}$ após ciclagem térmica a $50^{\circ} \mathrm{C}$.

A variação relativa dos valores de resistividade elétrica está dentro do erro experimental das condiçōes de medida. Por um período de avaliação de até 4 meses, os termistores mostraram variações maiores que as requeridas para aplicação industrial. 


\section{CONCLUSÕES}

- A análise dos óxidos precursores por fluorescência de raios $X$ mostrou que os teores de pureza determinados para a matéria prima utilizada correspondem aos especificados pelos fornecedores. Os experimentos de termogravimetria mostraram que os óxidos precursores apresentam número de oxidação como especificados pelos fornecedores com fórmulas químicas $\mathrm{NiO}, \mathrm{MnO}_{2}$ e $\mathrm{CO}_{3} \mathrm{O}_{4}$.

- Todas as amostras com composições $\mathrm{NiO}-\mathrm{MnO}_{2}, \mathrm{NiO}-\mathrm{Co}_{3} \mathrm{O}_{4}, \mathrm{MnO}_{2}-\mathrm{Co}_{3} \mathrm{O}_{4} \mathrm{e}$ $\mathrm{NiO}-\mathrm{CO}_{3} \mathrm{O}_{4}-\mathrm{MnO}_{2}$ sintetizadas por mistura de óxidos seguida de compactação e sinterização apresentaram comportamento termistor do tipo NTC. A variação dos teores relativos dos óxidos $\mathrm{NiO}, \mathrm{MnO}_{2}$ e $\mathrm{Co}_{3} \mathrm{O}_{4}$ permitiu a obtenção de termistores com diferentes valores de $\beta$ e de $\alpha$.

- Os experimentos de termogravimetria mostraram que na perda de massa durante o processo de sinterização a ordem dos eventos é sempre a mesma, segundo o potencial padrão de redução de cada íon metálico.

- As amostras de composição binária dos tipos $\mathrm{NiO}-\mathrm{MnO}_{2}, \mathrm{NiO}-\mathrm{Co}_{3} \mathrm{O}_{4}$ e $\mathrm{MnO}_{2}-$ $\mathrm{Co}_{3} \mathrm{O}_{4}$ apresentam melhores propriedades termistoras.

- Foi verificado um aumento do valor do fator $\beta$ com o aumento do teor relativo de $\mathrm{MnO}_{2}$. Entretanto, a presença de $\mathrm{MnO}_{2}$ promove a formação de fase amorfa. 


\section{Referências}

[1] R. W. A. Scarr, R. A. Setterington, "Thermistors, their theory, manufacture and application", Proc. I.E.E.E. 107B (1960) 395-404.

[2] E.C.Subbarao, "Solid electrolytes and their applications", Plenum Press, New York (1980).

[3] S. Fritsch, J. Sarrias, M. Brieu, J. J. Couderc, J. L. Baudour, E. Snoeck, A. Rousset, "Correlation between the structure, the microstructure and the electrical properties of nickel manganite negative temperature coefficient (NTC) thermistors", Solid State Ionics 109 (1998) 229-237.

[4] Manual Siemens Matsushita Components (1992).

[5] J. G. Fagan, V. R. W. Amarakoon, "Reliability and reproductibility of ceramics sensors: Part I: NTC Thermistor", Am. Ceram. Soc. Bull. 72 (1993) 70-78.

[6] J. S. Jung, J. W. Kim, M. S. Kim, J. S. Jang, D. S. Ryu, "Reliability evaluation and failure analysis for NTC thermistor", Int. J. Mod. Phys. B17, 8-9 (2003) 1254-1260.

[7] E. J. W. Verwey, P. W. Haayaman, F. C. Romeyn, Semiconductors with large negative temperature coefficient of resistance, Philips Technical Review 9 (1947) 239-248.

[8] S. M. Saviae, O. S. Aleksiae, P. M. Nikoliae, D. T. Lukoviae, "Geometrical and electrical properties of NTC polycrystalline thermistors vs. changes of sintering parameters", Science of Sintering 38 (2006) 223-229

[9] E. Macklen, "Thermistors", Electrochem. Publ. Ltd., Scotland (1979) p. 32.

[10] D. C. Hill, H. L. Tuller, "Ceramic sensors: theory and practice", in: R. C. Buchanan (Ed.), Ceramic Materials for Electronics, Marcel Dekker Inc., New York (1991).

[11] E. Kuzma, L. Kozlowski, "The synthesis of spinels and solid solution of thermistor manganese-cobalt compounds with liquid phase participation", Electronic Technology 10, 2 (1977) 63-73.

[12] T. Battault, R. Legros, A. Rousset, J. Eur. Ceram. Soc. 15 (1995) 1141.

[13] T. Battault, R. Legros, M. Brieu, J. J. Couderc, L. Bernard, A. Rousset, J. Phys. III 7 (1997) 979.

[14] J. P. Holman, "Experimental methods for engineers", $6^{\text {th }}$ Ed., McGraw-Hill, New York (1994). 
[15] http://www.semiconductors4u.philips.com.br/revistas/114/pagina05.htm, acesso em 20/08/2007.

[16] A. Feltz, J. Toupfer, F. Schirrmeister, "Conductivity data and preparation routes for $\mathrm{NiMn}_{2} \mathrm{O}_{4}$ thermistor ceramics", J. Eur. Ceram. Soc. 9 (1992) 187-191

[17] H. G. Paulo, E. B.Vânia, Rev. Bras. Ensino de Física 27, 3 (2005) 369-375.

[18] A. Feltz, "Spinel forming ceramics of the system $\mathrm{Fe}_{x} \mathrm{Ni}_{y} \mathrm{Mn}_{3-\mathrm{x}-\mathrm{y}} \mathrm{O}_{4}$ for high temperature NTC thermistor applications", J. Eur. Ceram. Soc. 20, 14-15 (2000)23532366.

[19] J. A. Varela, "Processos químicos para produção de pós cerâmicos", UNESP (1992)

[20] D. R. Ricci, F. Ambrozio F., Cerâmica 30 (1994) 337.

[21] S. J. Schneider Jr., "Engineered Materials Handbook - Ceramics and Glasses" 4, ASM International, Ohio, EUA (1987)

[22] I. R. Oliveira, A. R. Studart, R. G. Pileggi, V. C. Pandolfelli, "Dispersão e empacotamento de partículas: princípios básicos e aplicaçōes em processamento cerâmico", Fazendo Arte Editorial, São Paulo (2000).

[23] R. M. German, "Sintering: Theory and Practice", J. Wiley \& Sons, Inc., New York (1996) 181.

[24] Granulometer 1064, Compagnie Industrielle des laser, User Manual (1992).

[25] R. P. Speyer, "Thermal Analysis of Materials", Marcel Dekker, Inc., New York 1994.

[26] D. A. Skoog, F. J. Holler, T. A. Nieman, "Principles of Instrumental Analysis", $5^{\text {th }}$ Ed., Saunders College Publ., Florida, EUA (1998).

[27] B. D. Cullity, "Elements of X-ray Diffraction", $2^{\text {nd }}$ Ed., Addison-Wesley, Massachusets (1978) 86

[28] H. J. Kestenbach, W. J. Botta Filho, "Microscopia eletrônica: transmissão e varredura", Associação Brasileira de Metais, São Paulo (1989).

[29] E. M. Girotto, I. A. Santos, "Medidas de resistividade elétrica em sólidos: como efetuá-las", Química Nova 25, 4 (2002) 639-647.

[30] S. A. Kanade, V. Puri, "Composition dependent resistivity of thick film $\mathrm{Ni}_{1-x} \mathrm{Co}_{x} \mathrm{Mn}_{2} \mathrm{O}_{4}: 0 \leq \mathrm{x} \leq 1$ NTC thermistors", Mater. Lett. 60 (2006) 1428. 
Apêndice: Avaliação de evento, valores de temperatura de ocorrência e de perda de massa obtidos nos experimentos de termogravimetria com as diferentes composiçōes sob diferentes atmosferas.

\begin{tabular}{|c|c|c|c|}
\hline $\begin{array}{l}\text { oxido de niquel } \\
\text { atmosfera: } \mathrm{N}_{2} \text {, fluxo: } 50 \mathrm{~mL} / \mathrm{min}\end{array}$ & evento & $\mathrm{T}\left({ }^{\circ} \mathrm{C}\right)$ & $\begin{array}{c}\text { perda de massa } \\
(\%)\end{array}$ \\
\hline & $\begin{array}{l}\text { perda de água } \\
\text { superficial }\end{array}$ & 53 & 2,57 \\
\hline & $\mathrm{Ni}^{2+} / \mathrm{Ni}^{0}$ parcial & 470 & 16,40 \\
\hline & $\mathrm{Ni}^{2+} / \mathrm{Ni}^{0}$ & 592 & 2,61 \\
\hline & $\mathrm{Ni}^{2+} / \mathrm{Ni}^{\mathrm{U}}$ & 742 & 0,80 \\
\hline & $\mathrm{Ni}^{2+} / \mathrm{Ni}^{\mathrm{V}}$ total & 991 & 2,14 \\
\hline & & & Total $=24,52$ \\
\hline
\end{tabular}

\begin{tabular}{|l|l|c|c|}
\hline $\begin{array}{l}\text { óxido de niquel } \\
\text { atmosfera: } \mathrm{N}_{2} / \mathrm{H}_{2}, \\
\text { fluxo: } 75 \text { e } 25 \mathrm{~mL} / \mathrm{min}\end{array}$ & evento & $\begin{array}{c}\mathrm{T}\left({ }^{\circ} \mathrm{C}\right) \\
\text { perda de massa } \\
(\%)\end{array}$ \\
\hline & $\begin{array}{l}\text { perda de água } \\
\text { superficial }\end{array}$ & 46 & 2,18 \\
\cline { 2 - 4 } & $\mathrm{Ni}^{2+} / \mathrm{Ni}^{0}$ parcial & 475 & 14,86 \\
\hline & $\mathrm{Ni}^{2+} / \mathrm{Ni}^{0}$ & 670 & 2,98 \\
\cline { 2 - 4 } & $\mathrm{Ni}^{2+} / \mathrm{Ni}^{0}$ total & 997 & 2,41 \\
\hline & & Total $=22,43$ \\
\hline
\end{tabular}

\begin{tabular}{|l|c|c|c|}
\hline $\begin{array}{l}\text { óxido de manganês } \\
\text { Atmosfera: ar, fluxo:100mL /min }\end{array}$ & evento & $\mathrm{T}\left({ }^{\circ} \mathrm{C}\right)$ & $\begin{array}{c}\text { perda de massa } \\
(\%)\end{array}$ \\
\hline & $\begin{array}{l}\text { perda de água } \\
\text { superficial }\end{array}$ & 52 & 2,57 \\
\hline & $\mathrm{Mn}^{4+} / \mathrm{Mn}^{2+} \mathrm{parcial}$ & 470 & 16,4 \\
\cline { 2 - 4 } & $\mathrm{Mn}^{4+} / \mathrm{Mn}^{2+}$ total & 592 & 2,61 \\
\cline { 2 - 4 } & $\mathrm{Mn}^{2+} / \mathrm{Mn}^{0}$ total & 991 & 2,14 \\
\hline
\end{tabular}

\begin{tabular}{|l|c|c|c|}
\hline $\begin{array}{l}\text { óxido de manganês } \\
\text { atmosfera: } \mathrm{N}_{2} / \mathrm{H}_{2,} \text { fluxo: } 75 \mathrm{~mL} / \mathrm{min}\end{array}$ & evento & $\mathrm{T}\left({ }^{\circ} \mathrm{C}\right)$ & $\begin{array}{c}\text { perda de massa } \\
(\%)\end{array}$ \\
\hline & $\frac{\mathrm{Mn}^{4+} / \mathrm{Mn}^{2+}}{\mathrm{Mn}^{2+} / \mathrm{Mn}^{0}}$ & 308 & 4,43 \\
\hline & & 447 & 25,16 \\
\hline
\end{tabular}

\begin{tabular}{|l|c|c|c|}
\hline $\begin{array}{l}\text { óxido de cobalto } \\
\text { atmosfera: } \text { ar, fluxo: } 25 \mathrm{~mL} / \mathrm{min}\end{array}$ & evento & $\begin{array}{c}\text { T }\left({ }^{\circ} \mathrm{C}\right) \\
\text { perda de massa } \\
(\%)\end{array}$ \\
\hline & $\mathrm{Co}^{3+} / \mathrm{Co}^{2+}$ & 997 & 6,8 \\
\hline
\end{tabular}




\begin{tabular}{|l|r|c|c|}
\hline $\begin{array}{l}\text { óxido de cobalto } \\
\text { atmosfera: ar, fluxo: } 100 \mathrm{~mL} / \mathrm{min}\end{array}$ & evento & $\begin{array}{c}\text { perda de massa } \\
(\%)\end{array}$ \\
\hline & $\left.{ }^{\circ} \mathrm{C}\right)$ & 6,35 \\
\hline & & 1000 & Total $=6,35$ \\
\hline
\end{tabular}

\begin{tabular}{|l|c|c|c|}
\hline $\begin{array}{l}\text { Óxido de cobalto } \\
\text { atmosfera: } \mathrm{N}_{2} \text {, fluxo: } 50 \mathrm{~mL} / \mathrm{min}\end{array}$ & evento & $\begin{array}{c}\text { perda de massa } \\
(\%)\end{array}$ \\
\hline & $\mathrm{Co}^{3+} / \mathrm{Co}^{2+}$ & 977 & 6,35 \\
\hline & & Total $=6,35$ \\
\hline
\end{tabular}

\begin{tabular}{|l|c|c|c|}
\hline $\begin{array}{l}\text { óxido de cobalto } \\
\text { atmosfera: ar, fluxo: } 25 \mathrm{~mL} / \mathrm{min}\end{array}$ & evento & $\begin{array}{c}\mathrm{T}\left({ }^{\circ} \mathrm{C}\right) \\
\text { perda de massa } \\
(\%)\end{array}$ \\
\hline & $\mathrm{Co}^{3+} / \mathrm{Co}^{2+}$ & 425 & 26,1 \\
\hline & & & Total $=26,1$ \\
\hline
\end{tabular}

\begin{tabular}{|c|c|c|c|}
\hline $\begin{array}{l}50 \% \text { oxido de níquel }+ \\
50 \% \text { oxido de manganês } \\
\text { atmosfera: ar, fluxo: } 20 \mathrm{~mL} / \mathrm{min}\end{array}$ & evento & $\mathrm{T}\left({ }^{\circ} \mathrm{C}\right)$ & $\begin{array}{c}\text { perda de massa } \\
(\%)\end{array}$ \\
\hline & $\begin{array}{l}\text { perda de água } \\
\text { superficial }\end{array}$ & 50 & 0,63 \\
\hline & $\mathrm{Ni}^{2+} / \mathrm{Ni}^{0}$ parcial & 266 & $4, \overline{33}$ \\
\hline & $\mathrm{Mn}^{4+} / \mathrm{Mn}^{2+}$ & 340 & 0,79 \\
\hline & $\mathrm{Ni}^{2+} / \mathrm{Ni}^{\mathrm{O}}$ total & 470 & 4,79 \\
\hline & $\mathrm{Mn}^{2+} / \mathrm{Mn}^{0}$ & 998 & 2,77 \\
\hline & & & Total $=13,31$ \\
\hline
\end{tabular}

\begin{tabular}{|c|c|c|c|}
\hline $\begin{array}{l}50 \% \text { óxido de niquel }+ \\
50 \% \text { óxido de manganês } \\
\text { atmosfera: } \mathrm{N}_{2} \text {, fluxo: } 50 \mathrm{~mL} / \mathrm{min}\end{array}$ & evento & $\mathrm{T}\left({ }^{\circ} \mathrm{C}\right)$ & $\begin{array}{c}\text { perda de massa } \\
(\%)\end{array}$ \\
\hline & $\begin{array}{l}\text { perda de água } \\
\text { superficial }\end{array}$ & 50 & 0,88 \\
\hline & $\mathrm{Ni}^{2+} / \mathrm{Ni}^{0}$ parcial & 296 & 4,4 \\
\hline & $\mathrm{Mn}^{4+} / \mathrm{Mn}^{2+}$ & 330 & 0,86 \\
\hline & $\mathrm{Ni}^{2+} / \mathrm{Ni}^{0}$ total & 461 & 5,09 \\
\hline & $\mathrm{Mn}^{2+} / \mathrm{Mn}^{0}$ & 949 & 2,76 \\
\hline & & & Total $=14,0$ \\
\hline
\end{tabular}




\begin{tabular}{|l|c|c|c|}
\hline $\begin{array}{l}50 \% \text { óxido de níquel }+ \\
50 \% \text { óxido de manganês } \\
\text { atmosfera: } \mathrm{H}_{2} \text {, fluxo: } 75 \mathrm{~mL} / \mathrm{min}\end{array}$ & evento & $\mathrm{T}\left({ }^{\circ} \mathrm{C}\right)$ & $\begin{array}{c}\text { perda de massa } \\
(\%)\end{array}$ \\
\hline & $\mathrm{Ni}^{2+} / \mathrm{Ni}^{0}$ parcial & 296 & 2,62 \\
\hline & $\mathrm{Mn}^{4+} / \mathrm{Mn}^{2+}$ & 427 & 25,56 \\
\cline { 2 - 4 } & $\mathrm{Ni}^{2+} / \mathrm{Ni}^{\mathrm{C}}$ total & & \\
\hline & & Total $=28,2$ \\
\hline
\end{tabular}

\begin{tabular}{|c|c|c|c|}
\hline $\begin{array}{l}50 \% \text { óxido de niquel }+ \\
50 \% \text { óxido de cobalto } \\
\text { atmosfera: ar, fluxo: } 20 \mathrm{~mL} / \mathrm{min}\end{array}$ & evento & $\mathrm{T}\left({ }^{\circ} \mathrm{C}\right)$ & $\begin{array}{c}\text { perda de massa } \\
(\%)\end{array}$ \\
\hline & $\begin{array}{l}\text { perda de água } \\
\text { superficial }\end{array}$ & 50 & 1,8 \\
\hline & $\mathrm{Ni}^{2+} / \mathrm{Ni}^{0}$ parcial & 226 & 3,05 \\
\hline & $\mathrm{Co}^{3+} / \mathrm{Co}^{2+}$ & 459 & 7,95 \\
\hline & $\mathrm{Ni}^{2+} / \mathrm{Ni}^{0}$ total & 593 & 1,42 \\
\hline & $\mathrm{Mn}^{2+} / \mathrm{Mn}^{0}$ & 994 & 1,21 \\
\hline & & & Total $=15,43$ \\
\hline
\end{tabular}

$50 \%$ óxido de niquel + $50 \%$ óxido de cobalto atmosfera: ar, fluxo: $100 \mathrm{~mL} / \mathrm{min}$

\begin{tabular}{|l|c|c|}
\hline \multicolumn{1}{|c|}{ evento } & $\mathrm{T}\left({ }^{\circ} \mathrm{C}\right)$ & $\begin{array}{c}\text { perda de massa } \\
(\%)\end{array}$ \\
\hline $\begin{array}{l}\text { perda de água } \\
\text { superficial }\end{array}$ & 68 & 2,76 \\
\hline $\mathrm{Ni}^{2+} / \mathrm{Ni}^{0}$ parcial & 229 & 1,2 \\
\hline $\mathrm{Co}^{3+} / \mathrm{Co}^{2+}$ & 472 & 8,1 \\
\hline $\mathrm{Ni}^{2+} / \mathrm{Ni}^{0}$ total & 600 & 1,5 \\
\hline $\mathrm{Mn}^{2+} / \mathrm{Mn}^{0}$ & 1002 & 2,23 \\
\hline & & Total $=15,79$ \\
\hline
\end{tabular}

\begin{tabular}{|c|c|c|c|}
\hline $\begin{array}{l}50 \% \text { óxido de niquel }+ \\
50 \% \text { óxido de cobalto }\end{array}$ & evento & $\mathrm{T}\left({ }^{\circ} \mathrm{C}\right)$ & $\begin{array}{c}\text { perda de massa } \\
(\%)\end{array}$ \\
\hline & $\begin{array}{l}\text { perda de água } \\
\text { superficial }\end{array}$ & 68 & 2,76 \\
\hline & $\mathrm{Ni}^{2+} / \mathrm{Ni}^{\mathrm{O}} \rightarrow$ & 226 & 1.1 \\
\hline & $\mathrm{Co}^{3+} / \mathrm{Co}^{2+}$ & 418 & 24 \\
\hline
\end{tabular}




\begin{tabular}{|l|l|c|c|}
\hline $\begin{array}{l}50 \% \text { óxido de manganês + } \\
\text { 50\% óxido de cobalto } \\
\text { atmosfera: ar, fluxo: } 20 \mathrm{~mL} / \mathrm{min}\end{array}$ & evento & $\mathrm{T}\left({ }^{\circ} \mathrm{C}\right)$ & $\begin{array}{c}\text { perda de massa } \\
(\%)\end{array}$ \\
\hline & $\begin{array}{l}\text { perda de água } \\
\text { superficial }\end{array}$ & 50 & 0,73 \\
\cline { 2 - 4 } & $\mathrm{Mn}^{4+} / \mathrm{Mn}^{2+}$ & 250 & 4,06 \\
\hline $\mathrm{Co}^{3+} / \mathrm{Co}^{2+}$ & 466 & 8,35 \\
\cline { 2 - 4 } & $\mathrm{Mn}^{2+} / \mathrm{Mn}^{0}$ & 845 & 1,57 \\
\hline $\mathrm{Co}^{2+} / \mathrm{Co}^{0}$ & 1022 & 2,64 \\
\hline & & Total $=17,35$ \\
\hline
\end{tabular}

\begin{tabular}{|c|c|c|c|}
\hline $\begin{array}{l}50 \% \text { óxido de manganês }+ \\
50 \% \text { óxido de cobalto } \\
\end{array}$ & evento & $\mathrm{T}\left({ }^{\circ} \mathrm{C}\right)$ & $\begin{array}{c}\text { perda de massa } \\
(\%)\end{array}$ \\
\hline & $\begin{array}{l}\text { perda de água } \\
\text { superficial }\end{array}$ & 50 & 0,48 \\
\hline & $\mathrm{Mn}^{4+} / \mathrm{Mn}^{2+}$ & 248 & 3,84 \\
\hline & $\mathrm{Co}^{3+} / \mathrm{Co}^{2+}$ & 475 & 8,1 \\
\hline & $\mathrm{Mn}^{2+} / \mathrm{Mn}^{\sigma}$ & 838 & 1,3 \\
\hline & $\mathrm{Co}^{2+} / \mathrm{Co}^{\circ}$ & 1016 & 3,21 \\
\hline & & & Total $=15,84$ \\
\hline
\end{tabular}

$50 \%$ óxido de manganês $50 \%$ oxido de cobalto atmosfera: $N_{2}$ fluxo: $100 \mathrm{~mL} / \mathrm{min}$

\begin{tabular}{|l|c|c|}
\hline \multicolumn{1}{|c|}{ evento } & $\mathrm{T}\left({ }^{\circ} \mathrm{C}\right)$ & $\begin{array}{c}\text { perda de massa } \\
(\%)\end{array}$ \\
\hline $\mathrm{Mn}^{4+} / \mathrm{Mn}^{2+}$ & 310 & 5,18 \\
\hline $\mathrm{Co}^{3+} / \mathrm{Co}^{2+}$ & 468 & 7,9 \\
\hline $\mathrm{Mn}^{2+} / \mathrm{Mn}^{0}$ & 827 & 1,6 \\
\hline $\mathrm{Co}^{2+} / \mathrm{Co}^{0}$ & 982 & 2,93 \\
\hline & & Total $=17,6$ \\
\hline
\end{tabular}

\begin{tabular}{|l|c|c|c|}
\hline $\begin{array}{l}50 \% \text { óxido de manganês } \\
50 \% \text { oxido de cobalto } \\
\text { atmosfera } \mathrm{H}_{2}(75 \mathrm{~mL} / \mathrm{min})\end{array}$ & evento & $\mathrm{T}\left({ }^{\circ} \mathrm{C}\right)$ & $\begin{array}{c}\text { perda de massa } \\
(\%)\end{array}$ \\
\hline & & 300 & 2,6 \\
\hline & $\mathrm{Mn}^{4+} / \mathrm{Mn}^{2+}$ & & \\
\hline & $\mathrm{Co}^{3+} / \mathrm{Co}^{2+}$ & 430 & 26,2 \\
\cline { 2 - 4 } & $\mathrm{Mn}^{2+} / \mathrm{Mn}^{0}$ & & \\
\cline { 2 - 4 } & & Total $=28,8$ \\
\hline
\end{tabular}


$33 \%$ óxido de manganês

$33 \%$ óxido de cobalto

$33 \%$ óxido de níquel

atmosfera: ar, fluxo: $20 \mathrm{~mL} / \mathrm{min}$

\begin{tabular}{|l|c|c|}
\hline \multicolumn{1}{|c|}{ evento } & $\mathrm{T}\left({ }^{\circ} \mathrm{C}\right)$ & $\begin{array}{c}\text { perda de massa } \\
(\%)\end{array}$ \\
\hline $\begin{array}{l}\text { perda de água } \\
\text { superficial }\end{array}$ & 50 & 1,14 \\
\hline $\mathrm{Ni}^{2+} / \mathrm{Ni}^{0}$ & 267 & 4,54 \\
\hline $\mathrm{Mn}^{2+} / \mathrm{Mn}^{0}$ & 454 & 4,73 \\
\hline $\mathrm{Co}^{3+} / \mathrm{Co}^{2+}$ & 1002 & 1,83 \\
\hline & & Total $=12,2$ \\
\hline
\end{tabular}

$33 \%$ óxido de manganês $33 \%$ óxido de cobalto $33 \%$ óxido de níquel atmosfera: ar, fluxo: $100 \mathrm{~mL} / \mathrm{min}$

\begin{tabular}{|l|c|c|}
\hline \multicolumn{1}{|c|}{ evento } & $\mathrm{T}\left({ }^{\circ} \mathrm{C}\right)$ & $\begin{array}{c}\text { perda de massa } \\
(\%)\end{array}$ \\
\hline $\begin{array}{l}\text { perda de água } \\
\text { superficial }\end{array}$ & 50 & 0,63 \\
\hline $\mathrm{Ni}^{2+} / \mathrm{Ni}^{0}$ & 266 & 4,33 \\
\hline $\mathrm{Mn}^{2+} / \mathrm{Mn}^{0}$ & 470 & 4,78 \\
\hline $\mathrm{Co}^{3+} / \mathrm{Co}^{2+}$ & 998 & 1,94 \\
\hline & & Total $=11,7$ \\
\hline
\end{tabular}

$33 \%$ óxido de manganês $33 \%$ oxido de cobalto $33 \%$ óxido de niquel atmosfera: $\mathrm{N}_{2}$, fluxo: $50 \mathrm{~mL} / \mathrm{min}$

\begin{tabular}{|l|c|c|}
\hline \multicolumn{1}{|c|}{ evento } & $T\left({ }^{\circ} \mathrm{C}\right)$ & $\begin{array}{c}\text { perda de massa } \\
(\%)\end{array}$ \\
\hline $\begin{array}{l}\text { perda de água } \\
\text { superficial }\end{array}$ & 50 & 0,88 \\
\hline $\mathrm{Ni}^{2+} / \mathrm{Ni}^{0}$ & 296 & 4,4 \\
\hline $\mathrm{Mn}^{2+} / \mathrm{Mn}^{0}$ & 461 & 5,1 \\
\hline $\mathrm{Co}^{3+} / \mathrm{Co}^{2+}$ & 949 & 1,94 \\
\hline & & Total $=11,9$ \\
\hline
\end{tabular}

$33 \%$ óxido de manganês $33 \%$ óxido de cobalto $33 \%$ óxido de niquel atmosfera: $\mathrm{H}_{2}$ fluxo: $75 \mathrm{~mL} / \mathrm{min}$

\begin{tabular}{|l|c|c|}
\hline \multicolumn{1}{|c|}{ evento } & $\mathrm{T}\left({ }^{\circ} \mathrm{C}\right)$ & $\begin{array}{c}\text { perda de massa } \\
(\%)\end{array}$ \\
\hline $\mathrm{Ni}^{2+} / \mathrm{Ni}^{0} / / \mathrm{Mn}^{4+} / \mathrm{Mn}^{2+}$ & 283 & 2,62 \\
\hline $\mathrm{Co}^{3+} / \mathrm{Co}^{2+} / 1 \mathrm{Mn}^{2+} / \mathrm{Mn}^{0}$ & 427 & 25,6 \\
\hline & Total $=28,2$ \\
\hline
\end{tabular}

